\title{
Geographic variation of song within and between subspecies of the Mangrove Warbler (Setophaga petechia castaneiceps and S. p. rhizophorae)
}

Taryn Tuncer

West Virginia University

Follow this and additional works at: https://researchrepository.wvu.edu/etd

\section{Recommended Citation}

Tuncer, Taryn, "Geographic variation of song within and between subspecies of the Mangrove Warbler (Setophaga petechia castaneiceps and S. p. rhizophorae)" (2013). Graduate Theses, Dissertations, and Problem Reports. 574.

https://researchrepository.wvu.edu/etd/574

This Thesis is protected by copyright and/or related rights. It has been brought to you by the The Research Repository @ WVU with permission from the rights-holder(s). You are free to use this Thesis in any way that is permitted by the copyright and related rights legislation that applies to your use. For other uses you must obtain permission from the rights-holder(s) directly, unless additional rights are indicated by a Creative Commons license in the record and/ or on the work itself. This Thesis has been accepted for inclusion in WVU Graduate Theses, Dissertations, and Problem Reports collection by an authorized administrator of The Research Repository @ WVU. For more information, please contact researchrepository@mail.wvu.edu. 


\title{
GEOGRAPHIC VARIATION OF SONG WITHIN AND BETWEEN SUBSPECIES OF THE
} MANGROVE WARBLER

(SETOPHAGA PETECHIA CASTANEICEPS AND S. P. RHIZOPHORAE)

\author{
Taryn Tuncer
}

\begin{abstract}
Thesis submitted to the Davis College of Agriculture, Forestry, and Consumer Sciences at West Virginia University in partial fulfillment of the requirements for the degree of
\end{abstract}

\author{
Master of Science \\ in \\ Wildlife and Fisheries Resources
}

Robert C. Whitmore, Ph.D., Chair

Angelika Nelson, Ph.D.

Petra B. Wood, Ph.D.

Division of Forestry and Natural Resources

\author{
Morgantown, West Virginia \\ 2013
}

Keywords: birdsong, repertoires, dialects, song sharing, song types, geographic variation, subspecies, warblers, mangroves 


\section{ABSTRACT}

\section{GEOGRAPHIC SONG VARIATION WITHIN AND BETWEEN SUBSPECIES OF THE MANGROVE WARBLER \\ (SETOPHAGA PETECHIA CASTANEICEPS AND S. P. RHIZOPHORAE)}

\section{TARYN TUNCER}

Bird song characteristics are unique for each species, but songs are not identical among con-specific individuals and variations may occur at different geographic scales throughout a species distribution. Geographic song variation is common in many species, particularly in Passerines due to their song-learning behavior. Among Wood Warblers (Fam. Paruliade), The Yellow Warbler (Setophaga petechia) is one of the most widespread and geographically diverse species. It is comprised by three groups of several subspecies which represent a great variety on morphological traits, mainly on plumage coloration. Variations on behavioral traits, such as songs, have also been found in this species. Most research on geographic vocal variation has been done on subspecies of the Northern Yellow Warbler (aestiva group) but little has been published about the songs of tropical subspecies of the Mangrove Warbler (erithachorides group).

The purpose of this study is to describe the songs of the Mangrove Warblers of Northwestern Mexico and evaluate geographic variation of song on the subspecies Setophaga petechia castaneiceps and S. p rhizophorae. I recorded and analyzed the songs of 49 males from several locations throughout the distribution of both subspecies.

I described the songs of the mangrove warblers based on their general characteristics. I found that their songs are comprised by a sequence of notes that lasts about $1.5 \pm 0.9$ seconds and falls between a frequency range of $2.3 \pm 0.3-7.5 \pm 1.1 \mathrm{kHz}$. The arrangement of the notes 
exhibit an introductory, middle and ending part of the song. The introductory part is typically formed by a sequence of more or less $3 \pm 1.27$ identical notes, the middle part is formed by a sequence of varied notes and the ending part is characterized by a unique note which can either increase or decrease in frequency from its beginning to its end. According to this last note, all songs of the Mangrove Warblers were classified into accented ending songs (AES) or unaccented ending songs (UES) and 229 different song types were found among both of these categories. I found that a males' repertoire can be comprised by about $7 \pm 2.7$ song types of both of these categories.

I examined geographic variation of song within and between subspecies based on vocal variation and song repertoire sharing, expecting to find greater geographic variation between subspecies than within each. I found that geographic variation of song is mostly related to UES. Although repertoire sharing occurs on both song categories, only UES are shared throughout longer geographic distances other than between neighboring males. Also, vocal variation was determined by UES, particularly by its introductory part. Dialect among localities was based on its distinction in frequency while differences between subspecies were given by its temporal characteristics. The S. p rhizophorae subspecies sings the introductory part of UES faster than the S. p castaneiceps subspecies.

The vocal differentiation between S. petechia castaneiceps and S. p rhizophorae could be useful to support subspecific recognition. However it is necessary to consider that this distinction could be related to differences in ecological factors, such as habitat characteristics, population density or breeding conditions. 


\section{ACKNOWLEDGEMENTS}

Thanks to my advisor, Dr. Robert Whitmore, for giving me the opportunity to work with him towards my Master's of Science Degree. Throughout this process he was very kind and understanding and made me feel welcome. He encouraged me when making decisions that would be more constructive for my career. His support was an essential component for achieving my goals during this important process of my life.

I acknowledge my graduate committee, Dr. Petra Bohall Wood for her support and Dr. Angelika Nelson for her support, understanding and valuable suggestions and opinions in my thesis. I would also like to thank Dr. Doug Nelson from the Borror Laboratory of Bioacoustics for his general suggestions and guidance on my statistical analyses and my collaborators from CICESE in Mexico, Dr. Eduardo Palacios and Dr. Horacio de la Cueva, for assisting me during field work.

Special thanks to Cheryl Schweizer for supporting me in every way during this process. Her enthusiasm and help during field work made it a great experience and her friendly suggestions, during this period of my career, were always very genuine and helpful.

Finally, I would like to thank my family and my Colombian friends for their long distance support and constant encouragement.

Funding for this project was provided internally from The Division of Forestry and Natural Resources at West Virginia University. 


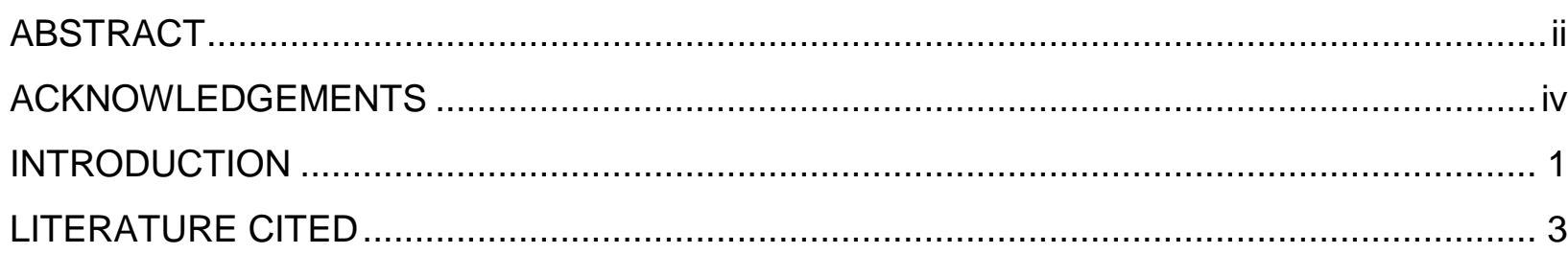

CHAPTER I

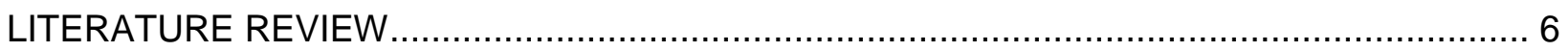

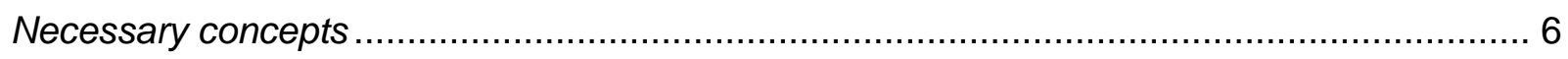

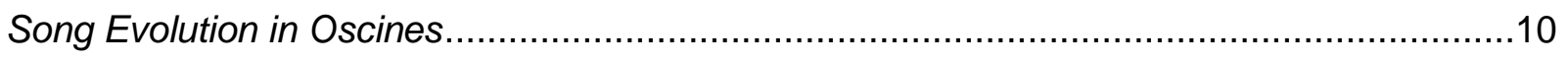

Geographic Variation, Dialect formation and Habitat-dependant Selection ...........................12

Mangrove Warbler distribution and characteristics .......................................................15

Wood Warblers' Song Systems ..................................................................................17

Setophaga Song Systems ..................................................................................

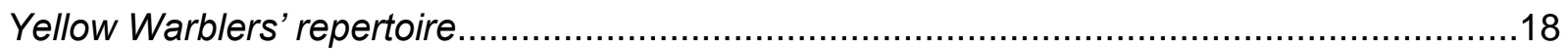

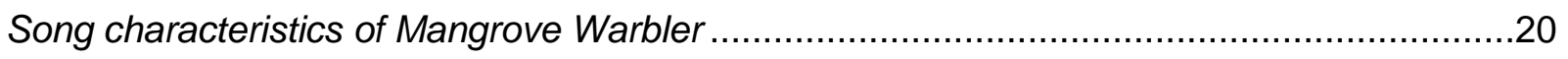

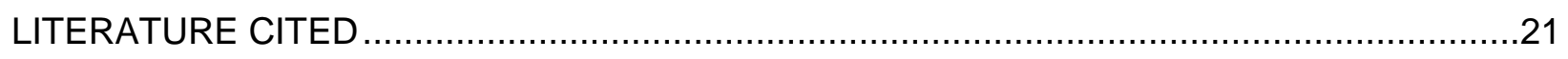

CHAPTER II

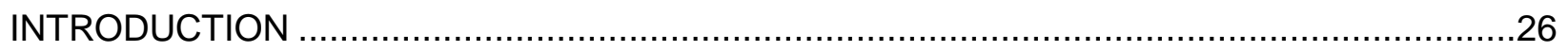

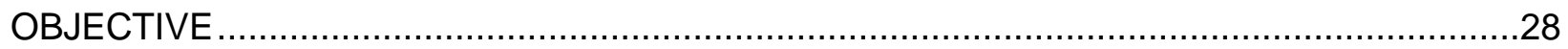

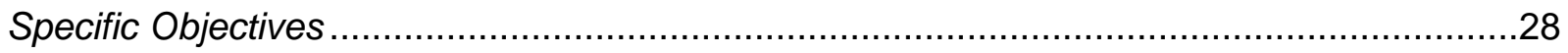

METHODS AND MATERIALS

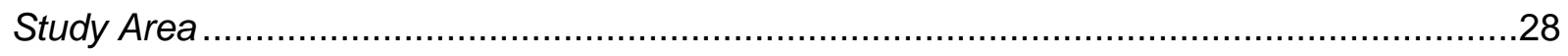

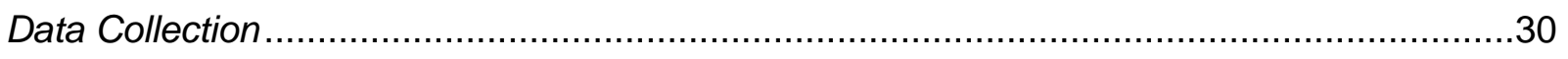

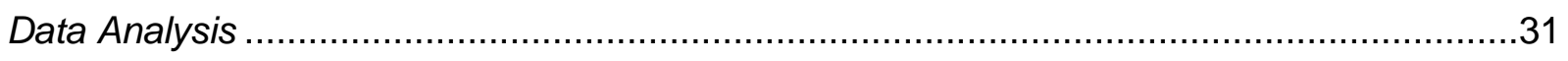

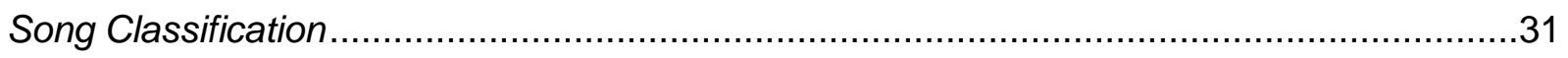

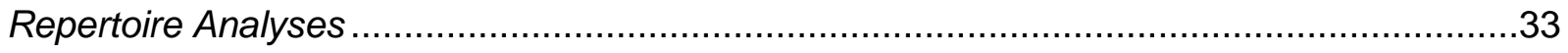

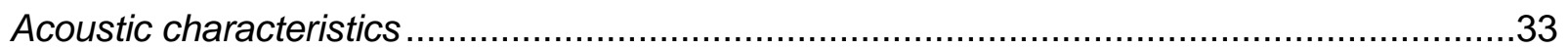

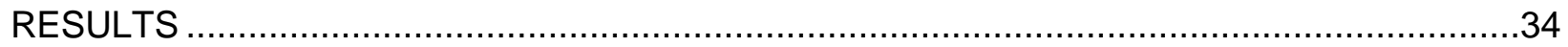

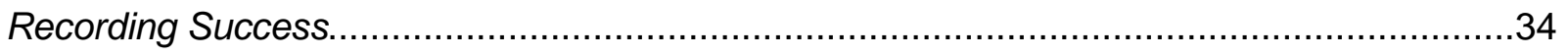




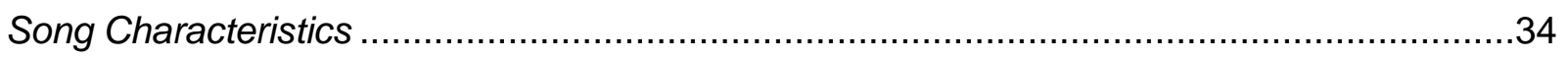

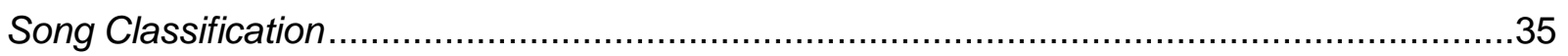

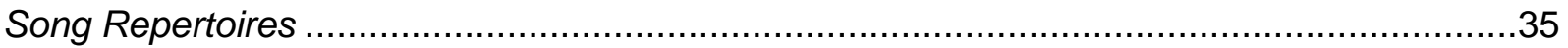

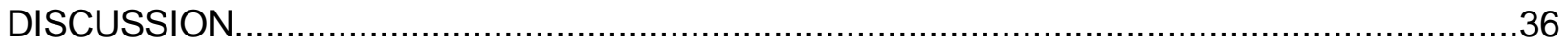

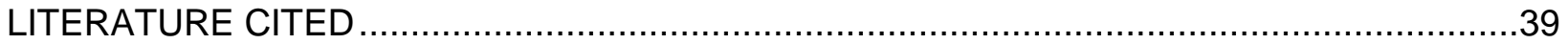

CHAPTER III

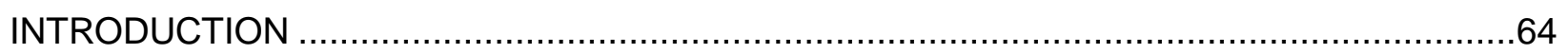

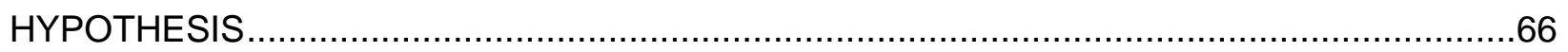

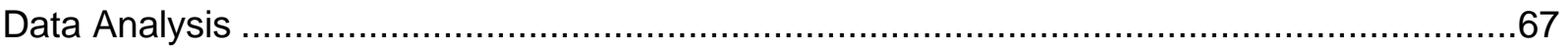

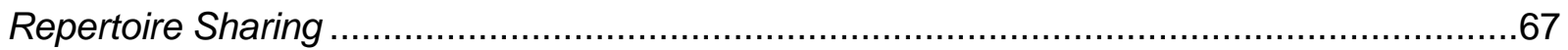

Statistical analysis of geographic variation of song repertoire ............................................68

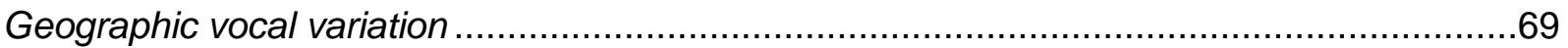

Statistical analysis of geographic vocal variation .........................................................69

Vocal variation between subspecies and localities ........................................................69

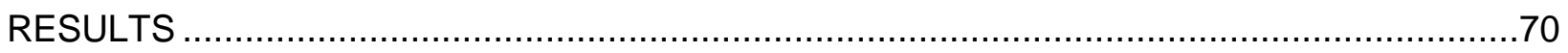

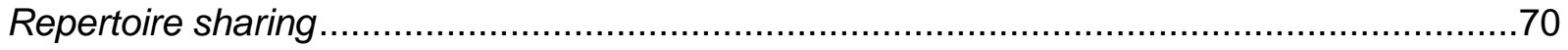

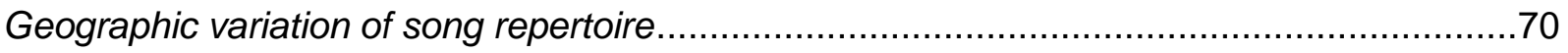

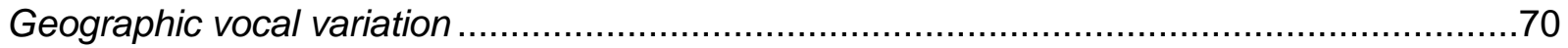

Vocal variation between subspecies and localities .........................................................

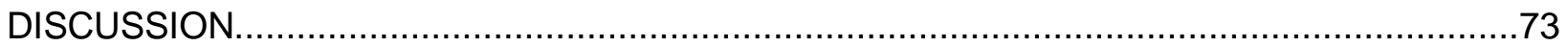

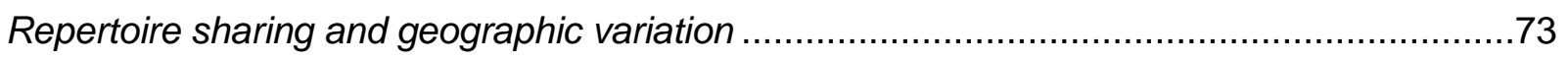

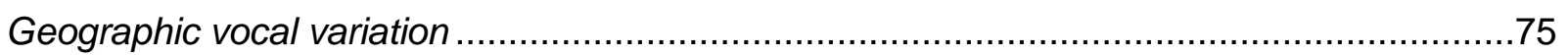

Vocal differences between subspecies.......................................................................

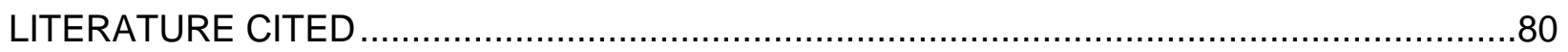

APPENDIX

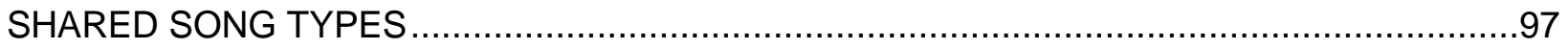




\section{LIST OF FIGURES}

\section{CHAPTER II}

Figure 1. Locations of study sites in Baja California Sur and Sonora, Mexico.........................41

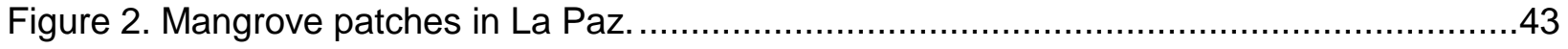

Figure 3. Locations of recorded males in mangroves of La Paz. .......................................44

Figure 4. Mangrove patches in Puerto San Carlos. .................................................................45

Figure 5. Locations of recorded males in mangroves of PSC. ........................................46

Figure 6. Mangrove patches in Puerto Adolfo López Mateos. ................................................47

Figure 7. Locations of recorded males in mangroves of PALM .........................................48

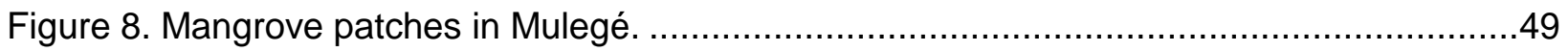

Figure 9. Locations of recorded males in mangroves of Mulegé..........................................50

Figure 10. Mangrove patches in San Lucas. ............................................................... 51

Figure 11. Locations of recorded males in mangroves of San Lucas....................................52

Figure 12. Locations of recorded males the mangrove of San Carlos. ....................................53

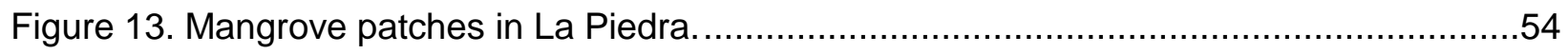

Figure 14. Locations of recorded males in mangroves of La Piedra.................................55

Figure 15. Mangrove patches in Yavaros............................................................56

Figure 16. Locations of recorded males in mangroves of Yavaros.. ...................................57

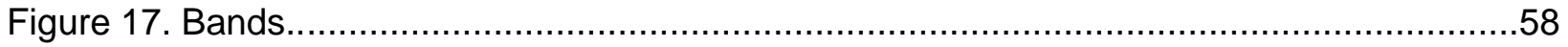

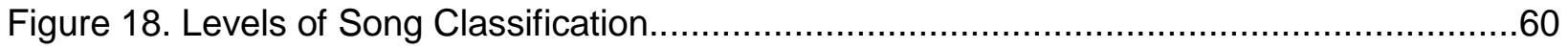

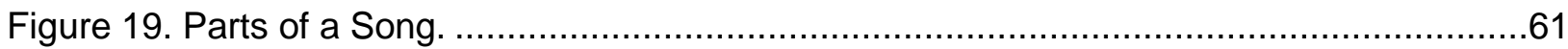

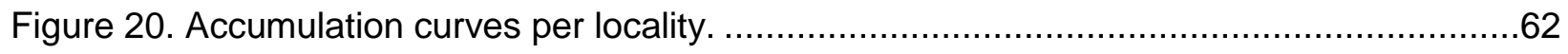

CHAPTER III

Figure 1. Correlation between distance and repertoire sharing when comparing entire

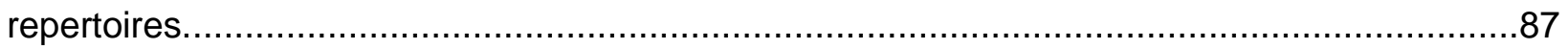

Figure 2. Correlation between distance and repertoire sharing of UES. ..............................8

Figure 3. Correlation between distance and repertoire sharing of AES. ...............................89

Figure 4. Correlation between distance and vocal variation based on the entire repertoire. ......90

Figure 5. Correlation between distance and vocal variation of UES. .................................91

Figure 6. Correlation between distance and vocal variation of AES...................................92 
Figure 7. Vocal variation of all songs explained by the first 3 principal components................93

Figure 8. Vocal variation of UES explained by the first 3 principal components.......................94

Figure 9. Vocal variation of AES explained by the first 3 principal components. ......................95 


\section{LIST OF TABLES}

CHAPTER II

Table 1. Distance between mangrove patches within each location of Baja California Sur (S. $p$. castaneiceps). 412

Table 2. Distance between mangrove patches within each location of Sonora (S. p. rhizophorae)

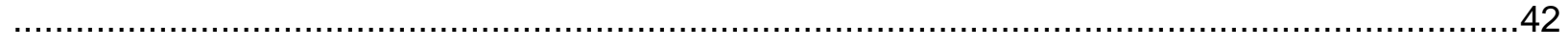

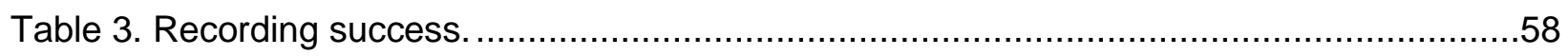

CHAPTER III

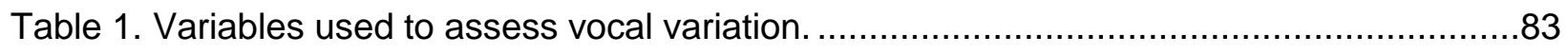

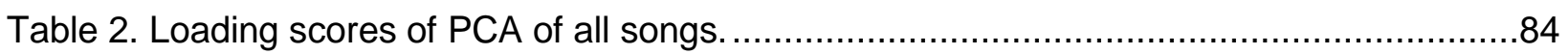

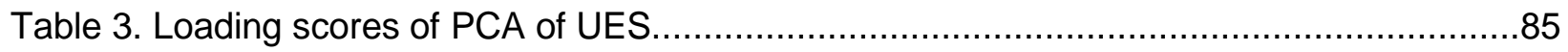

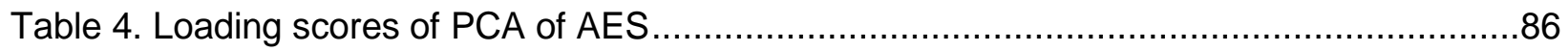

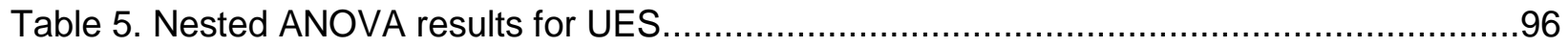

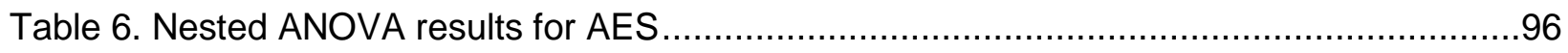




\section{INTRODUCTION}

Behavioral ecology has always been an interesting approach to evaluate animal diversity. Behavior is an important driver of evolutionary change because it allows animals to enter new adaptative zones, favoring selection on morphological, physiological and other behavioral traits (Sol et al. 2005). Bird song is a behavioral attribute that plays a role in species diversification. Because songs are species-specific, they serve as an isolating mechanism between bird species (Marler 1957). However, individual vocal variation on songbirds may lead to environmental adaptations favoring dispersal and intraspecific diversification (Mayr 1963, Podos and Warren 2007). When dispersal or geographic isolation in populations occur, the song characteristics that prevail in the latest populations are likely to vary from the original one favoring morphological adaptations that may as well differ (Mayr 1963, Podos et al. 2004). According to Mayr (1969), such populations that exhibit intraspecific geographic morphologic variation can be classified as different subspecies and Phillimore and Owens (2006) suggest that in fact, many avian subspecies are phylogenetically distinct. Therefore, eventually, the reproductive divergence among these subspecies may lead to a potential speciation (Marler and Tamura 1962).

As in most passerines, the songs of the Wood Warblers (Parulidae) have specific features that provide distinction among their species (Lemon et al. 1983). However, the structural and behavioral similarities of the songs among these species have a general pattern of song use that is shared by them (Spector 1992). Their songs can be classified into two main categories which have been designated as first and second category songs (Spector 1992) type I and type II songs (Kroodsma 1981, Spector 1991, Beebe 2002) or accented ending (AE) and unaccented ending (UE) songs (Morse 1966; Bankwitz and Thompson 1979, Byers 1995) respectively depending on the species an researcher. These two categories of songs are generally used in different contexts. First category songs are used by males to communicate 
mainly with females, while second category songs are used for communication between males (Spector 1992).

The extent at which geographic song variation occurs in Wood Warblers has been found to be related to these different song categories. Type II songs typically show more geographic variation than Type I songs (Kroodsma 1981, Byers 1996, Spector 1992, Beebe 2002). Such variation can be found at different levels of characteristics of the songs such as in song repertoire sharing (Kroodsma 1981, Byers 1996, Beebee 2002) as well as in vocal characteristics based on temporal and spectral traits (Bay 1999).

Several studies have been conducted on the Yellow Warbler species which support these findings on the song characteristics (e.g. Morse 1966, Bankwitz and Thompson 1979, Spector 1992) and geographic song variation (e.g. Beebee 2002). However, little is known about the singing behavior of tropical populations (Spector 1992) such as in subspecies of the Mangrove Warbler group (Dunn and Garrett 1997). The only vocal study on Mangrove Warblers was by Mennill (2001) on Setophaga petechia bryanti subspecies. He found that their songs are structurally, but not frequency, similar to those of the Northern Yellow Warbler.

. The purpose of this study is to describe the songs and repertoires of the Mangrove Warbler subspecies $S$. $p$ castaneiceps and S. p rhizophorae, and evaluate geographic vocal variation and repertoire sharing within and between these subspecies. Other than the morphological traits that have already been distinguished between these subspecies, geographic variation of song may provide another cue in subspecific recognition. 


\section{LITERATURE CITED}

BANKWITZ, K. G., AND W. L. THOMPSON. 1979. Song characteristics of the Yellow Warbler. Wilson Bulletin 91:533-550.

BAY, M. D. 1999. The type B song of the Northern Parula: Structure and geographic variation along proposed sub-species boundaries. Wilson Bulletin 111:505-514.

BEEBEE, M. D. 2002. Song sharing by Yellow Warblers differs between two modes of singing: implications for song function. Condor 104:146-155.

BYERS, B. E. 1996. Geographic variation of song form within and among Chestnut-sided Warbler populations. Auk 113:288-299.

DunN, J. L., AND K. L. GarRetT. 1997. A field guide to warblers of North America. Houghton Mifflin, Boston.

KROODSMA, D. E. 1981. Geographical variation and functions of song types in warblers (Parulidae). 98:743-751.

LEMON, R. E., J. StRugER AND M. J. LECHOWICZ. 1983. Song features as species discriminants in American warblers (Parulidae). Condor 85:308-322.

MARLER, P. 1957. Specific distinctiveness in the communication signals of birds. Behaviour 11:13-39.

MARLER, P AND M. TAMURA. 1964. Culturally transmitted patterns of vocal behavior in sparrows. Science 146:1483-14-86.

MAYR, E. 1963. Animal species and evolution. Hardvard University Press. Cambridge.

MAYR, E.1969. Discussion: Footnotes on the philosophy of biology. Philosophy of Science 36:197-202.

MENNILL, D. J. 2001. Song characteristics and singing behavior of the Mangrove Warbler (Dendroica petechia bryanti) (Características y conducta del canto de Dendroica petechia bryanti). Journal of Field Ornithology 72:327-337. 
MORSE, D. H. 1966. The context of songs in the Yellow Warbler. Wilson Bulletin 78:444-455.

PhILLIMORE, A. B AND I. P. F. OWENS. 2006. Are subspecies useful in evolutionary and conservation biology? Proceedings: Biological Sciences 273:1049-1053

PODOS, J., AND P. WARREN. 2007. The evolution of geographic variation in birdsong. Advances in the Study of Behavior 27:403-458.

SoL, D., D. G. StiRLing AND L. LefEBVRE. 2005. Behavioral drive or behavioral inhibition in evolution: subspecific diversification in holartic passerines. Evolution 59:2669-2677.

SPECTOR, D. A. 1991. The singing behaviour of Yellow Warblers. Behaviour 117:29-52.

SPECTOR, D. A. 1992. Wood-warbler song systems: A review of Paruline singing behaviors. Current Ornithology 9:199-238. 
CHAPTER I

ReView of Literature Relevant to Study 


\section{LITERATURE REVIEW}

Necessary concepts

Population

Several definitions have been proposed to describe the concept of population. Such definitions have been unified by Berryman (2002) who describes a population as “. . . a group of individuals of the same species that live together in an area of sufficient size to permit normal dispersal and/or migration behavior and in which numerical changes are largely determined by birth and death processes." Biologists tend to agree that it is important to take into account that scaling is key when it comes to defining populations (Shaefer 2006). With the arising concept of metapopulations, it is common to consider populations in a local and a regional scale (Berryman 2002). However as suggested by Shaefer (2006) in many cases restriction to just two scales is unlikely to capture the full spectrum of population structures or processes. Such is the case of my research, where population can be considered at three different scales. Therefore, I will designate and define all three population "levels" that are considered in this research according to the geographic scale:

Subspecies is the population distributed at the largest scale. It is defined by the limits of the geographic regions (associated to the states) in which the individuals of each of the subspecies that I studied are distributed. However, the word "subspecies" may also be used in this research referring to the conventional meaning (the biological definition of "subspecies" is described later in this section), but the differentiation should be clear depending on the context in which it is given. The "population" subspecies is used when other population "levels" are in perspective or when I refer to the S. p. castaneiceps and S. p. rhizophorae populations. The "biological" subspecies is used in a more literary context. 
Local population refers to a smaller distributional scale than the subspecies scale and it is related to a locality. It is confined to the surrounding area of a city or town in which individuals are found. Generally these areas are separated by larger aridic regions in which mangrove habitat is absent or only very few and small mangrove patches are present.

Mangrove patch population is confined to the individuals that inhabit a mangrove patch within a local population.

\section{Species}

The species concept is the oldest and most frustrating problem in biology (Mayr 1992). It has been discussed since the early 1900 after the biological species concept (BSC) replaced the typically accepted concept of typological species (Mayr 1992). Many definitions have been proposed since then, such as the Phenetic, Evolutionary or Phylogenetic concepts, However, the BSC proposed by Ernst Mayr (1969) and the Phylogenetic concept developed in the 1908s by Nelson and Platnick (1981), Cracraft (1983) and Nixon and Wheeler (1990) are the most considered and discussed now days (Hay 2001). Although these concepts lead to dissimilar definitions, both consider the evolutionary theory stating that a species is a group of related organisms joined by evolutionary processes that go on within it, which are separate from other groups that do not share such evolutionary processes.

For the purpose of this study will use the BSC. It is based empirically on the biological criteria which defines a species as an interbreeding community of populations that is reproductively isolated from other such communities (Mayr 1992). The BCS concept would imply that populations ideally have the chance to be in contact to allow interbreeding. I assume this definition in my research, taking into account that populations of a species that are not in actual contact with each other and therefore do not interbreed with each other, does not make them different species. As suggested by Mayr (1992), species are the product of evolution and the process of speciation is an ongoing and gradual one, where there will always be "incipient" 
species, that is, populations that are in the process of acquiring the attributes of species. Therefore any isolated population will either slowly or more speedily become genetically more distinct until species status has finally been reached. This means that all truly isolated populations, unless they become extinct, are potentially incipient species (Mayr 1992). By assuming this definition it is also necessary to consider that the BSC encounters difficulties when discerning potential reproductive barriers and also when hybridization takes place (Agapow et al. 2004).

\section{Subspecies}

In this study I use the biological concept of subspecies described by Mayr (1982) in which the term subspecies is used to designate geographical varieties of populations that have not been yet considered sufficiently different to be named a separate species. I use this definition because according to Mayr (1963) behavioral traits should be considered when designating subspecies. As suggested by him, behavioral traits such as birdsongs may favor selection on morphological, physiological and other behavioral traits when new adaptative zones have been colonized.

\section{Sonogram}

Is a type of graph to visualize sound. It includes information of frequency (y-axis), time (x-axis) and amplitude (grey-scale darkness) (Slabbekoorn 2004).

\section{Song and parts of a song}

Song is the sound produced by birds with the purpose of communication. In general, they are defined as long complex vocalizations produced by males during the breeding season (Catchpole and Slater 2008). Songs consist of different sections called phrases which are formed by a series of notes that exhibit a particular pattern (Catchpole and Slater 2008). Such 
phrases tend to distinguish and introductory, middle, and ending part of the song. A note is a continuous sound; it is the smallest element of the song (Catchpole and Slater 2008).

\section{Song type}

This is a category into which a song can be classified, based on its structural characteristics determined by the arrangement and frequency of its individual notes. Although song types can be similar in some ways, each song type is defined by certain characteristics that are not shared by other song types.

\section{$\underline{\text { Song repertoire }}$}

As it is generally used, "song repertoire" is defined as the number and composition of all song types that are sung by a male.

\section{$\underline{\text { Vocal variation }}$}

Although "vocal variation" has been used as a generalized concept of song variation, for the purpose of this study I use it to define the way in which songs vary depending on their structural, spectral and temporal characteristics only. I use this term to distinguish other song characteristics that may vary such as song repertoire.

\section{Dialect}

Dialects can be defined as the way in which geographic variation of song characterizes the songs of each population. Therefore in this research they could be related to the same population levels I described above. However "dialect" is often used in a small scale, in which individuals are in contact with each other. For instance, Krebs and Kroodsma (1980) have described dialects as a referring to cultural song traditions, song neighborhoods or microgeographical variations of song. The criteria they used is that "neighboring birds have songs which are more similar to one another than to more distant birds". The problem with this definition is that the boundaries between dialects are not clearly delineated as they seem to be 
related to where and when birds learn their songs (Krebs and Kroodsma 1980, Nelson 2000). For the purpose of my study I use "dialects" as a definition of the songs characterized by local populations and use the term "geographic variation" as a more general concept.

\section{Song Evolution in Oscines}

One of the main mechanisms for avian communication is bird song. It has evolved primarily as a mechanism to avoid breeding between different species, resulting in unique songs that characterize each species (ten Cate, 2004). Such songs allow conspecific identification and intraspecific and interspecific communication (Orians 1985).

In intraspecific communication birds sing to communicate with individuals of the same sex or different sex, mainly for territorial defense and mate attraction. These functions suggest that songs should be very similar among individuals of the same species to favor proper intraspecific communication (Orians 1985, Baptista and Gaunt 1994, Podos and Warren 2007). Because females and males both respond to songs, both sexes influence the evolution of the songs (Spector 1992)

The similarity and variation of song that can be found among individuals of the same population is established by two fundamentals: the vocal mechanisms and the cultural tradition. The vocal mechanisms refer to the control, production and ontogeny of the song and the cultural tradition is determined by the transmission of songs between individuals due to imitation and improvisation (Marler and Tamura 1964, Hultsch and Todt 2004). Because songbirds learn their songs by imitating a tutor, songs in a population are transmitted from generation to generation, allowing flexibility and variation (Podos et al. 2004). Although the song copied by an immature bird is precise, it may not be exact; because cultural transmission is limited by the vocal mechanisms. The different physiological conditions of an individual rearrange the information, 
creating small changes in the repertoire throughout generations of a population (Podos et al. 2004).

The cultural traditions and the vocal mechanisms that shape songs have been put under different selection pressures (Podos et al. 2004) which are determined by the functions of song (Baptista and Gaunt 1994). Because mate attraction is one of the most important functions of song, sexual selection plays an important role. Songs are used by females, not only to recognize a male as a conspecific individual, but also to evaluate its fitness; those males which have a better physiological condition, will sing better and more complex songs (Podos et al. 2004, Slabbekoorn and Smith 2002, Baptista and Gaunt 1994) which gives them an advantage when competing for territory and other resources (Krebs and Kroodsma 1980). Females also benefit from choosing these males, because they will have offspring that will most likely exhibit the physiological characteristics of their father (Krebs and Kroodsma 1980).

The different physiological characteristics that males have may cause song variation during the learning process, these variations lead to differences in status and capacities that females consider when choosing a male. Females evaluate characteristics such as: learning capability (Nowicki and Searcy 2005, Brainard and Doupe 2002, Marler and Doupe 2000, Baptista and Gaunt 1994), size of repertoire (Nowicki and Searcy 2005, De Vooged 2004, Podos et al. 2004, Baptista and Gaunt 1994, Orians 1985), song speed (Podos et al. 2004), song vibration (Podos et al. 2004, Elemans et al. 2004), and song pitch (Nowicki and Searcy 2005).

Due to the variability of these characteristics, the songs found in a population share similar features, but also show individual differences some of which are passed on to future generations. These differences are the origin of geographic variation, either because individual differences may lead to adaptations to certain environmental conditions (Mayr 1963) or because 
song copying errors due to disabilities during the learning process may persist in a population (Payne 1981, Podos et al. 2004). When a population is divided due to geographic barriers, such differences can be accentuated over time in the resulting populations, creating intraspecific variability that could eventually lead to speciation (Marler and Tamura 1962, Mayr 1963, Podos et al. 2004).

Geographic Variation, Dialect formation and Habitat-dependant Selection

Geographic variation in animal traits has been studied to understand the process of speciation. Species' features that vary geographically can be a clue in identifying early stages of divergence that can lead to full reproductive isolation, thus separate species (Mayr 1963). The geographic divergence of mating signals can contribute to selective mating and reproductive isolation which contribute to population divergence (Marler and Tamura 1962). The vocal signals of birds are one of these features that can vary geographically in so-called dialects (Krebs and Kroodsma 1980, Nelson 2000). In subspecies, such dialects seem to accentuate, due to learning preferences (Nelson 2000) and different habitat qualities (Rothstein and Fleisher 1987). This, could therefore, favor reproductive isolation and speciation (Marler and Tamura 1962, Podos and Warren 2007).

Dialect formation of a species is determined by functional and non functional factors. The functional factors are those related to cultural tradition like the song learning process that allows similar songs to be kept in a population (Nelson 1999, Podos and Warren 2007). The non-functional factors are those related to the vocal mechanisms, which intervene in the learning process, creating secondary products (new song characteristics) that throughout cultural tradition can be incorporated in a population (Podos and Warren 2007). Secondary products may be different for each population, leading to geographic variation over time. According to this, the Epiphenomenon Hypothesis has been developed, and it suggests that in case of divergence of a population, the dialect formation can be the result of the different 
trajectories of selection effecting the resulting populations (Andrew 1962, Baptista 1975, Podos and Warren 2007).

Such selection pressures promote those songs that can be adequately transmitted in the acoustical environment which each population inhabits. The environmental differences of each population can lead to intraspecific vocal divergence which results in different patterns of dialects related to the habitats that each population occupies according to the Acoustic Adaptation Hypothesis (Morton 1975, Rothstein and Fleisher 1987). Ecology and natural selection play an important role in geographic variation where habitat-dependent selection allows intraspecific divergence of vocalizations (Slabbekoorn and Smith 2002).

Habitat-dependent selection can lead to divergence of morphological and behavioral features that can be seen in birdsongs. Habitats that differ in density and type of vegetation have different selection pressures on the acoustic signals. The way in which sound is accentuated and degraded when it travels in the physical environment can be related to the characteristics of each habitat that can interfere differently in sound transmission (Slabbekoorn and Smith 2002). In contrast with most habitats, mangrove ecosystems are relatively homogeneous because they are mostly comprised by one dominant type of mangrove species. The sound transmission throughout an environment with regular distribution of the trees along with the uniformity of the types of leaves and twigs is less affected by attenuation than in heterogeneous habitats (Slabbekoorn 2004). However, song may be affected by the presence of water in the surface which may increase reverberation rates (Slabbekoorn 2004).

Mangrove habitats may differ depending on the tree species and density, which may influence in song characteristics providing distinct dialects. During dialect formation there is habitat-dependent mate selection. Those males which are better adapted to the environment 
will sing songs fine tuned to transmit and be received better in its environment and females will choose these males when inferring their fitness by their song (Slabbekoorn and Smith 2002).

Ecological studies are very important to understand the function of song in events of divergence and speciation. Geographic variation analysis of songs should be evaluated in different habitat types and the acoustical characteristics that can be influenced by habitatdependent selection should be considered (Slabekoorn and Smith 2002).In Northwestern Mexico, mangrove habitats are mostly dominated by one of three possible mangrove species: Red Mangrove (Rhizophora mangle), White Mangrove (Laguncularia racemosa) or Black Mangrove (Avicennia germinans) (Ruiz-Luna et al. 2010). Few habitats in these areas are composed by mixed stands: Red Mangrove predominates.

\section{Song and Systematics}

Birdsongs have been used to study bird phylogenetic relationships. The similarity of songs of different populations can be used to prove specific identity of those populations which are isolated (Payne 1986). The song recordings of a species which has allopatric populations can be useful to determine if a population belongs to a particular species. This suggests a rule: one song equals one species. However this rule is not appropriate in all circumstances, in some cases the song variability within a population can be very large and in other cases the songs between species can be so similar that they can seem conspecific (Payne 1986).

If bird species are well defined by their songs, several song characteristics should be consistent among all individuals, according to the Invariant Feature Hypothesis proposed by Marler (1960) fewer, mostly intraspecific variant features, should provide subspecific distinction. So, do songs behave the same way as morphological characters when defining subspecies? Morphologically, the same characters that are typically used to identify species are generally used to define subspecies (Rensch 1960) mostly based on plumage coloration pattern and body 
size (e.g. Browning 1994). However, bird song does not seem to behave the same way. The Invariant Feature Hypothesis has been disapproved in some cases (e.g. Nelson 1989). Nelson (1989) suggested that several features are needed to distinguish conspecific from heterospecific songs. It remains unclear if there are unique song features that distinguish subspecies. However, because birds discriminate when learning songs from their own or other subspecies (Nelson 2000), there should be certain distinctive subspecific song features that birds use as an indicator. Furthermore, it seems that song variations at the subspecies level are mostly linked to local variations like dialects related to geographic variation and not to subspecific characteristics itself. However, in most cases, such local variation corresponds with the geographic areas occupied by each subspecies. It is most likely that ecological factors enhance in song differentiation between subspecies than taxonomy itself. Although, in some cases it is possible to find that the morphological and acoustic differences in populations vary equally allowing a functional or historical interpretation (Payne 1986).

The ambiguity when the difference between populations is large enough to be considered as different species is unavoidable. Speciation, as well as geographic variation is a gradual process and assigning a taxonomic level of subspecies seems to establish a discrete limit, not a continuous one. Therefore, in most cases, the differentiation between species and subspecies is not as clear as the taxonomical nomenclature suggests (Cadena 2003).

\section{Mangrove Warbler distribution and characteristics}

The Mangrove Warbler is a subspecies that belongs to the Yellow Warbler complex. The Yellow Warbler is the most widespread of the wood warblers (Parulidae) and has the strongest geographic variation. Its 34 subspecies can be divided into three main groups according to the males' head color in the breeding season. The Northern Yellow Warbler (aestiva) group lacks chestnut color on the head except on the crown, where, if present, it is diffuse or concentrated on the feather shafts (Browning 1994). Its 6 subspecies (Clements 2011) are distributed 
throughout North America (Dunn and Garrett 1997). The Golden Warbler (petechia) group has a well-defined chestnut color in the crown (Browning 1994) and it is confined by 16 subspecies (Clements 2011) which are distributed in the Caribbean islands (Dunn and Garrett 1997). The Mangrove Warbler (erithachorides) group has chestnut color heads (Browning 1994), and is formed of 12 (Clements 2011) subspecies which are found in mangroves of the Pacific and Atlantic coasts of Mexico, Middle America, north of South America, Cocos islands and the Galapagos (Dunn and Garrett 1997).

Mangrove Warbler males are distinguished from the northern types by a complete dark chestnut hood (Browning 1994, Howell and Webb 1995), their larger size, their narrower chestnut streaking on the abdomen (Howell and Webb 1995) and their rounded wings (Browning 1994). Also, their life-history traits are more similar to those of other tropical species than to the conspecific subspecies of the Yellow Warbler complex. They have longer breeding seasons, smaller clutch sizes, longer incubation and nestling periods, lower nestling success, higher rates of nest depredation and higher annual adult survival rates. They defend territories and maintain permanent pair bonds and a stable population density all year round (SalgadoOrtiz et al. 2008).

The subspecies castaneiceps and rhizophorae inhabit mangroves of the western part of Mexico and their distribution is separated by the Gulf of California (also known as Sea of Cortez). The subspecies castaneiceps is distributed in the mangroves of the southern Baja California peninsula (Browning 1994, Whitmore et al. 2005) and the subspecies rhizophorae on the eastern coast of the gulf in the states of Sonora and Sinaloa (Browning 1994). Morphologically, both subspecies are very similar, however the castaneiceps subspecies is larger (C.L. Schweizer unpubl. data) slightly greener above and the males have less dense and narrower chestnut streaks (Browning 1994). 
Wood Warblers' Song Systems

In wood warblers, there are similarities in song repertoire size and structure that represent their phylogenetic relationships. The common song system among Vermivora, Mniotilta, and Setophaga (including former Parula, former Dendroica which is now eliminated from the Check-list of North American birds and its species now belong to the genus Setophaga (Chesser et al. 2011)), seems to be a derived character of the monophyly of this group. The characteristics and uses of the songs which help classify each species repertories into categories, seems to be consistent in the species that belong to this group (Spector 1992).

In many songbirds, the song repertoire is divided into song systems related to the patterns of song use. Wood warblers have song systems that have been well studied and some of these species share song patterns. Some species have a song system conformed by primary and extended songs. The primary seems to be an all-purpose song for inter- and intrasexual communication and the extended seems to be given in specialized displays (Spector 1992).

In wood warblers like the ones found in the genera Vermivora, Mniotilta, and Setophaga, there is a consistency in the classification of their song systems into First Category and Second Category songs. The First category songs tend to dominate early in the breeding season before males are mated and then decline after pairing; second category songs are more common later in the breeding season and during low light levels at dawn and dusk. Also, second category songs are sung at faster rate than first category songs. When species have a large repertoire most of their repertoire is made of second category songs and these are given with a greater immediate variety than first category songs. First category songs are used more frequently when a female is present and are given mostly in the center of the territory, second category songs are used for communication between males in territorial encounters and are used preferentially at the edges of the territories (Spector 1992). 


\section{Setophaga Song Systems}

Among various behavioral aspects of the Setophaga species, their song repertoire structure is very similar (Spector 1992). There is only one song in the first category songs and several in the second category. The first category songs are sung copiously, especially during the daylight, when unmated and the second category songs are used in a dawn song bout, at or before sunrise (Spector 1992).

\section{Yellow Warblers' repertoire}

The song system of Yellow Warblers can be classified mainly in two groups: the First Category songs also called Type I (Spector 1992, Beebee 2002) or Accented Ending songs (AE) (Morse 1966; Bankwitz and Thompson 1979) and the Second Category songs also called Type II (Spector 1992, Beebee 2002) or Unaccented Ending songs (UE) (Morse 1966, Bankwitz and Thompson 1979). Type I songs are characterized by having higher frequencies and being sung with a low immediate variety (small variations within a same song type) at a relatively slow rate (Spector 1992). They are used preferentially during the breeding season, prior to and during pair formation (Bankwitz and Thompson 1979, Morse 1966), in the presence of females (Morse 1966, Bankwitz and Thompson 1979, Spector 1992), when delivering food to nestlings (Morse 1966, Spector 1992) and in the presence of other species, particularly closely related species (Morse 1966). Type II songs are characterized by having a lower frequency, being more complex and being sung at a relatively fast rate with a high immediate variety often followed by chip-like call notes (Spector 1992). They are sung during the end of the breeding season after pair formation and on territorial boundaries (Bankwitz and Thompson 1979). They appear to be given to males of the same species (Morse 1966) during disputes with other males (Morse 1966, Bankwitz and Thompson 1979, Spector 1992), and in close encounters it is common to find that these songs are muted (Morse 1966) or shortened as a modification of a particular song type (Spector 1992). In addition, there are Intermediate songs, which are sometimes sung 
when birds are changing from one song type to another. This song type has usually a weak upslurred accented ending but it has a lackluster quality compared to the Type I song (Morse, 1966).

Yellow warblers have large song repertoires (Spector 1992). They can combine up to 40 different notes, to produce about 64 different song types and an individual males' repertoire can be composed of up to 16 song types (Bankwitz and Thompson 1979). Although there is an extensive sharing of song types among individuals (Bankwitz and Thompson 1979), it has been found that each male has only one Type I song which is not standardized among males but can be similar to a song that another male uses as a Type II song (Spector 1992).

Song variation in a repertoire is due to variation in number, arrangement and kind of notes, deletion or addition of phrases and changes in arrangements of phrases within song types (Bankwitz and Thompson 1979). The variability of Type I songs is a lot smaller than the one of Type II. Such characteristic provides a faster and better recognition of conspecifics by the use of Type I songs. After pair formation, when Type I songs decrease and the use of Type II songs increases, the variability of these songs enhance individual identity that allow territorial males to differentiate between songs of neighboring male or a stranger (Bankwitz and Thompson 1979).

Although such song systems have been found in most Yellow warblers, these can vary depending on the circumstances. The existence of two different categories of songs occur mostly when closely related sympatric species are present, when song Type I is useful for species recognition (Morse 1966). Populations that lack closely related sympatric species in their habitat posses a single, but variable, song system (Morse 1996). It has been found that tropical populations of Yellow warblers like Mangrove warbles sing only Type II songs when they are the only warblers in the habitat (Morse 1996). 


\section{Song characteristics of Mangrove Warbler}

As many other birds, Mangrove Warblers learn their songs from other local conspecific males, so song types tend to be shared between neighboring males. Compared to the Northern Yellow Warbler, their songs are significantly lower in pitch, they contain more syllables and syllable types and have longer features (Mennill 2001).

Their song system can be phonetically categorized into two groups: those that have upslurred terminal syllables, equivalent to the accented ending song of Yellow warblers, and those that have down-slurred terminal syllables, equivalent to the unaccented ending songs of Yellow warblers (Morse 1966). However, these do not appear to be functionally equivalent to the Type I (AE) and Type II (UE) songs of Yellow warblers (Mennill 2001). 


\section{LITERATURE CITED}

Agapow, P.M., O. R. P. Bininda-Emonds, K. A. CRAndall, J. L. GitTleman. 2004. The quarterly review of Biology 79:161-179.

ANDREW, R. J. 1962. Evolution of Intelligence and vocal mimicking. Science 137:585-589.

BANKWITZ, K. G., AND W. L. THOMPSON. 1979. Song characteristics of the Yellow Warbler. Wilson Bulletin 91:533-550.

BerRyman, A. A. 2002. Population: a central concept for Ecology? Oikos 97:439-442.

BAPTISTA, L. F. 1975. Song dialects and demes in sedentary populations of the White-crowned Sparrow (Zonotrichia luecophrys nuttalli). Publications in Zoology, University of California 105:1-52.

BAPTISTA, L., AND S. GAUNT. 1994. Advances in studies of avian sound communication. Condor 96:817-830.

BEEBEE, M. D. 2002. Song sharing by Yellow Warblers differs between two modes of singing: implications for song function. Condor 104:146-155.

BRAINARD, M., AND A. DOUPE. 2002. What songbirds teach us about learning. Nature 417:351358.

BrownING, M. R. 1994. A taxonomic review of Dendroica petechia (Yellow Warbler) (Aves: Parulinae). Proceedings of Biological Sciences of Washington 107:27-51.

CATChPOle, C.K., AND P. J. B. SlAter. 2008. Bird song: Biological themes and variations. Cambridge University Press, Cambridge.

CADENA, D. 2003. Taxonomía de Cistothorus apolinari (Trogodytidae) conceptos de especie y conservación de las aves amenazadas de Colombia. Ornitología Colombiana 1:71-75.

Chesser, R. T., R.C. Banks, F.K Barker, C. Cicero, J. L. Dunn, A. W. Kratter, I. J. Lovete, P.C. Rasmussen, J.V. Remsen, J.D. Rising, D. F. Stotz And K. WinKeR. 2011. FiftySecond Supplement to the American Ornithologists' Union Check list of North American Birds 128:600-613. 
Clements, J. F., T. S. Schulenberg, M. J. IlifF, B.L. Sullivan, C. L. WoOd, And D. Roberson. 2011. The eBird/Clements checklist of birds of the world: Version 6.7. Downloaded from http://www.birds.cornell.edu/clementschecklist/downloadable-clements-checklist

CRACRAFT, J. 1983. Species concepts and speciation analysis. Current Ornithology 1:159-187.

DE VoOGED, T. 2004. Neural constrains on the complexity of avian song. Brain, Behaviour and Evolution 63:221-232.

DunN, J., AND K. GARRETt. 1997. A field guide to Warblers of North America. Houghton Mifflin, Boston.

Elemans, C. P., I. L. SpieRts, U. K. Muller and J. L. VAn LeeuWen AND F. GolleR. 2004. Superfast muscles control dove's trill. Nature 431:146.

HEY, J. 2001. The mind of the species problem. Trends in Ecology and Evolution 16:326-329.

HowelL, S. N. G., AND S. WeBB. 1995. A guide to the birds of Mexico and Northern Central America. Oxford University Press, New York.

HULTSCH, H., AND D. TODT. 2004. Learning to sing. In: Nature's Music: The science of birdsong. (Ed. by P. M. Marler and H. Slabbekoorn). Elsevier Academic press, pp. 80-107.

KREBS, J. R., AND D. E. KROODSMA. 1980. Repertoires and geographical variation in bird song. Advances in the study of behavior 11:143-177.

LANYON, S. 1994. Polyphyly of the blackbird genus Agelaius and the importance of assumptions of monophyly in comparative studies. Evolution 48:679-693.

MARLER, P. R. 1960. Bird songs and mate selection. In Animal sounds and communication (ed.W. N. Tavolga). American Institute of biological sciences symposium proceedings. Washington D.C. pp 348-367.

MARleR, P. R., AND A.J. Doupe. 2000. Singing in the brain. Proceedings of the National Academy of Sciences of the United States of America 97:2965-2967.

MAYR, E. 1963. Animal species and evolution. Harvard University Press, Cambridge.

MAYR, E. 1982. Of what use are subspecies? Auk 99:593-595. 
MAYR, E. 1992. A local flora and the Biological Species Concept. American Journal of Botany. 79:222-238.

MENNILL, D. 2001. Song characteristics and singing behavior of the Mangrove Warbler (Dendroica petechia bryanti). Journal of Field Ornithology 72:327-337.

MORSE, D.1966. The context of songs in the Yellow Warbler. Wilson Ornithological Society 78:444-455.

MORTON, E. S. 1975. Ecological sources on selection on avian sounds. American Naturalist 109:17-34.

NELSON, D. A. 1989. The importance of invariant and distinctive features in species recognition of bird song. Condor 91:120-130.

NELSON, D. A. 2000. A preference for own-subspecies' song guides vocal learning in a song bird. Proceedings of the National Academy of Sciences of the United States of America. 97:13348-13353

NELSON, D. A. 2000. Song overproduction, selective attrition and song dialects in the Whitecrowned Sparrow. Animal Behaviour 60:887-898.

NeLSON, G., AND N. I. PLANTICK. 1981. Systematics and biogeography. Columbia University Press, New York.

NIXON, K. C AND Q. D. WHEELER 1990. An amplification of the phylogenetic species concept. Cladistics 6:211-223.

NOWICKI, S., AND W. SEARCY. 2005. Song and mate choice in birds: how the development of behavior helps. Auk 122:1-14.

ORIANS, G. H. 1985. Blackbirds of the Americas. University of Washington Press, Seattle.

PAYNE, R.B. 1986. Birdsong and avian systematics. Current Ornithology 3:87-126.

PODOS, J., AND P. WARREN. 2007. The evolution of geographic variation in birdsong. Advances in the Study of Behavior 27:403-458.

PODOS, J., S. HUBER AND B. TAFT. 2004. Bird song: The interface of evolution and mechanism. Annual review of Ecology, Evolution and Systematics 35:55-87. 
RENSCH, B. 1960. Evolution above the species level. Columbia University Press, New York.

ROTHSTEIN, S. I., AND R.C. FLEISHER. 1987. Vocal dialects and their possible relation to honest status signaling in the Brown-headed cowbird. Condor 89:1-23.

Ruiz, A., A. Cervantes and C. Berlanga. 2010. Assessing distribution patterns, extent, and current condition of Northwest Mexico mangroves. Wetlands 30:717-723.

Salgado, J., P. MarRA., S. Sillet and R. RoberTSON. 2008. Breeding ecology of the Mangrove Warbler (Dendroica petechia bryanti) and comparative life history of the Yellow Warbler subspecies complex. Auk 125:402-410.

SCHWEIZER, C. L. 2011.Biometric variation among two Mangrove Warbler Setophaga petechia populations of northwestern Mexico. Master Thesis. Davis College of Agriculture, Forestry, and Consumer Sciences, West Virginia University.

SHAEFER, J. A. 2006. Towards maturation of the population concept. Oikos 112:236-240.

SLABbeKoORn, H., AND T. SMITH. 2002. Birdsong, ecology and speciation. Philosophical Transactions of the Royal Society 357:493-503.

SLABBEKOORN, H. 2004. In: Nature's Music: The science of birdsong. (Ed. by P.M. Marler and H. Slabbekoorn). Elsevier Academic press, pp. 5.

SPECTOR, D. 1992. Wood-warbler song systems: A review of Parulinae singing behaviors. Current Ornithology 9:199-292.

TEN CATE, C. 2004. Birdsong and Evolution. In: Nature's Music: The science of birdsong. (Ed. by P.M. Marler and H. Slabbekoorn). Elsevier Academic press, pp. 296-317.

Whitmore, R. C., R. C. Brusca, J. L. L. De La Luz, P. González-Zamorano, R. MendozASalgado, E. S. Amador-Silva, G. Holguin, F. Galván-Magaña, P. A. Hastings, J. E. Cartron, R. S. Felger, J. A. Seminoff., AND C. C. Mclvor. 2005. The ecological importance of mangroves in Baja California Sur: conservation implications for an endangered ecosystem pages 298-333 in Biodiversity, Ecosystems, and Conservation in Northern Mexico (J. E. Cartron, G. Ceballos, and F. S. Felger, Eds.) Oxford University Press, New York. 


\section{CHAPTER II}

\section{SONG DESCRIPTION OF the MANGRove WARBLER}




\section{INTRODUCTION}

Describing the songs of species or populations is the first step in any analysis based on bird vocalizations. It is necessary to understand how birdsong is characterized at its different levels of organization and how these may be related to different functions in order to understand which song features are important to use depending on the goal of the research. Geographic song variation may be analyzed using vocal characteristics and song repertoires. Vocal characteristics are those related to the general features of a song, such as the structural, spectral and temporal traits of a song which usually fall into a range of the species and can be useful to describe frequencies, note arrangement and duration of units that compose the songs. Song repertoire is the set of different song types sung by a male (Catchpole and Slater 1995). It can vary in size and composition among males.

Wood warblers share similarities in their songs which represent their phylogenetic relationships (Spector 1992). Because of the consistency of the characteristics and uses of the songs found among the different species, their songs have been classified into two main categories: First Category and Second Category songs (Spector 1992). It has been noticed that their First Category songs (also called Type I or accented ending songs, depending on the researcher and species) are mostly used to communicate with females and are given mostly at the beginning of the breading season, prior to pair formation (Spector 1992). On the other hand, Second Category songs (also called Type II or unaccented ending songs) are used for communication between males, for territorial encounters, later in the breeding season, after pair formation (Spector 1992).

Although a species song has some characteristic features which are similar among all song types regardless of what category they belong to, the fact that Type I songs of the Yellow Warbler are less variable than Type II songs, suggests that they may be used in different 
contexts. Type I songs may have evolved as a better means for conspecific recognition, while Type II songs may enhance individual identity that allow territorial males to identify other males (Bankwitz and Thompson 1979).

In the Yellow Warbler Type I songs are characterized by higher frequencies or pitch and are sung with a low immediate variety at a relatively slow rate (Spector 1992). They are used preferentially to communicate with females (Morse 1966, Bankwitz and Thompson 1979, Spector 1992), during the breeding season, prior to and during pair formation (Bankwitz and Thompson 1979, Morse 1966). They also seem to be used to communicate with nestlings, because they are sung while delivering food to them (Morse 1966, Spector 1992) and in the presence of other species, particularly closely related species (Morse 1966). Type II songs are characterized by having a lower frequency, being more complex and being sung at a relatively fast rate with a high immediate variety often followed by chip-like call notes (Spector 1992). They are used exclusively to communicate with males of the same species (Morse 1966). They are sung at the end of the breeding season, after pair formation, on territorial boundaries (Bankwitz and Thompson 1979) and during territorial encounters (Morse 1966, Bankwitz and Thompson 1979, Spector 1992).

Among Wood Warblers, Yellow warblers have large song repertoires (Spector 1992). The males of a population studied by Bankwitz and Thompson (1979) combined up to 40 different notes, to produce about 64 different song types with an average of 16 song types in a males' repertoire. Although there is an extensive sharing of song types among individuals (Bankwitz and Thompson 1979), it has been found that each male has only one Type I song which is not the same type among males but can be similar to a song that another male uses as a Type II song (Spector 1992). 
The Mangrove Warbler has similar song characteristics and singing behaviors to the rest of the Yellow Warblers. However, their different habitats may have been a factor in differentiating their songs on certain aspects. The fact that Yellow Warblers prefer open habitats, while Mangrove Warblers are restricted to mangrove ecosystems, may be the reason for these differences. Mangrove Warbler songs are significantly lower in pitch, contain more note and note types, which tend to have a longer duration than those of the Yellow Warbler (Mennill 2001). Their songs can be structurally categorized into up-slurred terminal syllables versus down-slurred terminal syllables equivalent to AE or Type I and UE or Type II songs respectively. However these song categories do not seem to be functionally equivalent to the general categories in Wood Warblers.

\section{OBJECTIVE}

The first objective of this study is to describe the general acoustic characteristics of the songs and the song repertoire of the Mangrove Warbler based on the populations of $S . p$ castaneiceps and S. p rhizophorae.

\section{Specific Objectives}

1. Describe the song characteristics of the Mangrove Warbler.

2. Describe the song repertoire of the Mangrove Warbler based on size, composition and frequency of songs.

\section{METHODS AND MATERIALS}

\section{Study area}

The study was carried out in western Mexico in mangrove ecosystems of the peninsula of Baja California and the coasts of mainland Sonora. The population of S. p. castaneiceps is distributed in the state of Baja California Sur in mangrove patches that can be found from Cabo 
San Lucas to Laguna Pond and Laguna San Carlos respectively (Wilbur 1987). The population of S. p. rhizophorae inhabits mangrove patches from the coasts of Sonora and Sinaloa that are distributed from Tetopa Bay in Sonora to Mazatlán, Sinaloa (Browning 1994).

The subspecies S. p. castaneiceps was sampled throughout most of its distribution in the state of Baja California Sur. The study sites of this subspecies were chosen based on the locations described by Whitmore et al. (2000). A total of 11 different mangrove patches were sampled at five different locations: La Paz, Puerto San Carlos (hereafter referred to as PSC), Puerto Adolfo López Mateos (hereafter referred to as PALM), Mulegé and San Lucas (Figure1). All of these locations are found in the eastern coast of the peninsula in the Gulf of California, except for PSC and PALM which are located in Magdalena Bay at the western coast of the peninsula. Mangrove patches sampled in these two locations were grouped into one location named Bahia Magdalena for all analyses, because they are nearby and isolated from the rest of the locations.

Many of these locations have several mangrove patches. However, only mangroves in which singing males were found were considered and they were numbered according to the order in which they were sampled. The number of mangrove patches and distance between them varied in each locality (Table1). Overall, I sampled 23 individuals in 11 mangrove patches. In La Paz two mangrove patches were sampled (Figure 2) in mangrove 1 four males were recorded (Figure 3-a) and in mangrove 2 two males were recorded (Figure 3-b). The localities of PSC and PALM in Bahia Magdalena are $43.5 \mathrm{Km}$ apart. In PSC two mangrove patches were sampled (Figure 4) and only one male was recorded in each of these mangroves (Figure 5). In PALM two mangrove patches were sampled (Figure 6) and only one male was recorded in each of these mangroves (Figure 7). In Mulegé three mangrove patches were sampled (Figure 8). At Requesón beach (mangrove 7) two individuals were recorded (Figure 9-b). At Cocos beach (mangrove 8) three males were recorded (Figure 9-b) and at Santispac beach (mangrove 9) 
three individuals were recorded (Figure 9-c). In San Lucas two small mangrove patches were sampled (Figure10). In mangrove 10 two individuals were recorded (Figure 11-a) and in mangrove 11 three individuals were recorded (Figure11-b).

Although the subspecies $S$. p. rhizophorae is distributed on the main-land in the states of Sonora and Sinaloa, my study sites were located only in the state of Sonora due to travel restrictions in Sinaloa. A total of eight different mangrove patches were sampled in three locations: El Soldado, La Piedra and Yavaros (Figure1). The number of mangrove patches and distance between them varied in each locality (Table 2).

In Sonora the mangroves were not as fragmented as in Baja California Sur. Mangrove patches were bigger and continuous. The number of mangrove patches and distance between them varied in each locality (Table 2). I sampled 26 individuals in 8 mangrove patches. In San Carlos at the estuary El Soldado there was one mangrove patch that was accessible to be sampled (mangrove 12). Eight males were recorded here (Figure12). In La Piedra a large continuous mangrove patch and a smaller one were sampled (Figure 13). Six males were recorded in mangrove 13 (Figure 14-a) and one in mangrove 14 (Figure 14-b). In Yavaros five mangrove patches were sampled (Figure 15). In mangrove 15 four males were recorded (Figure 16-a), in mangrove 16 two males were recorded (Figure 16-b), in mangrove 17 one male was recorded (Figure16-c), in mangrove 18 two males were recorded (Figure16-d) and in mangrove 19 two males were recorded (Figure 16-e).

\section{Data Collection}

I collected data during the breeding season (March- April) of 2011. The subspecies S. p. rhizophorae was banded and recorded from March 25 to April 7 and the subspecies S. p. castaneiceps was recorded from April 11 to April 24 (these birds had been banded the previous year). 
Each of the mangrove patches was inspected to determine the presence of the Mangrove Warbler. Once an individual was located, it was captured using mist nets and then banded. One leg was banded with a U.S. Geological Survey aluminum band and a color band corresponding to one of the locations and the other leg was banded with three color bands giving a unique color combination for each bird for individual identity (Figure 17) (For color abbreviations code see Table 3). For each captured bird the following data was obtained: geographic coordinates, using a GPS; age, by plumage and skull ossification; biometric measurements, and photos of the plumage and color bands.

Because their singing behavior has not frequent and constant, only the birds that were singing more often were recorded. Therefore, not all birds that were banded were recorded and some birds that were not banded but were singing were recorded. Fortunately, their territoriality made it possible to recognize an individual even if he was not banded. Each day, starting form 6:00 am until 6:00 pm, I recorded as many individuals as possible. Each bird was recorded only one day during one recording session, lasting approximately one hour to obtain as much as possible from its repertoire. The recording was not continuous, a bird was recorded as soon as he was seen, even if he was not singing, to avoid incomplete recordings of the first song and it was stopped either when the bird stopped singing for over 2 minutes or when it flew away. Therefore, several recordings were obtained for each bird (Table 4). Most recordings were done at a distance between $4 \mathrm{~m}$ and $15 \mathrm{~m}$ from the individual. For each recorded male the following data were obtained: Location, date, hour, males' identity (color band combinations when banded) and particular behaviors if observed.

\section{Data Analysis}

Song Classification

Each of the recordings of a male was examined to group similar songs and to determine its repertoire of song types. I used the software Raven Pro 1.4 which displays visualization 
graphics of sound in waveforms and sonograms. The sonogram view was used to look at each song and determine similarities and differences with other songs. This program has a feature for manually selecting the desired sounds while looking at the sonogram, so the songs recorded from the target bird were selected and saved into a new file to ignore the songs of other birds in the recording. The songs given by other birds had been detected previously while recording in the field and they were specified by the narrator in the recording. Then the new and "clean" file of each recording was examined to determine similarity among songs and classify them into several song types according to their similarities following Beebee (2002). This was done by manually selecting each song while the program automatically creates a list of these selections. Once the total songs of an individual were selected each song was visually and auditively examined and named after a particular song type depending on its similarities. Each bird had A, B, C, D... song types depending on the number of song types found for each individual. The distinction between song types of an individual was very clear because most birds sing the same song repeatedly before switching to another song type and all songs within a song type are almost identical to each other and very different to the songs of another song type in syllable composition.

Once the songs of each individual were classified into song types, these were used to compare song types between all individuals. I reclassified song types as Beebee (2002) depending on their note arrangement. Similar song types were grouped together taking into account that slight differences such as addition or deletion of some notes could occur among males. All these song groupings were then relabeled according to a new song type classification done with numbers. These new song types were then classified again into two levels of organization and into a category of acoustic ending. Levels of organization: 1) Shared \& Unshared Song Types: Shared song types were those that were given by different birds and had the same syllables presented in the same order, taking into account that there could be small individual variation such as adding or deleting a few notes, or switching a few notes but 
always keeping the general pattern of the whole song (Figure 18-a). Unshared song types were the ones that were given only by one bird. 2) Patterns: The song types that had greater differences than the shared song types but had similar note patterns in part of their songs were considered to have shared patterns. Such patterns can be distinguished by a few successive and unrepeated notes that were found equally in other song types, usually at the end of the song, but having a completely different set of introductory notes (Figure 18-b). Categories of acoustical ending: All song types were classified into two groups depending on the terminal note characteristics. Song types that showed an increase in frequency of at least $2 \mathrm{kHz}$ from the beginning to the end of the terminal note were classified into accented ending songs (hereafter referred to as $A E S$ ) and songs that did not have this frequency change in their last note were classified into unaccented ending songs (hereafter referred to as UES) (Figure 18-c), referring to the terminology used by Morse (1966) and Bankwitz and Thompson (1979).

\section{Repertoire Analyses}

Song repertoire was described by its size and composition. Repertoire size was obtained by counting the number of different song types given by a bird and cumulative plots were done to evaluate if the entire repertoire had been sampled and if the repertoire size estimation was accurate. Cumulative plots were created by estimating sample-based rarefaction in EstimateS 8.2 and then using the results of Sobs (number of species observed) to produce an Excel graph of $x=$ number of songs recorded and $y=$ number of song types. Repertoire was also described depending on the order in which songs were sung to evaluate if there is any pattern of song delivery. Also, repertoire composition was assessed on the number of AES and UES.

\section{Acoustic characteristics}

To describe the general song characteristics of the Mangrove Warbler, general patterns of the song were evaluated and different measurements were taken on one example, the most complete and clear sonogram, of each of the song types from all birds. Six variables were 
measured: song duration, maximum and minimum frequency, number of notes, number of note types and number of introductory notes. A versatility index (VI), which describes how complex the song is, was calculated by $\mathrm{VI}=$ number of notes/number of different note types. The mean and standard deviations were estimated for all of these variables.

\section{RESULTS}

\section{Recording Success}

A total of 4959 songs were recorded from 49 Mangrove Warbler males of northwestern Mexico. Of these, 2596 songs were recorded from 23 males belonging to the castaneiceps subspecies and 2363 songs were recorded form 26 males belonging to the rhizophorae subspecies (Table 4).

\section{Song Characteristics}

The typical song of a Mangrove Warbler is $1.5 \pm 0.9$ seconds long and falls between a frequency of 1.6 and $9.6 \mathrm{kHz}$ (minimum frequency $\bar{x}=2.3 \pm 0.3$, maximum frequency $\bar{x}=7.5 \pm$ 1.1). It is comprised by a sequence of 4 to 17 notes $(\bar{x}=10.2 \pm 2)$ that are diverse (VI: $\bar{x}=0.65$ \pm 0.12 ). The arrangement of the notes exhibit an introductory, middle and ending part of the song (Figure 19). The introductory part of the song is a phrase formed by a sequence of about 3 identical notes $(\bar{x}=3.14 \pm 1.27)$, or syllables in a few cases, which show a frequency decline from the beginning to the end of the note (Figure 19-a). The middle part of the song is generally formed by a sequence of varied notes, usually having a pair of identical consecutive notes somewhere in between this sequence (Figure 19-b). The ending part of the song is usually characterized by a single accented or unaccented terminal note (Figure 19-c). 


\section{Song Classification}

I identified 229 different song types in the studied populations. These songs did not occur with the same frequency. Some song types were sung by only one bird $(71 \%)$, while others were shared by at least 2 or more individuals (29\%).

Some of these song types (47\%) had similar song patterns. A total of 43 general song patterns were found. Only $38 \%$ of the song types were exclusive, they were given by only one individual and did not share similar patterns with any of the other songs.

\section{Song Repertoires}

Mangrove Warblers deliver their song types with eventual variety, meaning that several songs of the same type are sung consecutively before switching to a different type. A male's repertoire is usually dominated by one song type that is delivered more frequently than the rest of the song types.

The estimated repertoire size for the Mangrove Warbler males ranges from 2 to 14 song types $(\bar{x}=7.2 \pm 2.7)$. Repertoire size for the castaneiceps subspecies ranges from 2 to $12(\bar{x}=$ $6.9 \pm 2.9)$ and for the rhizophorae subspecies ranges from 2 to $14(\bar{x}=7.4 \pm 2.5)$. However, the accumulation curves did not show a clear pattern of the number of songs that needed to be recorded in order to reach the asymptote and obtain an accurate estimate of the repertoire size (Figure 20). Some of the birds clearly reached the asymptote before 60 songs had been analyzed, even some birds for which I had fewer recordings reached the asymptote before 30 songs had been analyzed and, thus, a reliable estimate of repertoire size could be obtained in these cases. On the other hand, for other birds the cumulative plots kept on increasing, even for those for which I had over 150 songs recorded. According to Botero et al (2008), if there is an incomplete sampling, repertoire size estimation using cumulative plots may yield to similar of greater magnitude errors than those made by researchers when estimating repertoire size 
based on counting the different song types of a males' repertoire. Therefore, the repertoire size was estimated by simply counting the number of different song types given by each male, regardless if the cumulative plot of the sampling effort for each male had reached the asymptote.

The repertoire of a Mangrove Warbler is composed by several UES and AES. However, the proportion of AES is typically less than that of UES. I found that (34.5\%) of the song types were AES and (65.5\%) were UES. Most males' repertoires contained several song types of both kinds of endings, only 12 out of the 49 males had no more than one song type with accented ending and just one male lacked accented ending songs in his repertoire.

\section{DISCUSSION}

The song characteristics of the Mangrove Warbler are similar to those of other Wood Warblers. They are comprised by several phrases consisting of a series of identical notes, with a unique note ending that can be categorized into accented or unaccented ending note as described by Bankwitz and Thompson (1979) on Yellow Warblers. Also, these song phrases of the Mangrove Warblers tend to exhibit a clear introductory, middle and ending part of a song like in those of the Hermit Warblers studied by Gil and Slater (2000). These different parts of the songs may have different functions. For example, in Hermit Warblers (Setophaga occidentalis) the introductory part of the songs determines dialect formation based on distinctions on length and frequency (Janes and Ryker 2006) and in White-crowned sparrows the whistle part of the song provides the species identification, while the note complex serves in individual identification and the trill varies geographically in song dialects (Nelson and Poesel 2011).

The frequency range of the songs of the Mangrove Warblers subspecies S. p. castaneiceps and S. p. rhizophorae is similar to the findings of Mennill (2001) on the S. p. bryanti subspecies. 
Mennill (2001) compared these song characteristics to those of the Northern Yellow Warbler and found that Mangrove Warbler songs are given through a lower frequency range that those of Northern Yellow Warblers. His findings could be explained by several interpretations related to physiological, morphological or ecological differences. One of such interpretations suggest that these differences could be due to different habitat qualities where in forested or more dense habitats higher frequency sounds are better transmitted than in open areas. Further research on such acoustic adaptation hypothesis would be needed to test whether differences in song frequency between Northern and Mangrove Warblers are related to different habitat types.

Although Curson et al. (1994) suggests that Mangrove Warbler song system is comprised by only AES, except for the Galapagos subspecies (S. p. aureola) which only sings UES, my findings are more similar to those of Mennill (2001) on the S. p. bryanti subspecies which has a repertoire comprised by several AES and UES. Furthermore, the categories in which I classified the repertoire of the Mangrove Warbler subspecies that I studied, have structural characteristics of the terminal syllable which are equivalent to those of other Yellow Warblers song categories described by Bankwitz \& Thompson (1979) and Spector (1991). Although my classification was based on structural characteristics only and does not have behavioral data to support it, the song categories found on the Mangrove Warbler population studied by Mennill (2001) are functionally equivalent to those of the Yellow Warbler described by Spector (1991).

However, it has been noticed that Type I (AES) are preferably used during the breeding season, prior to and during pair formation (Bankwitz and Thompson 1979, Morse 1966), in the presence of females (Morse 1966, Bankwitz and Thompson 1979, Spector 1992), when delivering food to nestlings (Morse 1966, Spector 1992) and in the presence of other species, particularly closely related species (Morse 1966); and Type II songs are used mostly during the end of the breeding season after pair formation, on territorial boundaries (Bankwitz 
and Thompson 1979), for intraspecific use species (Morse 1966) and during disputes with other males (Morse 1966, Bankwitz and Thompson 1979, Spector 1992). I believe that future research on these behavioral aspects should be done to evaluate the song repertoire classification of the Mangrove Warbler.

The number of AES and UES that compose a Mangrove Warblers' repertoire is different from that found in Yellow Warblers. I found that a Mangrove Warblers' repertoire can have several AES and UES. Although the proportion of AES is much less than that of UES, in Yellow Warblers described by Spector (1991) a males' repertoire is composed by only one Type I song (AES) and several Type II songs (UES).

The songs of the populations I sampled were generally delivered with eventual variety. However, Mennill (2001) found that songs of the S. p. bryanti were delivered with immediate variety. In Yellow Warblers the only song of type I song in a males repertoire is delivered consecutively while type II are delivered frequently switching several song types (Byers 1995). Such relationship of song delivery to the different song ending categories has not been analyzed in Mangrove Warbler populations, but they could provide a cue on differences of song type use. In several brid species it has been found that immediate variation in song delivery could be related to territorial maintenance. Because neighboring males may habituate to song types and increase in song type switching rate may serve to maintain their response (Collins, 2004) 


\section{LITERATURE CITED}

BYERS, B. E. 1996. Geographic variation of song form within and among Chestnut-sided Warbler populations. Auk 113:288-299.

BANKWITZ, K. G., AND W. L. THOMPSON. 1979. Song characteristics of the Yellow Warbler. Wilson Bulletin 91:533-550.

BEEBEE, M. D. 2002. Song sharing by Yellow Warblers differs between two modes of singing: implications for song function. Condor 104:146-155.

BRownING, M. R. 1994. A taxonomic review of Dendroica petechia (Yellow Warbler) (Aves: Parulinae). Proceedings of Biological Sciences of Washington 107:27-51.

Botero, C. A., A. E. Mudge, A. M. Koltz, W. M. HochachKa, and S. L. Vehrencamp. How reliable are the methods for estimating repertoire size? 2008. Ethology 114:1227-1238.

CAtChPOle, C. K., AND P. J. B. Slater. 2008. Bird song: biological themes and variations. Cambridge University Press, Cambridge.

COLLINS, S. 2004. Vocal fighting and flirting: the functions of birdsong. In: Nature's Music: The science of birdsong. (Ed. by P.M. Marler and H. Slabbekoorn). Elsevier Academic press, pp. 48

GIL, D., AND P.J. B. SLATER. 2000. Song organization and singing patterns of the Willow Warbler, Phylloscopus trochilus. Behavior 137:759-782.

JANES, S. W., AND L. RYKER. 2006. Singing of Hermit Warblers: Dialects of type I songs. Condor 108:336-347.

MENNILL, D. 2001. Song characteristics and singing behavior of the Mangrove Warbler (Dendroica petechia bryanti). Journal of Field Ornithology 72:327-337.

MORSE, D.1966. The context of songs in the Yellow Warbler. Wilson Ornithological Society 78:444-455.

Nelson, D. A., AND A. POESEL. 2011. Song length variation serves multiple functions in the White-crowned Sparrow. Behavioral Ecology and Sociobiology 65:1103-1111. 
SPECTOR, D. 1992. Wood-warbler song systems: a review of Parulinae singing behaviors. Current Ornithology 9:199-292.

Whitmore, R. C., R. C. Whitmore, AND M. M. Whitmore. 2000. Distributional notes on the Mangrove Warbler (Dendroica petechia castaneiceps) near the northern edge of its range in Eastern Baja California Sur, Mexico. Western North American Naturalist 60:228-229.

WilBuR, S. R. 1987. Birds of Baja California. University of California Press, California. 


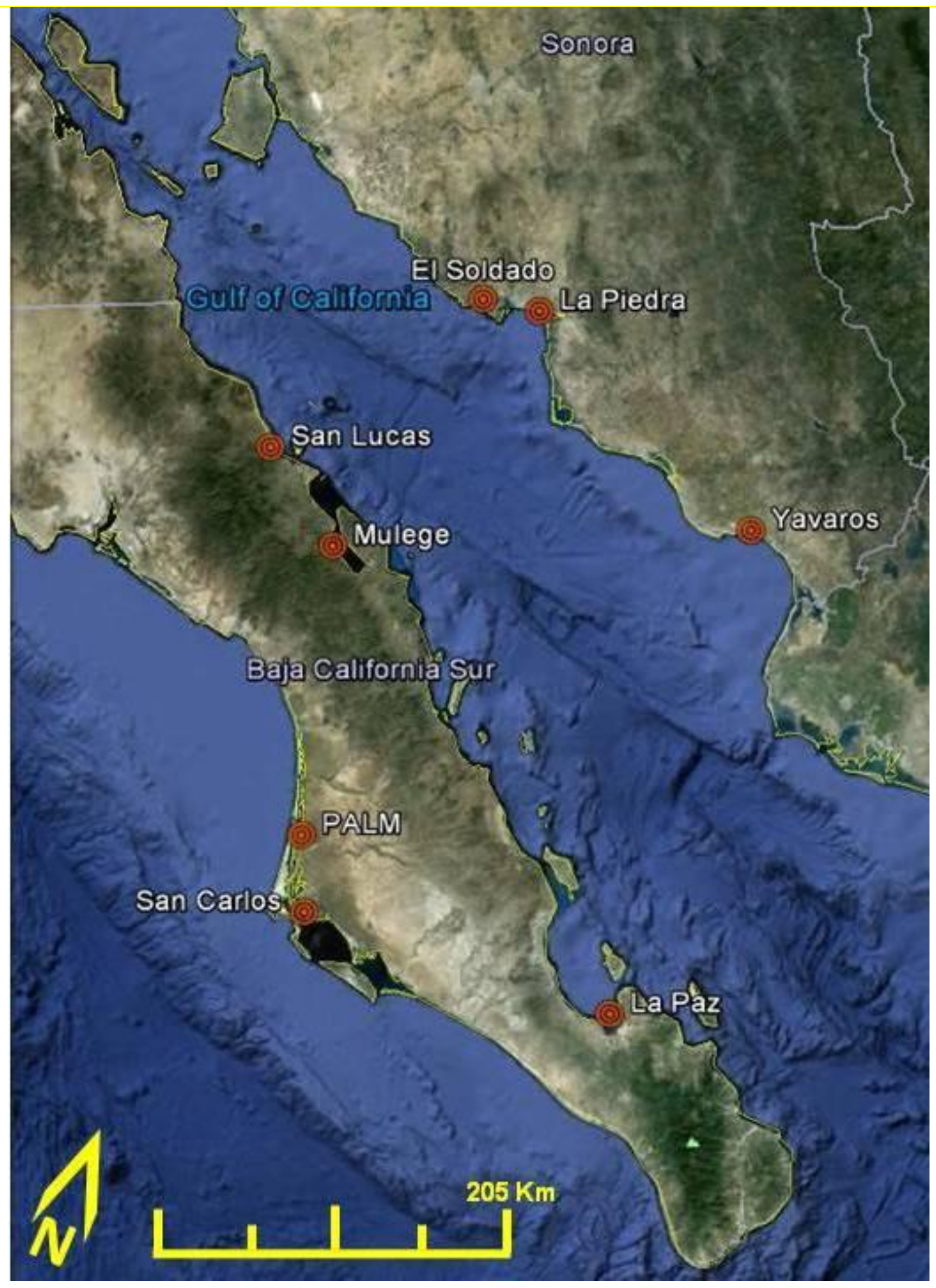

Figure 1. Locations of study sites in Baja California Sur and Sonora, México. Map data: Google, TerraMetrics, 2012. North arrow and distance scale redrawn by Taryn Tuncer. 
Table 1. Distance between mangrove patches within each location of Baja California Sur, México (S. p. castaneiceps)

\begin{tabular}{|c|c|c|c|c|c|c|c|}
\hline Location & $\underline{\text { La Paz }}$ & $\mathrm{PSC}$ & PALM & & Mulegé & & San Lucas \\
\hline Mangrove Patch & $1-2$ & $3-4$ & $5-6$ & $7-8$ & $7-9$ & $8-9$ & $10-11$ \\
\hline Distance $(\mathrm{Km})$ & 6.76 & 2.63 & 1.66 & 13.41 & 15.13 & 2.22 & 1.08 \\
\hline
\end{tabular}

Table 2. Distance between mangrove patches within each location of Sonora ( $S$. $p$. rhizophorae). The location of San Carlos is not included because there was only one mangrove patch sampled.

\begin{tabular}{lcccccccccccc}
\hline Location & La Piedra & \multicolumn{10}{c}{ Yavaros } \\
\cline { 2 - 13 } Mangrove Patch & $13-14$ & $15-16$ & $15-17$ & $15-18$ & $15-19$ & $16-17$ & $16-18$ & $16-19$ & $17-18$ & $17-19$ & $18-19$ \\
Distance $(\mathrm{Km})$ & 1.35 & 2.6 & 5.35 & 6.22 & 7.06 & 8.01 & 8.81 & 9.67 & 0.83 & 1.71 & 0.97 \\
\hline
\end{tabular}




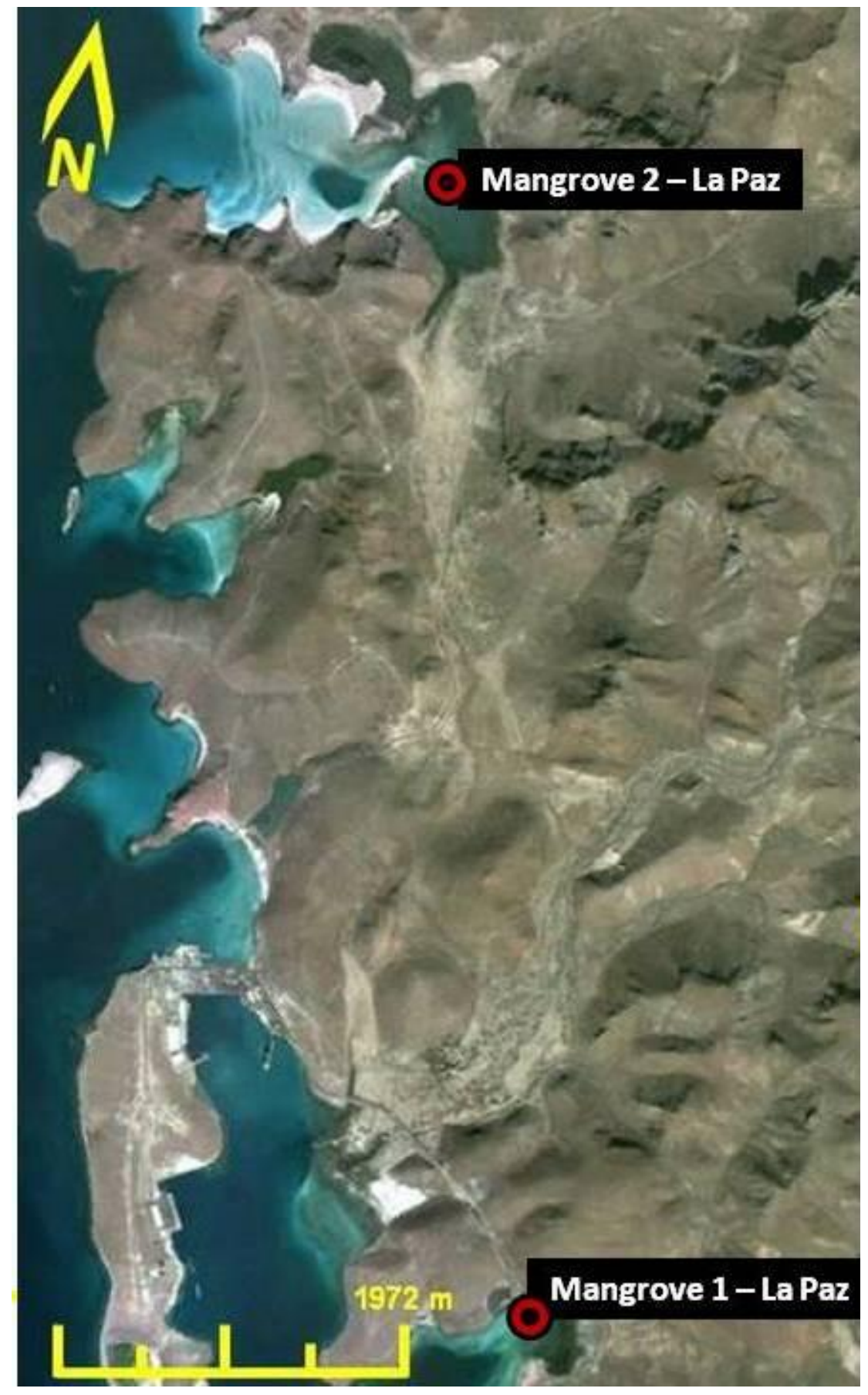

Figure 2. Mangrove patches in La Paz, Baja California Sur, México. Map data: Google, DigitalGlobe, 2012. North arrow, distance scale and labels redrawn by Taryn Tuncer. 


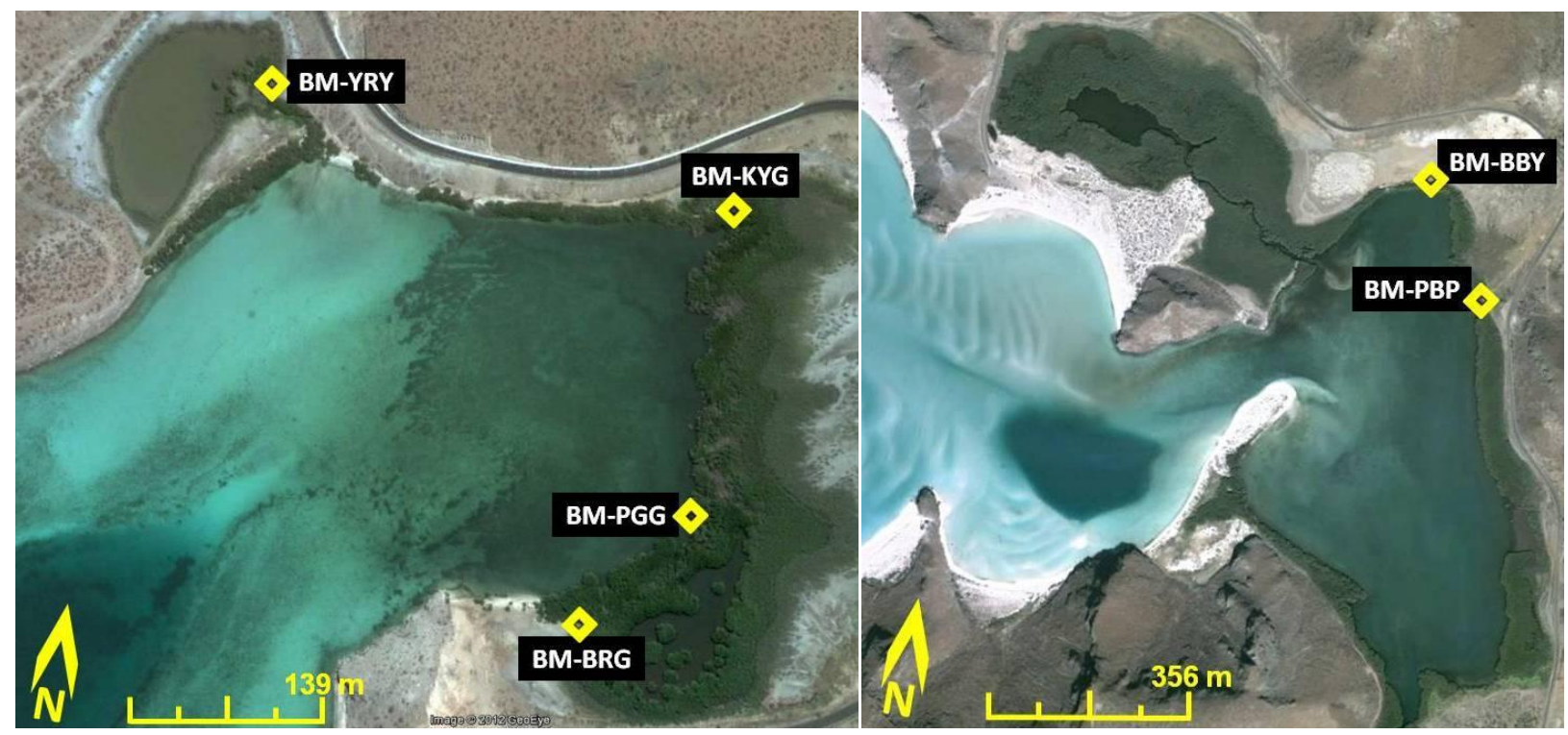

Figure 3. Locations of recorded males in mangroves of La Paz, Baja California Sur, México. Left: Mangrove 1. Map data: Google, GeoEye, 2012. North arrow, distance scale and labels redrawn by Taryn Tuncer. Right: Mangrove 2. Map data: Google, DigitalGlobe, 2012. North arrow, distance scale and labels redrawn by Taryn Tuncer. 


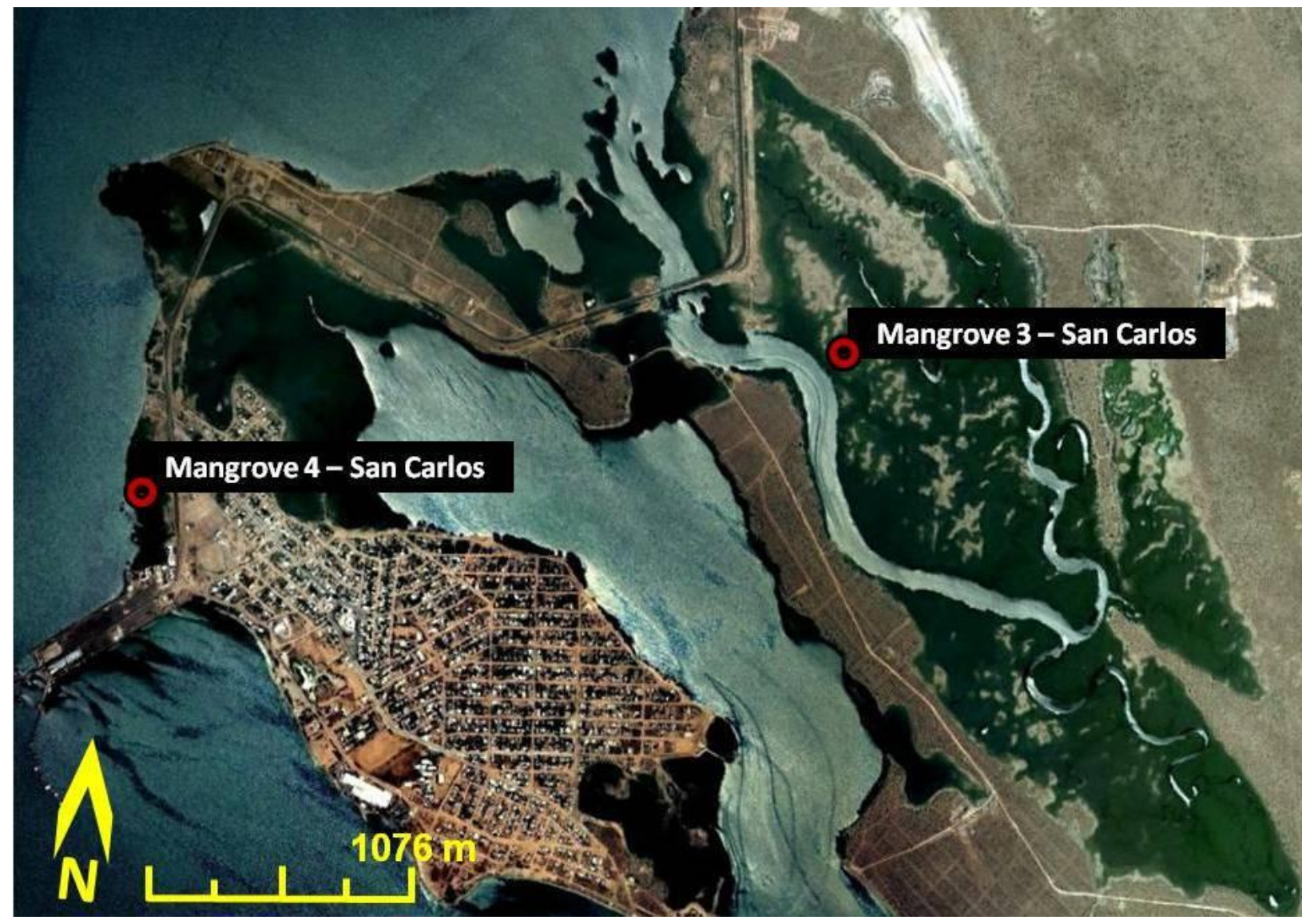

Figure 4. Mangrove patches in Puerto San Carlos, Baja California Sur, México. Map data: Google, TerraMetrics, GeoEye, 2012. North arrow, distance scale and labels redrawn by Taryn Tuncer. 


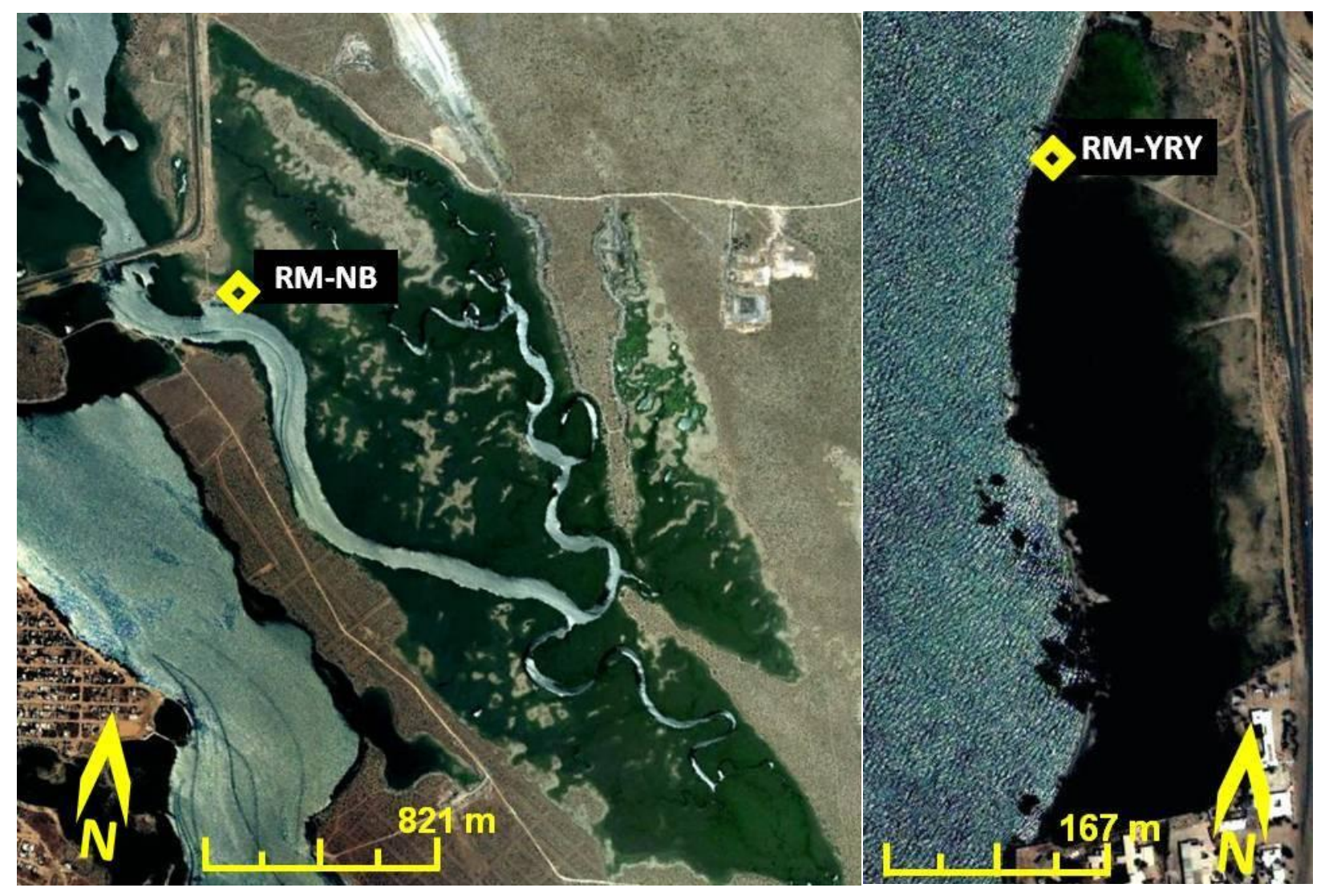

Figure 5. Locations of recorded males in mangroves of Puerto San Carlos, Baja California Sur, México. Left: Mangrove 3. Right: Mangrove 4. Maps data: Google, GeoEye, 2012. North arrow, distance scale and labels redrawn by Taryn Tuncer. 


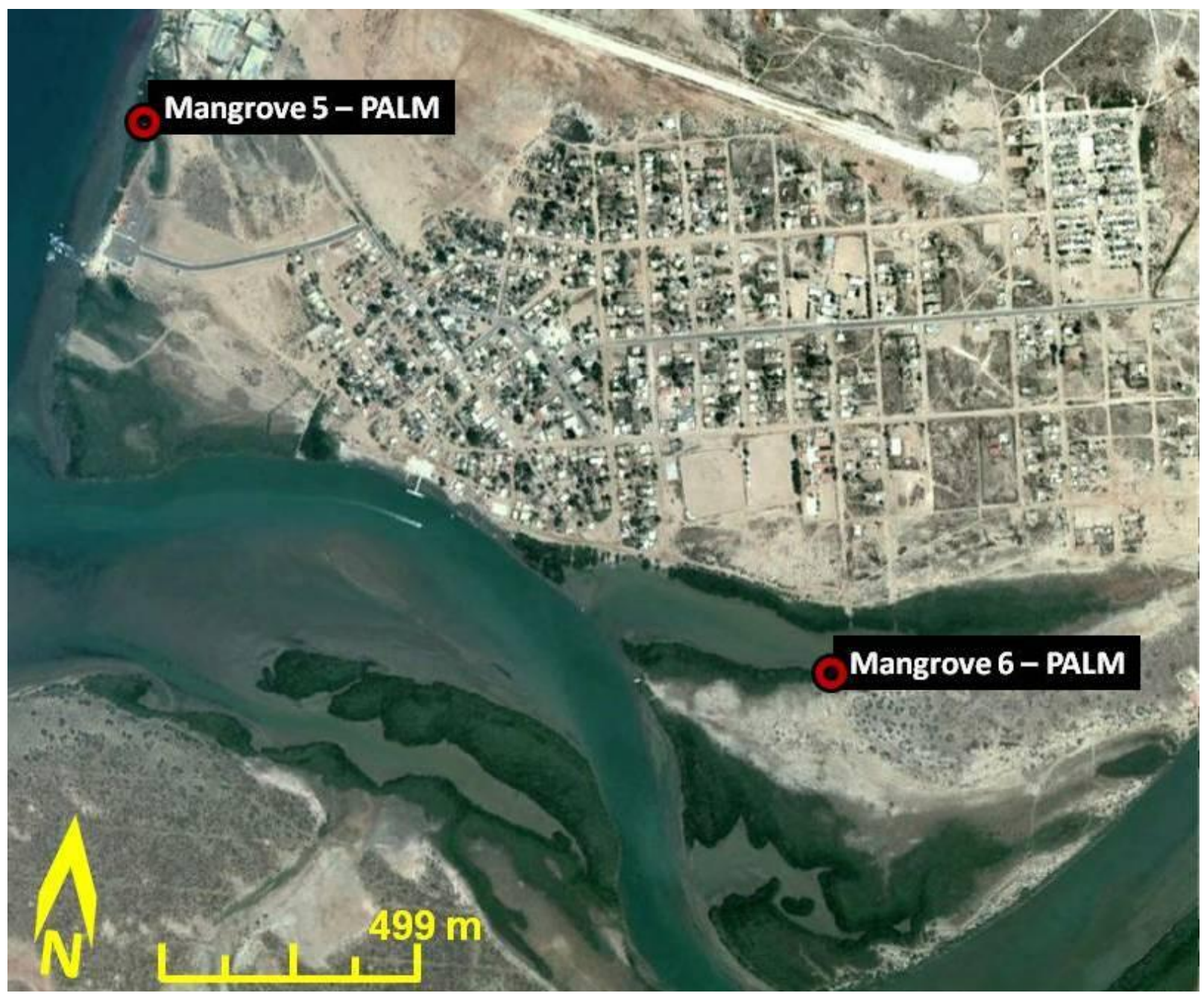

Figure 6. Mangrove patches in Puerto Adolfo López Mateos, Baja California Sur, México. Map data: Google, GeoEye, 2012. North arrow, distance scale and labels redrawn by Taryn Tuncer. 


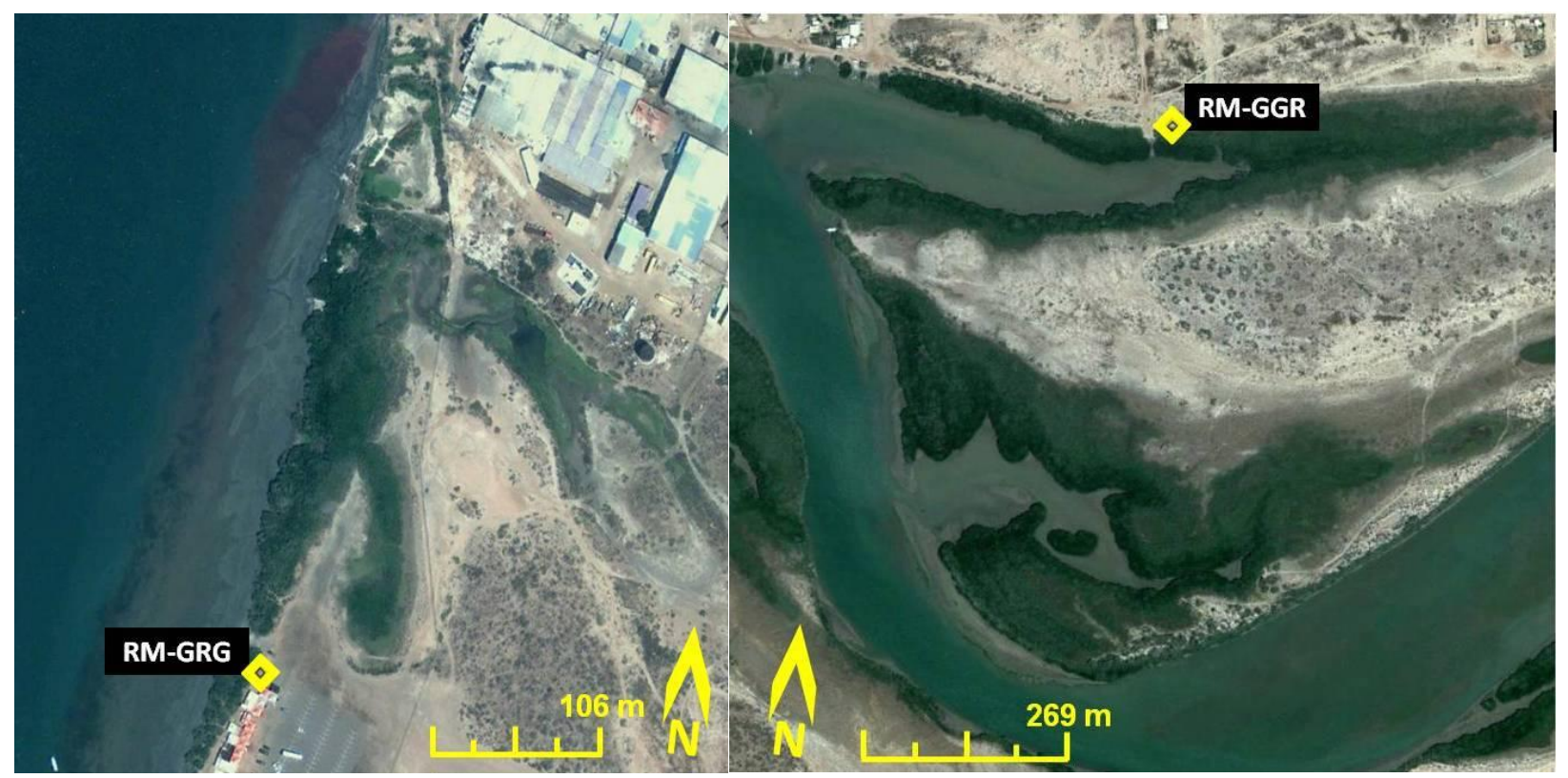

Figure 7. Locations of recorded males in mangroves of Puerto Adolfo López Mateos, Baja California Sur, México. Left: Mangrove 5. Right: Mangrove 6. Maps data: Google, GeoEye, 2012. North arrow, distance scale and labels redrawn by Taryn Tuncer. 


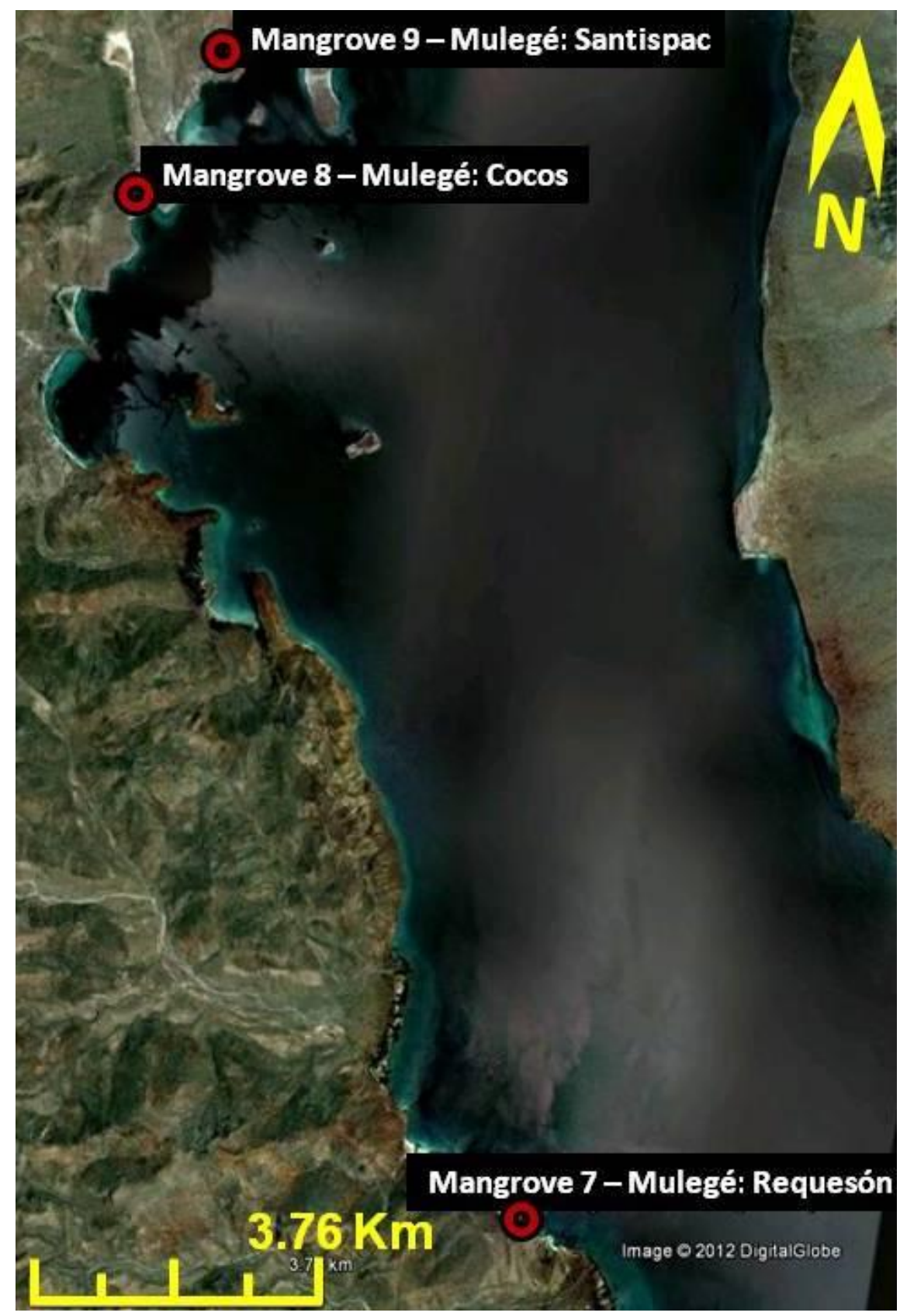

Figure 8. Mangrove patches in Mulegé, Baja California Sur, México. Map data: Google, DigitalGlobe, 2012. North arrow, distance scale and labels redrawn by Taryn Tuncer. 

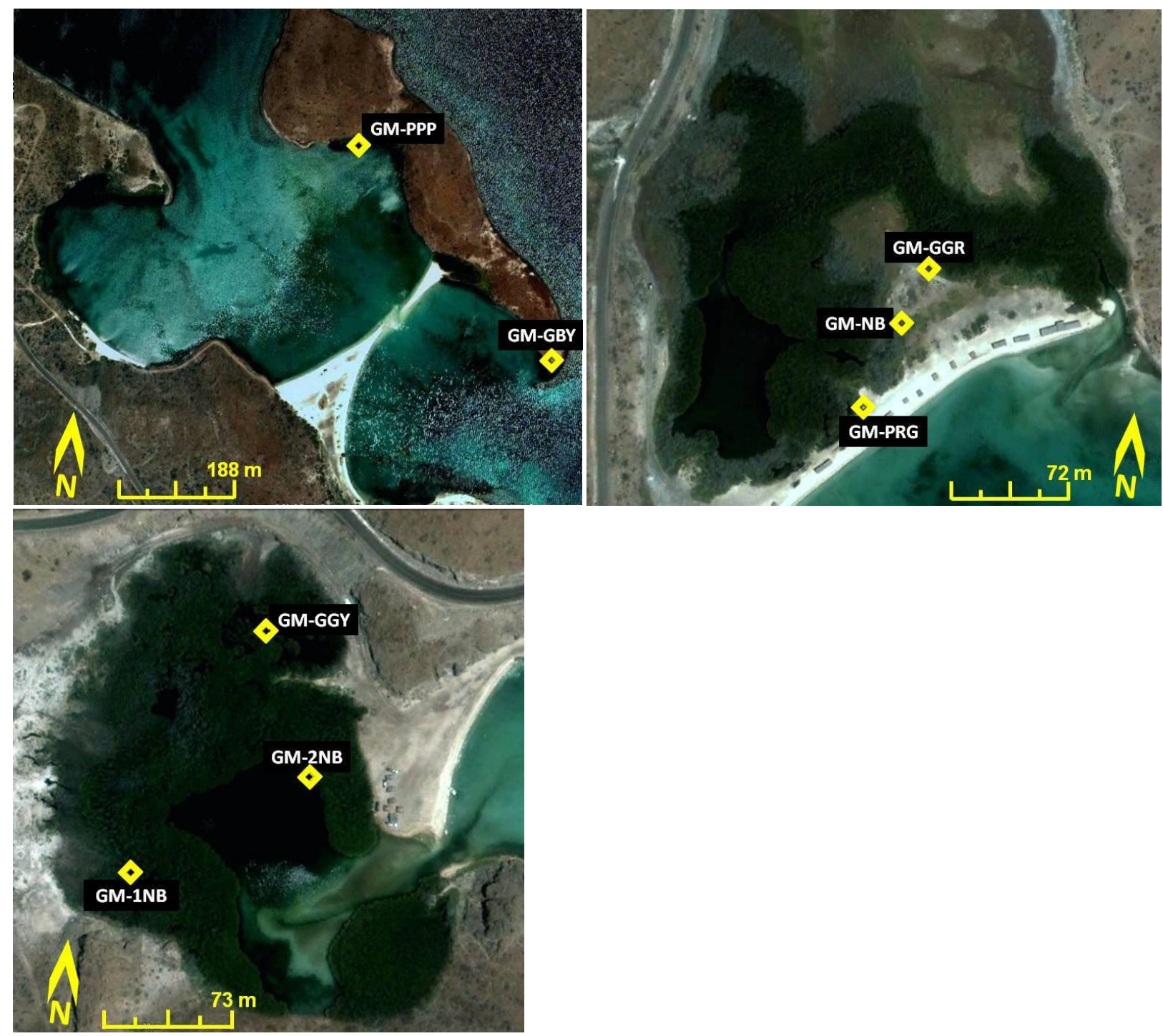

Figure 9. Locations of recorded males in mangroves of Mulegé, Baja California Sur, México. Top left: Mangrove 7. Top right: Mangrove 8. Bottom left: Mangrove 9. Maps data: Google, DigitalGlobe, 2012. North arrow, distance scale and labels redrawn by Taryn Tuncer. 


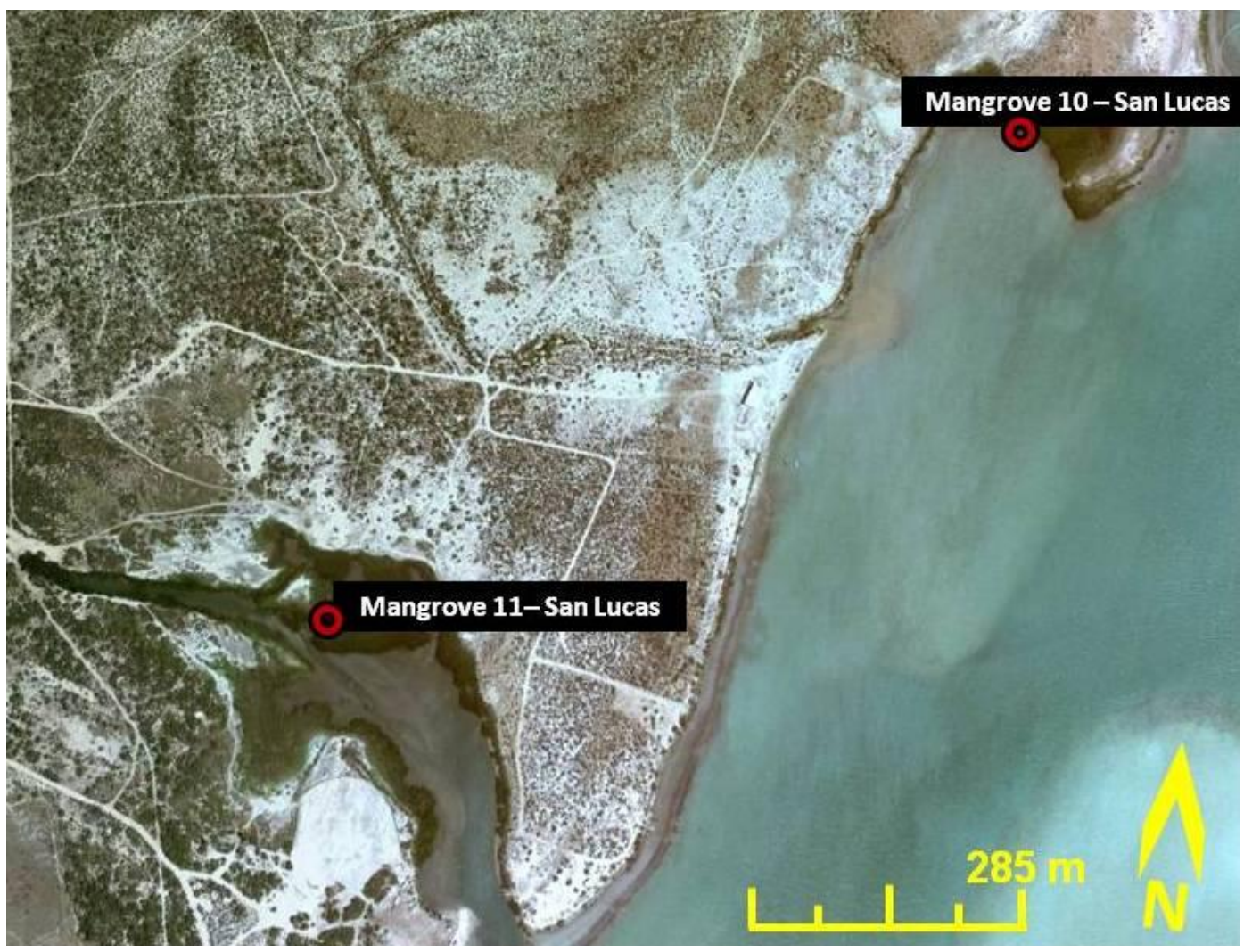

Figure 10. Mangrove patches in San Lucas, Baja California Sur, México. Map data: Google, GeoEye, 2012. North arrow, distance scale and labels redrawn by Taryn Tuncer. 


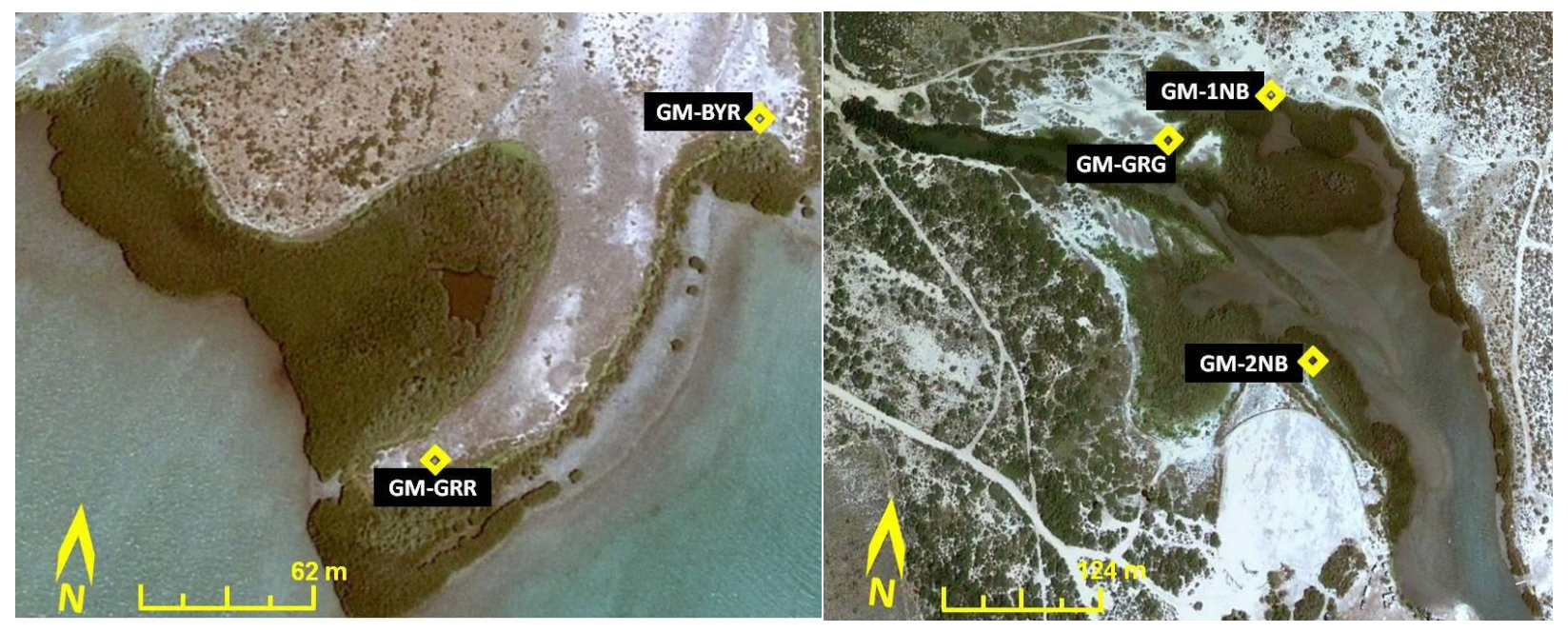

Figure 11. Locations of recorded males in mangroves of San Lucas, Baja California Sur, México. Left: Mangrove 10. Right: Mangrove 11. Maps data: Google, GeoEye, 2012. North arrow, distance scale and labels redrawn by Taryn Tuncer. 


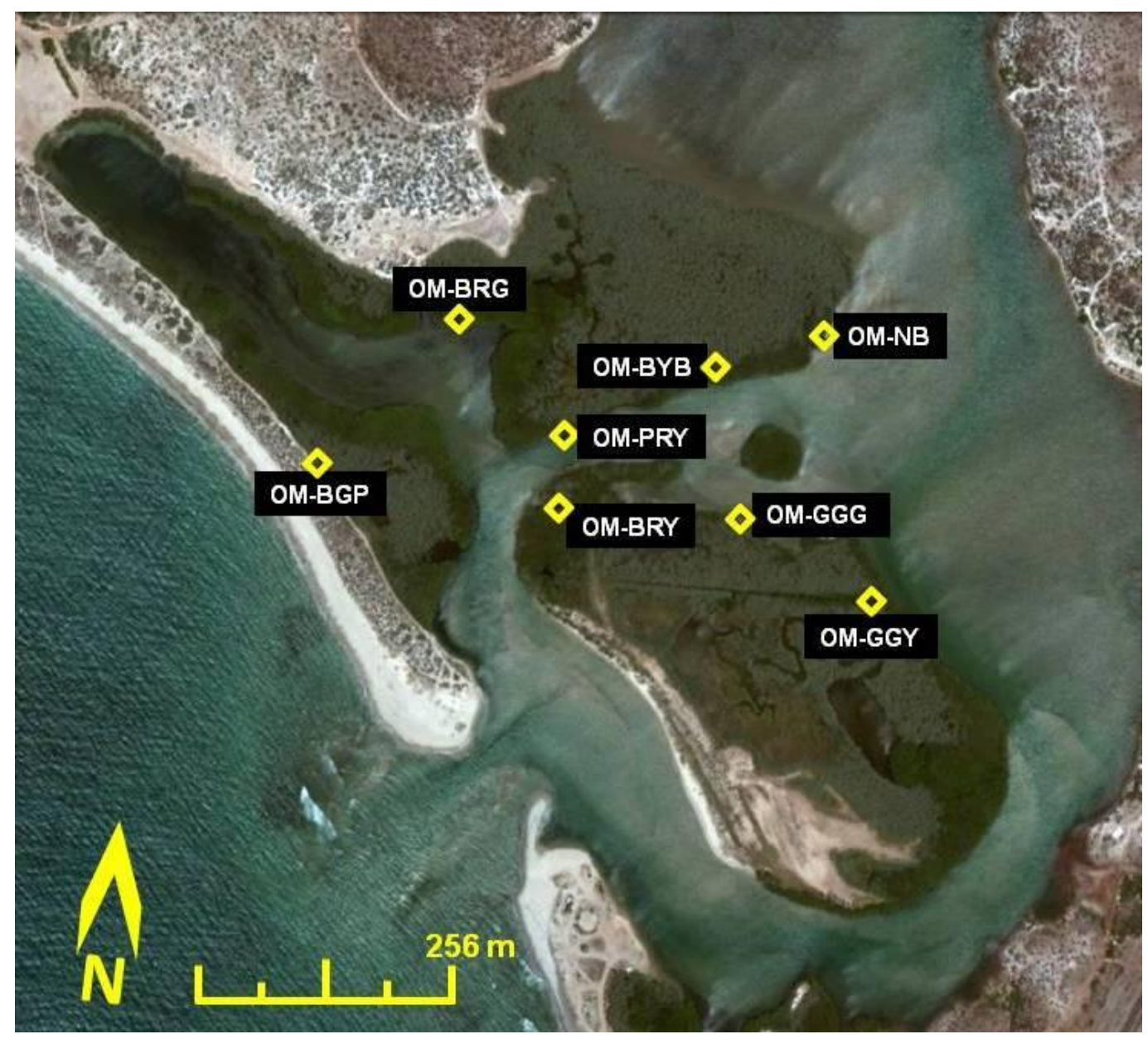

Figure 12. Locations of recorded males in mangrove Estero el Soldado, San Carlos, Sonora, México.Map data: Google, DigitalGlobe, 2012. North arrow, distance scale and labels redrawn by Taryn Tuncer. 


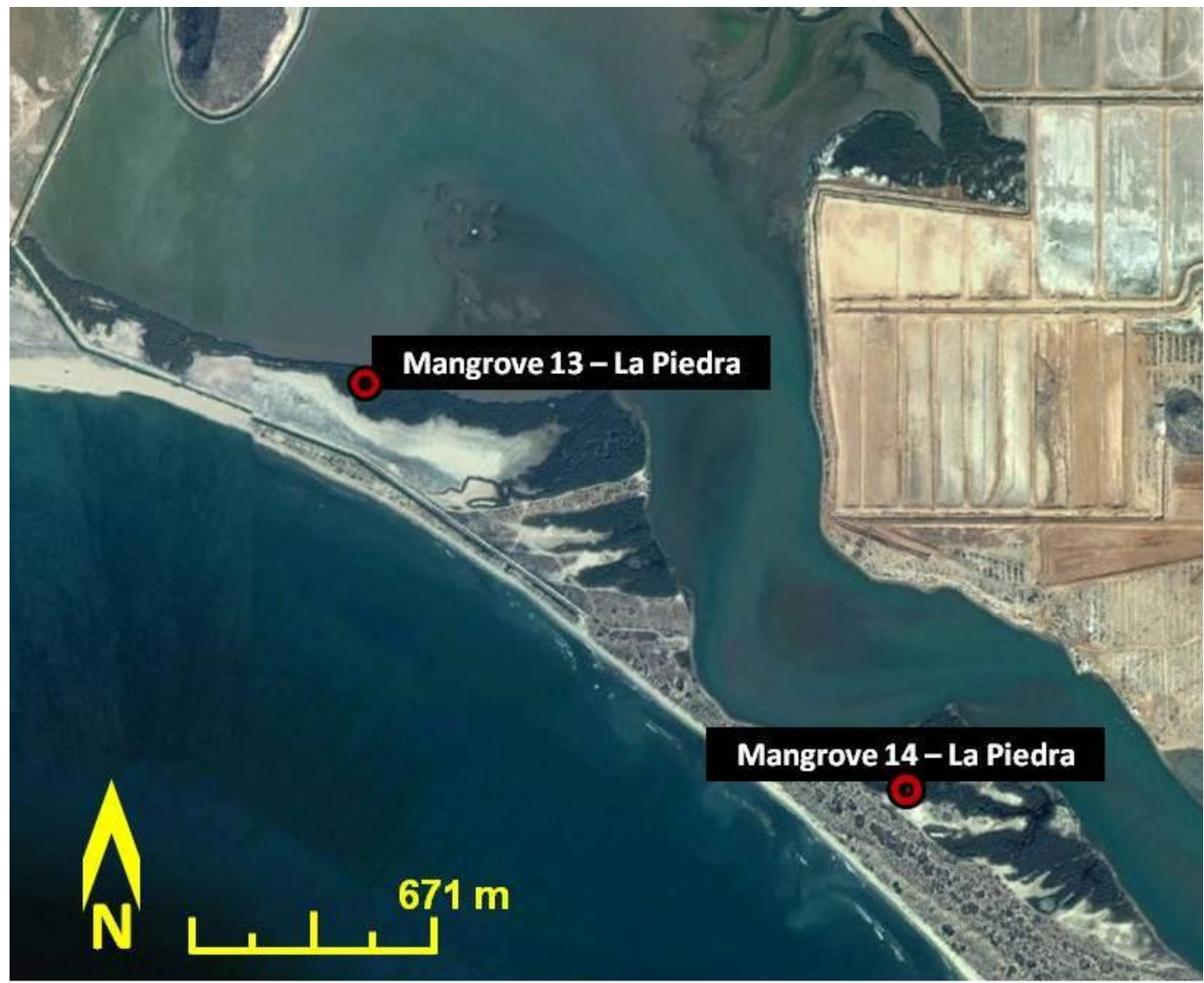

Figure 13. Mangrove patches in La Piedra, Sonora, México. Map data: Google, DigitalGlobe, GeoEye, TerraMetrics, 2012. North arrow, distance scale and labels redrawn by Taryn Tuncer. 

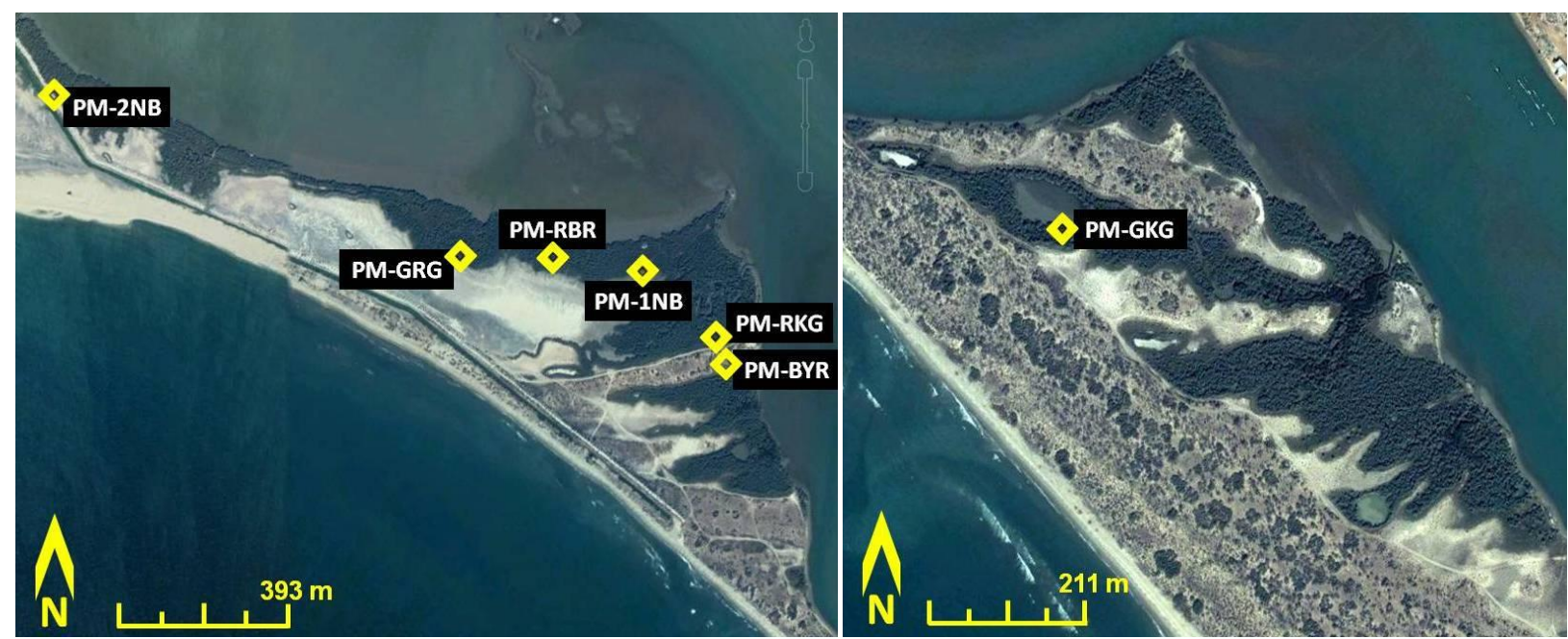

Figure 14. Locations of recorded males in mangroves of La Piedra, Sonora, México. Left: Mangrove 13. Map data: Google, DigitalGlobe, GeoEye, TerraMetrics, 2012. North arrow, distance scale and labels redrawn by Taryn Tuncer. Right: Mangrove 14. Map data: Google, DigitalGlobe, 2012. North arrow, distance scale and labels redrawn by Taryn Tuncer. 


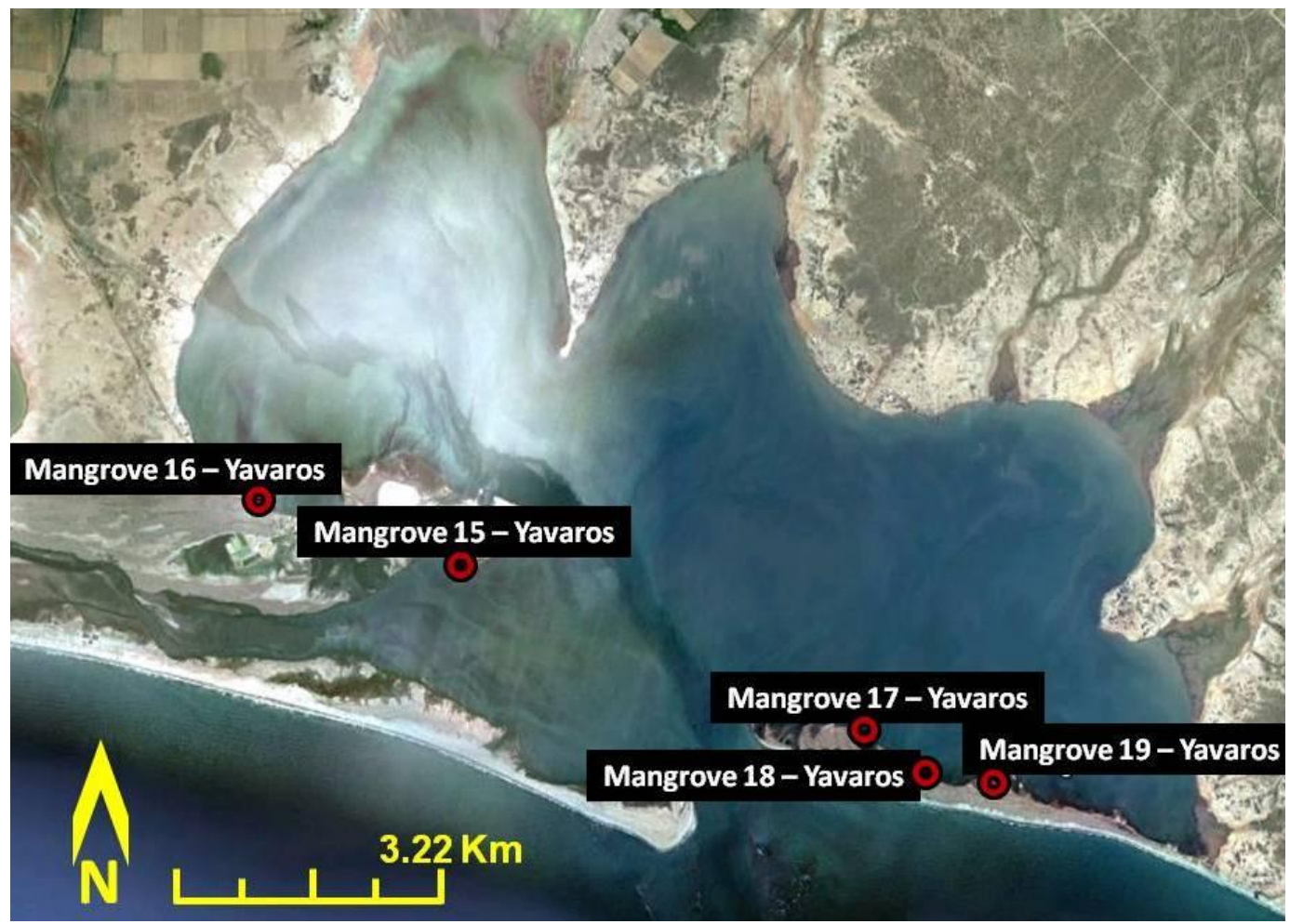

Figure 15. Mangrove patches in Yavaros, Sonora, México. Map data: Google, GeoEye, 2012. North arrow, distance scale and labels redrawn by Taryn Tuncer. 

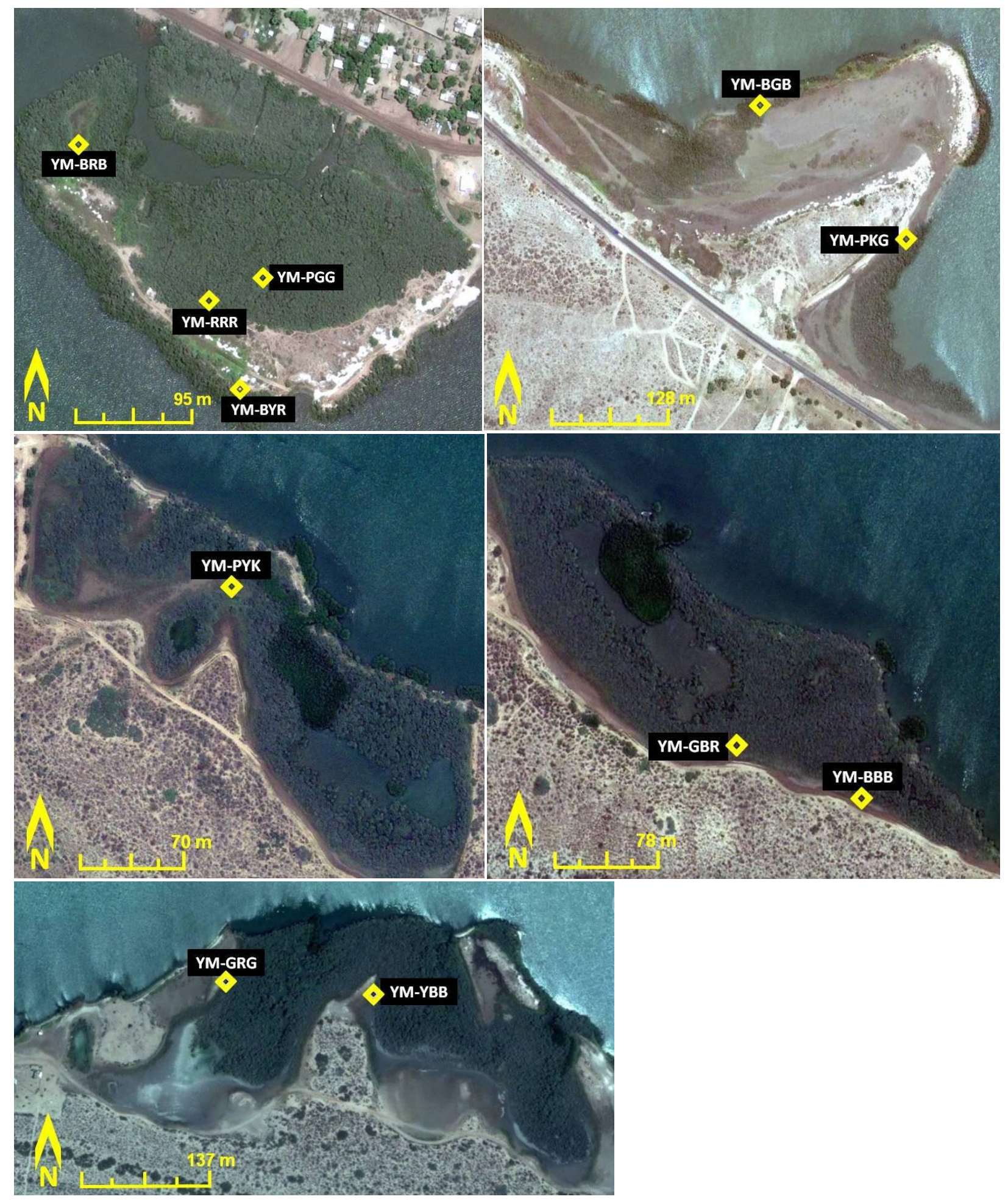

Figure 16. Locations of recorded males in mangroves of Yavaros, Sonora, México.Upper left: Mangrove 15. Upper right: Mangrove 16. Middle left: Mangrove 17. Middle right: Mangrove 18. Bottom: Mangrove 19. Maps data: Google, GeoEye, 2012. North arrow, distance scale and labels redrawn by Taryn Tuncer. 


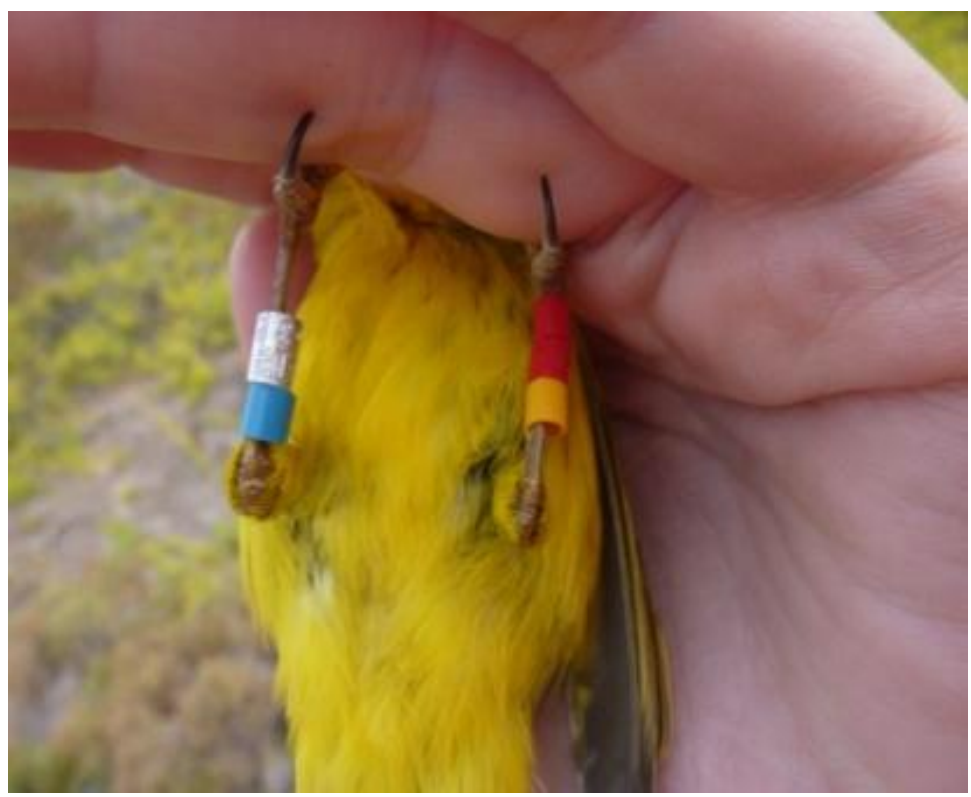

Figure 17. Bands. Federal and locality color bands on the right foot and individual color combinations bands on the left foot. In this example, the birds ID is: $B / M-Y / R / R$.

Table 3. Band color abbreviation codes.

\begin{tabular}{|c|c|}
\hline Abbreviation & Color \\
\hline M & Metal \\
\hline B & Blue \\
\hline Y & Yellow \\
\hline R & Red \\
\hline K & Black \\
\hline P & Pink \\
\hline G & Green \\
\hline O & Orange \\
\hline
\end{tabular}

Table 4. Recording success. 


\begin{tabular}{|c|c|c|c|c|c|c|c|c|c|c|c|}
\hline \multicolumn{6}{|c|}{ S.p. castaneiceps } & \multicolumn{6}{|c|}{ S.p. rhizophorae } \\
\hline Location & $\begin{array}{l}\text { Mangrove } \\
\text { Patch }\end{array}$ & Bird ID & Recordings & $\begin{array}{c}\text { Songs } \\
\text { Recorded }\end{array}$ & $\begin{array}{l}\text { Song } \\
\text { Types }\end{array}$ & Location & $\begin{array}{c}\text { Mangrove } \\
\text { Patch }\end{array}$ & Bird ID & Recordings & $\begin{array}{c}\text { Songs } \\
\text { Recorded }\end{array}$ & $\begin{array}{l}\text { Song } \\
\text { Types }\end{array}$ \\
\hline \multirow[t]{6}{*}{ La Paz } & 1 & $\mathrm{~B} / \mathrm{R} / \mathrm{G}$ & 14 & 77 & 4 & El Soldado & 12 & $\mathrm{~B} / \mathrm{R} / \mathrm{G}$ & 8 & 76 & 10 \\
\hline & 1 & $\mathrm{~K} / \mathrm{Y} / \mathrm{G}$ & 9 & 85 & 5 & & 12 & $\mathrm{P} / \mathrm{R} / \mathrm{Y}$ & 9 & 108 & 5 \\
\hline & 1 & $P / G / G$ & 12 & 115 & 5 & & 12 & $\mathrm{~B} / \mathrm{R} / \mathrm{Y}$ & 10 & 31 & 6 \\
\hline & 1 & $\mathrm{Y} / \mathrm{R} / \mathrm{Y}$ & 16 & 117 & 5 & & 12 & NB & 13 & 182 & 14 \\
\hline & 2 & $\mathrm{~B} / \mathrm{B} / \mathrm{Y}$ & 12 & 64 & 2 & & 12 & $\mathrm{G} / \mathrm{G} / \mathrm{G}$ & 5 & 26 & 5 \\
\hline & 2 & $\mathrm{P} / \mathrm{B} / \mathrm{P}$ & 11 & 152 & 6 & & 12 & $\mathrm{~B} / \mathrm{G} / \mathrm{P}$ & 10 & 31 & 8 \\
\hline Magdalena & 3 & NB & 13 & 96 & 8 & & 12 & $\mathrm{~B} / \mathrm{Y} / \mathrm{B}$ & 16 & 155 & 9 \\
\hline \multirow[t]{3}{*}{ Bay } & 4 & $\mathrm{Y} / \mathrm{R} / \mathrm{Y}$ & 14 & 110 & 9 & & 12 & $\mathrm{G} / \mathrm{G} / \mathrm{Y}$ & 12 & 68 & 6 \\
\hline & 5 & $\mathrm{G} / \mathrm{R} / \mathrm{G}$ & 11 & 94 & 11 & La Piedra & 13 & $\mathrm{G} / \mathrm{R} / \mathrm{G}$ & 9 & 98 & 6 \\
\hline & 6 & $\mathrm{G} / \mathrm{G} / \mathrm{R}$ & 10 & 51 & 6 & & 13 & $1 \mathrm{NB}$ & 9 & 81 & 2 \\
\hline \multirow[t]{8}{*}{ Mulegé } & 7 & $\mathrm{G} / \mathrm{B} / \mathrm{Y}$ & 14 & 130 & 12 & & 13 & $2 N B$ & 10 & 85 & 7 \\
\hline & 7 & $\mathrm{P} / \mathrm{P} / \mathrm{P}$ & 18 & 150 & 9 & & 13 & $\mathrm{~B} / \mathrm{Y} / \mathrm{R}$ & 5 & 38 & 7 \\
\hline & 8 & $\mathrm{G} / \mathrm{G} / \mathrm{R}$ & 15 & 172 & 7 & & 13 & $\mathrm{R} / \mathrm{B} / \mathrm{R}$ & 9 & 67 & 6 \\
\hline & 8 & $P / G / R$ & 10 & 107 & 12 & & 13 & $\mathrm{R} / \mathrm{K} / \mathrm{G}$ & 15 & 36 & 6 \\
\hline & 8 & NB & 15 & 128 & 10 & & 14 & $\mathrm{G} / \mathrm{K} / \mathrm{G}$ & 13 & 56 & 7 \\
\hline & 9 & GGY & 9 & 55 & 3 & Yavaros & 15 & $\mathrm{~B} / \mathrm{Y} / \mathrm{R}$ & 14 & 122 & 9 \\
\hline & 9 & $1 \mathrm{NB}$ & 17 & 132 & 4 & & 15 & $\mathrm{R} / \mathrm{R} / \mathrm{R}$ & 13 & 104 & 8 \\
\hline & 9 & 2 NB & 15 & 142 & 5 & & 15 & $P / G / G$ & 9 & 49 & 9 \\
\hline \multirow[t]{8}{*}{ San Lucas } & 10 & $\mathrm{G} / \mathrm{R} / \mathrm{R}$ & 16 & 117 & 8 & & 15 & $\mathrm{~B} / \mathrm{R} / \mathrm{B}$ & 14 & 175 & 5 \\
\hline & 10 & $\mathrm{~B} / \mathrm{Y} / \mathrm{R}$ & 21 & 231 & 6 & & 16 & $P / K / G$ & 12 & 136 & 8 \\
\hline & 11 & $1 \mathrm{NB}$ & 13 & 70 & 4 & & 16 & $\mathrm{~B} / \mathrm{G} / \mathrm{B}$ & 14 & 136 & 5 \\
\hline & 11 & $\mathrm{G} / \mathrm{R} / \mathrm{G}$ & 16 & 97 & 7 & & 17 & $\mathrm{P} / \mathrm{Y} / \mathrm{K}$ & 14 & 111 & 10 \\
\hline & 11 & $2 \mathrm{NB}$ & 8 & 104 & 11 & & 18 & $\mathrm{~B} / \mathrm{B} / \mathrm{B}$ & 10 & 159 & 12 \\
\hline & & & & & & & 18 & $\mathrm{G} / \mathrm{B} / \mathrm{R}$ & 13 & 67 & 10 \\
\hline & & & & & & & 19 & $\mathrm{G} / \mathrm{R} / \mathrm{G}$ & 8 & 94 & 6 \\
\hline & & & & & & & 19 & Y/B/B & 14 & 72 & 6 \\
\hline
\end{tabular}

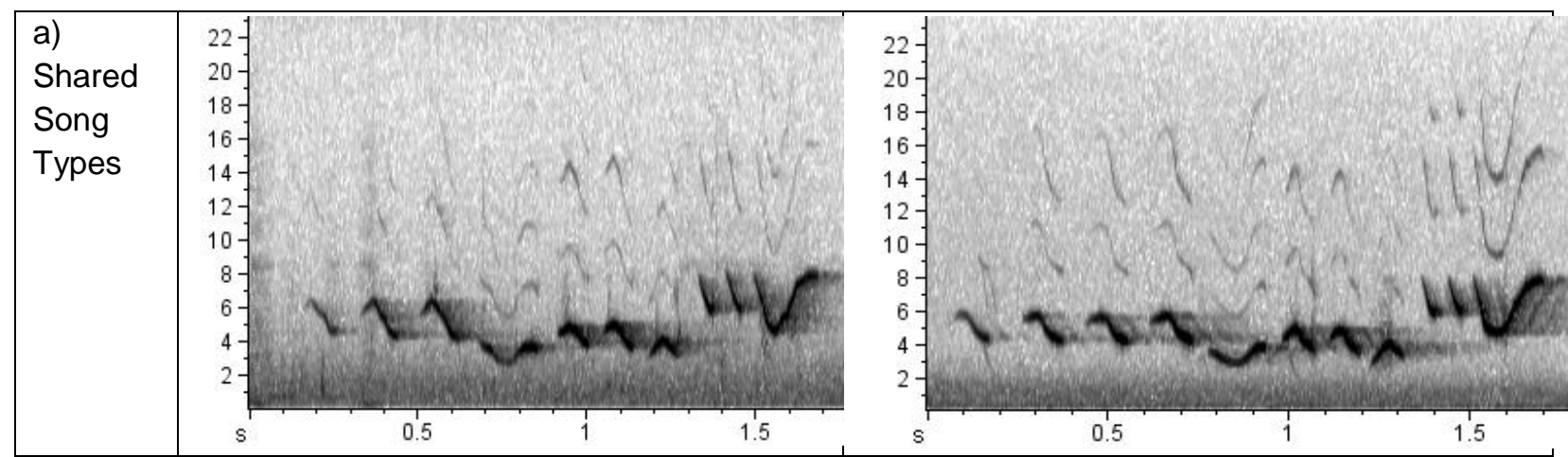




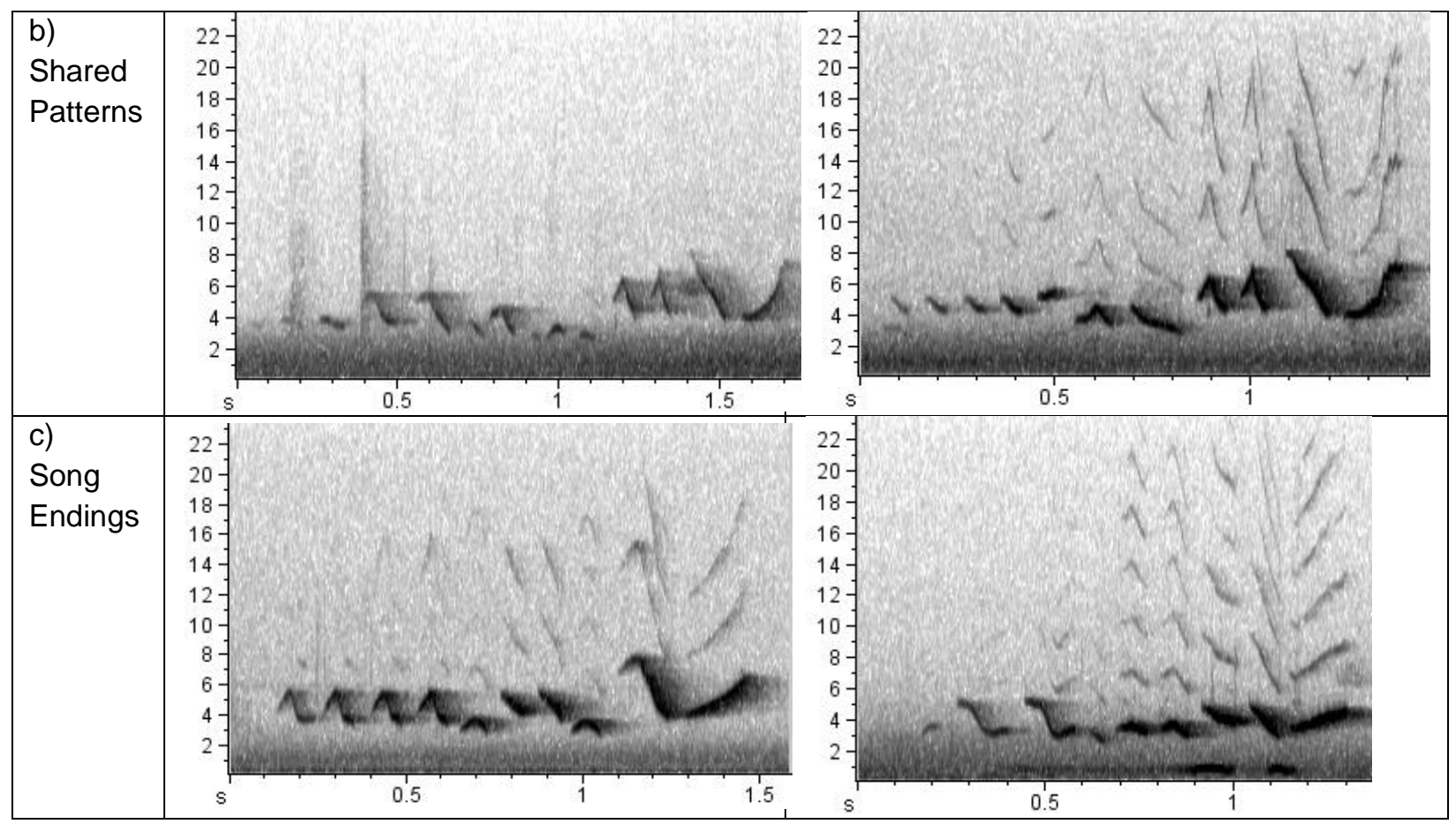

Figure 18. Levels of Song Classification.

a) Shared song types: Minor differences are accepted for songs to be shared. The sonogram on the left is the same song as the one in the right, but one of the introductory notes has been deleted. b) Shared patterns: part of the song is shared with another song. Both sonograms show that the last four notes of these songs are the same notes in the same sequence. However, the initial part of these songs is composed of completely different notes. c) Song endings: the sonogram on the left shows an example of an AES and the sonogram on the right shows an example of an UES. 


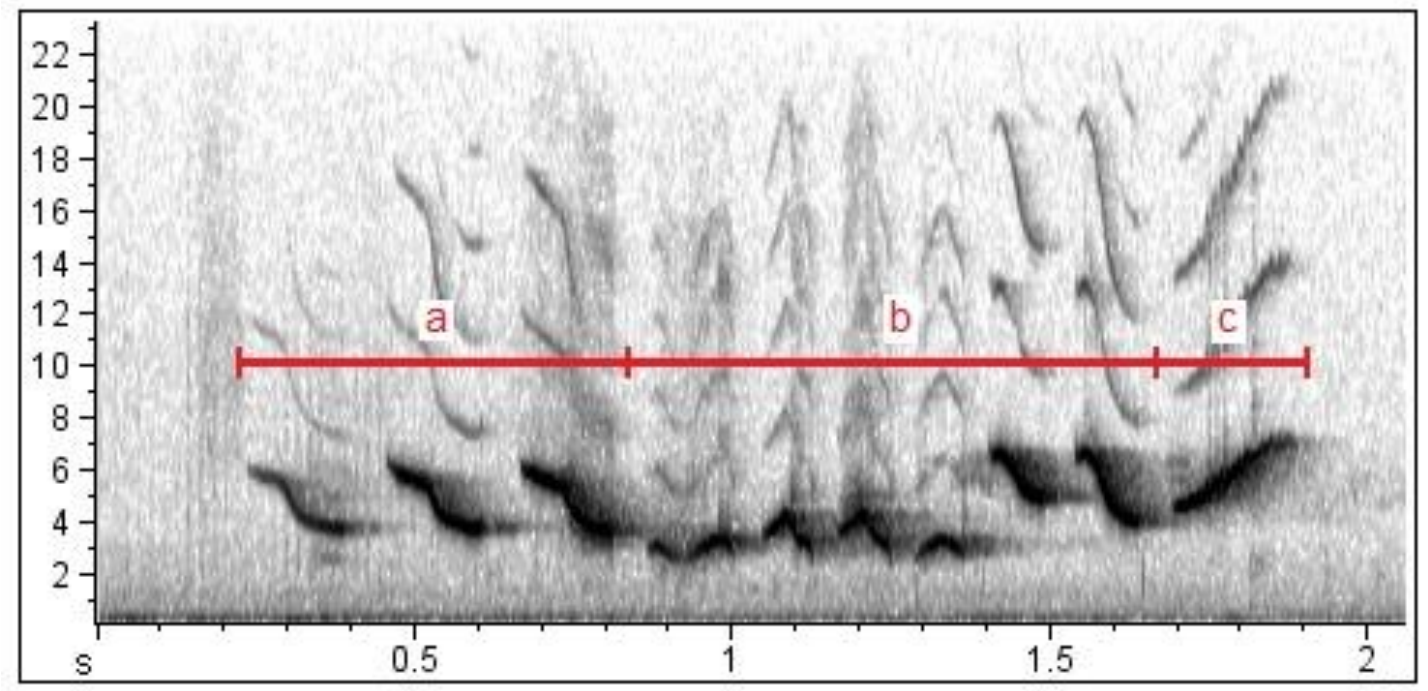

Figure 19. Parts of a Song. a) Introductory part. b) Middle part. c) Terminal note. 


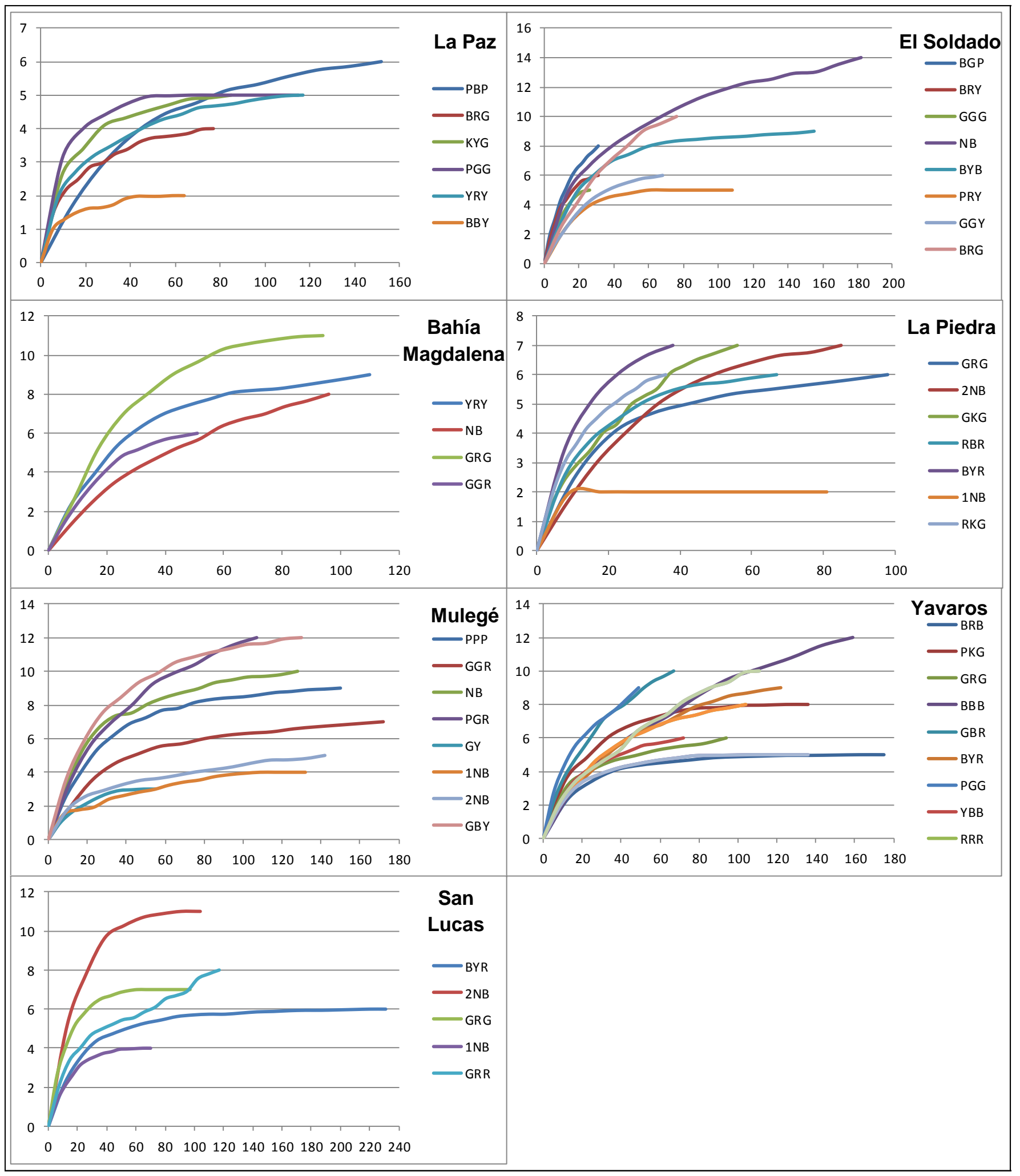

Figure 20. Accumulation curves per locality. Cumulative plots on the left correspond to the localities of the castaneiceps subspecies and on the right to localities of the rhizophorae subspecies. The $X$ axis represents number of songs recorded and the $Y$ axis represents number of song types. 


\section{CHAPTER III}

Geographic Song VARIATION OF THe MANGROVE WARBLER 


\section{INTRODUCTION}

The song of a species may vary geographically in different ways at different scales. Variation can be evaluated based on the general vocal characteristics of a species or by comparing repertoire composition among males. Such song characteristics may vary depending on the geographic scales in which we evaluate them.

Vocal variation is related to the different acoustic characteristics of a song and consists of three separate features. Structural characteristics may refer to the different features on the notes of a song such as note type and syntax, while temporal characteristics are related to the duration of features of the song and the number of notes in the song. The spectral characteristics are the frequencies of the different part of the song (Slabbekoorn and Smith 2002). On the other hand, Song repertoire variation is related to the number and types of song variants that an individual bird has (Krebs and Kroodsma 1980).

Much of the geographic variation of song is related to the way in which vocal variation is originated in individuals of a population. Songbirds acquire their songs through a learned behavior in which immature birds copy the songs from a tutor such as parent or con-specific neighbor (Marler 1960, Marler and Doupe 2000, Podos et al. 2004). However copying imprecision may occur throughout the learning process and vocal variation may result among individuals (Marler 1960). Therefore, the different evolutionary pathways that develop in the songs of populations may be accentuated over time providing geographic variation (Podos and Warren 2007). It is likely that the most recently evolved populations have song characteristics that prevail and differ from those of the original population which could favor morphological adaptations necessary in this new habitat (Mayr 1963). According to this, both, songs and morphological traits exhibit geographic variation which may lead to subspecific distinction (Mayr 
1969) and eventually, the reproductive divergence among these subspecies may lead to a potential speciation (Marler and Tamura 1962).

Geographic variation of song structure and song repertoires may occur throughout the spatial distribution of a species. Microgeographic variation occurs when there are differences between neighboring groups of birds which might potentially interact or interbreed with each other and macrogeographic variation occurs when there are differences between populations that are many kilometers apart and individuals between these populations are unlikely to interact with each other (Catchpole and Slater 2008).

Song repertoire variation occurs for numerous species of songbirds. Although, several studies have shown that the song types of a male's repertoire are shared most commonly with males whose territories are established closer (e.g. Dussourd and Ritchison 2003, Price and Yuan 2011), other studies suggest that geographic variation of repertoire can occur at larger scales (e.g. Peters et al. 2000, Nelson 2000).

The extent at which geographic variation of song occurs in Wood Warblers has been found to be related to the different categories of song ending. First category songs (Type I) show much less geographic variation than second category songs (Type II) (Kroodsma 1981). This could be due to the different learning processes for songs in the two categories (Spector 1992). First category songs could be learned by a young bird from its parent prior to his dispersal and learning of the second category song could be influenced by social interaction with other males after dispersal and territory settling (Spector 1992).

In wood warblers (Fam. Parulidae), repertoire sharing can happen between both, neighboring males and males separated by larger spatial scales. However, the degree in which geographic repertoire variation occurs depends on the different categories of song ending. In most species, like the Blue-winged Warbler (Vermivora cyanoptera) (Kroodsma 1981), the 
Chestnut-sided Warbler (Setophaga pensylvanica) (Kroodsma 1981, Byers 1996) and the Yellow Warbler (Beebee 2002), Type II or unaccented ending songs, tend to represent geographic repertoire variation at larger scales than accented ending songs, while in the Blackthroated Gray Warbler (Setophaga nigrescens) (Janes and Ryker 2010) this occurs on Type I songs.

\section{OBJECTIVE}

Evaluate geographic variation and dialect formation among the subspecies $D . p$. castaneiceps and D. p. rhizophorae.

\section{HYPOTHESIS}

Because the Mangrove Warbler's specific habitat in western Mexico is discontinuous and can be found in few locations throughout a wide geographic area, I hypothesize that geographic variation in song can be found among these locations and among mangrove patches. Differences in song repertoires and acoustic characteristics of the songs should be greater when increasing geographic distances. Also, because UES tend to be most commonly shared among neighboring males of Yellow Warblers than AES (Beebee 2004), I expect that if geographic variation occurs it should be mostly associated to UES than to AES.

According to this, geographic variation of repertoire sharing was tested on: all song types, UE song types only and AE song types only:

Ho: Repertoire sharing in the Mangrove Warbler is not correlated with geographic distance. Ha: Repertoire sharing of all songs of the Mangrove Warbler is correlated with geographic distance.

Geographic vocal variation was tested separately for UES and AES. 
Ho: Vocal variation of the Mangrove Warbler is not correlated with geographic distance.

Ha: Vocal variation of the Mangrove Warbler is correlated with geographic distance.

Dialect formation based on vocal variation was assessed among localities within each subspecies.

Ho: Vocal characteristics of the Mangrove Warbler are not different among localities within each subspecies.

Ha: Vocal characteristics of the Mangrove Warbler are different among localities within each subspecies.

Ho: Vocal characteristics are not different between the subspecies S. p. castaneiceps and S. $p$. rhizophorae.

Ha: Vocal characteristics are different between the subspecies S. p. castaneiceps and S. $p$. rhizophorae.

\section{STUDY SITES AND METHODOLOGY}

Geographic variation on Mangrove Warbler was assessed based on the same study sites, recorded individuals, collected data and song classification described in Chapter II. For geographic references, maps and descriptions of AES and UES see Chapter II.

\section{Data Analysis}

\section{Repertoire Sharing}

The repertoire similarity was defined as the extent of how many song types are shared among different males. Repertoire sharing was calculated for three groupings of songs: 1) The entire song repertoire, 2) UE song types only and 3) AE song types only. I followed the methodology used by Byers (1996) and Beebee (2002), who measured repertoire similarity using the formula RS $=2 s /\left(r_{1}+r_{2}\right)$, where $s=$ the number of song types shared between individuals, and $r_{1}$ and $r_{2}$ are the repertoire sizes of male 1 and male 2 . For repertoire sharing of 
all song types, the complete repertoire was used for repertoire size. For UE song types, only the total number of UE song types for each bird was taken into account to estimate repertoire size. The same was done for AE song types. Repertoire similarity values range from 0 to 1 , were 1 is complete repertoire sharing and 0 is no repertoire sharing.

Repertoire similarity was calculated between all possible pairs of the 49 birds recorded, regardless of what subspecies they belonged to. A repertoire sharing correlation matrix which was then transformed into a dissimilarity matrix by subtracting each value from 1 , was obtained for each of the three groupings of songs.

The geographic distance between all birds, was measured by calculating the Euclidean distance between each pair of birds based on the geographic coordinates taken where each bird was recorded. Measurements were taken by transforming the geographic coordinates into decimal degrees and obtaining a correlation matrix with NTSys. The values of the distance correlation matrix were then transformed to the reciprocal distance in order to emphasize local effects.

Statistical analysis of geographic variation of song repertoire

I used partial Mantel tests to evaluate whether repertoire sharing was correlated with the spatial arrangement of the birds, testing separately the three groupings of songs. I evaluated correlation between the repertoire sharing dissimilarity matrix and the distance matrix. Because the correlation between repertoire sharing and distance was evaluated among each possible pair of all recorded birds, the fact that some birds could belong to the same subspecies while others not, could be an interfering factor in determining such correlation. Therefore it was necessary to control the effect of subspecific variation by adding a dissimilarity subspecies matrix for the analysis. 


\section{Geographic vocal variation}

To assess whether geographic variation occurs on vocalizations of the Mangrove Warbler, I used several numeric variables that described specific song features. I measured 15 variables (Table 1) on one sonogram which represented the most complete and clear song, of each of the song types of each bird. I also calculated note rate of the introductory part of the song only, by dividing the duration by number of notes (Table 1). The means and standard deviations of each of these variables for each bird were obtained for the three categories: entire song repertoire, UES only and AES only. Normality and homogeneity of variance were tested on all variables at the three different grouping levels and transformations were required for some of the variables (identified in Table 1).

\section{Statistical analysis of geographic vocal variation}

I performed PCA analyses for each of the groupings based on measured variables only. The factor scores obtained from the PCA were used to compare vocal variation between each possible pair of birds and obtain a dissimilarity correlation matrix. Partial Mantel tests were used to evaluate the correlation between vocal variation and geographic distance controlling the subspecies effect by using a third matrix.

\section{Vocal variation between subspecies and localities}

I performed nested ANOVAs to evaluate vocal differences between subspecies and among localities within subspecies. This was a hierarchal nested ANOVA where Factor A represents subspecies in two levels: S.p. castaneiceps and S.p. rhizophorae, and Factor B represents the localities sampled within each of the subspecies. Therefore the levels of Factor $B$ are localities of La Paz, Bahía Magdalena, Mulegé and San Lucas within the S.p. castaneiceps subspecies and localities of El Soldado, La Piedra and Yavaros are levels within the S.p. rhizophorae subspecies. I used the factor scores obtained from the PCA and test separately UES and AES to evaluate if these two groupings of songs have different impact at a subspecies 
level and a local level. Also, I performed multiple comparison tests on localities within the subspecies to examine differences among means.

All statistical analyses were done with the program SPSS, except for the Mantel Tests which were done with NTSys.

\section{RESULTS}

\section{Repertoire sharing}

Repertoire sharing among the birds I sampled was low. Of all possible pairings for comparison between birds, only $12 \%$ of song types were shared among males. When comparing the entire repertoire, only $7 \%$ UES and $5 \%$ of AES were shared.

\section{Geographic variation of song repertoire}

I found a strong geographic relationship with repertoire sharing. Repertoire similarities declined significantly with increasing geographic distance (Mantel test: $r=-0.52, t=-17.65, p<$ 0.001 , Figure 1). Correlation between distance and repertoire sharing occurred in both UES (Mantel test: $r=-0.50, t=-16.92, p<0.001$, Figure 2) and AES (Mantel test: $r=-0.30, t=-$ $10.47, p<0.001$, Figure 3).

\section{Geographic vocal variation}

Seventy two percent of the vocal variation of the measurements taken on songs representing the entire song repertoire was explained by 4 principal components. PC1 described $25 \%$ of the variation, particularly characteristics of the introductory part of the song loaded on this component. PC2 explained $22 \%$ of the variation and described characteristics of length in the song, particularly on the introduction, PC3 (16\%) and PC4 (10\%) did not show a clear pattern of the relationship between the variables that have the highest loadings (Table 2). 
The vocal variation on UES was also explained by 4 principal components (75\%). PC1 described $27 \%$ of the variation and represented the frequency of the introductory part of the song. PC2 explained $19 \%$ of the variation and described the duration of the introductory part of the song. PC3 represented $15 \%$ of the variation given mostly by the frequency bandwidth of the song, particularly on the terminal note. PC4 described $12 \%$ of the variation and explained song complexity (Table 3).

The vocal variation on AES was also explained by 4 principal components (71\%). PC1 explained $25 \%$ of the variation related to general characteristics of the introductory part of the song, PC2 represented $18 \%$ of the variation given mostly by characteristics of the terminal note, PC3 (18\%) and PC4 (10\%) did not show a clear pattern of the relationship between the variables that have the highest loadings (Table 4).

Vocal variation correlated with geographic distances to some extent. Complete repertoire vocal similarities showed geographic correlation (Mantel test: $r=-0.09, t=-3.15, p<$ 0.01 , Figure 4). UES also varied geographically (Mantel test: $r=-0.12, t=-3.80, p<0.001$, Figure 5), but AES did not (Mantel test: $r=-0.03, t=-1.08, p>0.05$, Figure 6).

Vocal variation between subspecies and localities

Subspecies were vocally more distinct than localities (PCA all songs, Figure 7). UES differed between subspecies and among localities in both subspecies but there was stronger dialect formation on the S. p. rhizophorae subspecies (PCA UES, Figure 8). Vocal characteristics on AES differed more among localities in S.p. rhizophorae than S. p. castaneiceps, providing distinctive characteristics only to one locality of the S. p. castaneiceps subspecies (PCA AES, Figure 9).

Geographic vocal variation is given mostly by the introductory part of the song. Local song variation is given by differences in frequency of the introductory part of UES and dialect 
formation based on these characteristics is stronger in the $S . p$. rhizophorae subspecies than in the S. p. castaneiceps subspecies. In the S. p. rhizophorae subspecies all locations can be distinguished in the frequency of UES (Tukey: $p<0.05$ ) and in the $S$. $p$. castaneiceps subspecies these kind of differences can be found between La Paz and Mulegé, La Paz and San Lucas and Bahia Magdalena and San Lucas. AES provided distinctive characteristics of the introductory part of songs only in the S. p. castaneiceps subspecies in the locality of La Paz which was different from the northern localities of Mulegé and San Lucas (Tukey: $p<0.05$ ). Other characteristics of the song did not show much vocal variation among localities within subspecies (Tables 5 and 6). However, the locations of Mulegé and San Lucas had differences in frequency of the terminal part of UES (Tukey: $p=0.047$ ).

Differences between the subspecies S. p. rhizophorae and S. p. castaneiceps were found in UES (Table 5) but not on AES (Table 6). These differences are found in the duration of the song, particularly in the length of the introductory part and in the number of introductory notes (See Table 3 for highest loadings of PC2) (Table 5). The songs of the S. p. castaneiceps subspecies were longer $(\bar{x}=1.5 \mathrm{~s}, \mathrm{SD}=1.6)$ than the ones of the $\mathrm{S}$. $p$. rhizophorae subspecies $(\bar{x}=1.3 \mathrm{~s}, \mathrm{SD}=1.7)$. Such differences were found mainly on the length of the introductory part of the song. Songs of S. p. castaneiceps had a longer introduction $(\bar{x}=0.5 \mathrm{~s}, \mathrm{SD}=1.2)$ than the S. p. rhizophorae subspecies $(\bar{x}=0.3 ., \mathrm{SD}=1.2)$, and also has more introductory notes $(S$. $p$. castaneiceps $(\bar{x}=3.5, \mathrm{SD}=0.7)$, S. p. rhizophorae $(\bar{x}=2.8 .5, \mathrm{SD}=0.6))$. When looking at the relationship between these variables on each bird, I found that also the note rate (number of notes /seconds) of the introductory part of the song differed between the two subspecies (MannWhitney $U$ test: $\alpha=0.05 p=0.018$ ), the notes of the introductory part of the song were delivered at a higher rate in the S. p. rhizophorae subspecies $(\bar{x}=8.3, \mathrm{SD}=1.6)$ than in the $S . p$. castaneiceps subspecies $(\bar{x}=6.9, \mathrm{SD}=1.1)$. 


\section{DISCUSSION}

\section{Repertoire sharing and geographic variation}

The males of the populations of Mangrove Warblers that I studied shared part of their repertoire. After comparing repertoires between all birds, I found a low proportion of birds who shared at least one of their song types. The fact that I sampled at many different locations and mangrove patches could be the reason why repertoire sharing was relatively uncommon when comparing all birds. Because the populations I sampled inhabit mostly small mangrove patches with few birds and adult males do not switch their territories to other patches (Schweizer, 2011), repertoire sharing could be related to territory neighboring which only occurred on few males inhabiting the same mangrove patch. Still, there were cases in which repertoire sharing occurred between males from different mangrove patches. This could be associated to dispersal of young birds (Spector 1992). It would be interesting and useful to understand when juveniles disperse (if they do) and how this is related to the moment in which they learn their songs. According to Nelson (2000), White-crowned Sparrows (Zonotrichia leucophrys puegtensis) learn several dialects during their after-hatch year, and then, after migrating and acquiring a territory, they retain only the dialect that best matches the neighboring males. His findings support the Selective Attrition Hypothesis but it remains unclear whether warblers use this same mechanism. Further research on this would be useful to clarify how dialects are related to the learning process of Mangrove Warblers. Moreover, because I found that the extent to which song repertoire sharing occurred is related to the different song ending categories, it would be interesting to evaluate if song learning differs between AES and UES.

The overall repertoire sharing in Mangrove Warbles decreases when estimating separately UES and AES. This shows that song sharing between males is not necessarily linked to one particular song category and also that there can be cases in which males share only their 
UES or their AES. However, I did find that repertoire sharing was more common among UES than AES. These findings are similar to those in the population of Northern Yellow Warblers studied by Beebee (2002). Taking into account that Northern Yellow Warblers sing only one Type I song (AES) in their repertoire (Beebee 2002), while Mangrove Warblers sing many, my results are consistent with infrequent repertoire sharing of Type I songs (AES) of the Yellow Warbler.

Geographic scale of repertoire sharing of the different song categories of the Mangrove Warbler is consistent with the general tendency in Wood Warblers. Repertoire sharing in Wood Warblers tends to vary in geographic scales depending on the category of song ending. Unaccented ending songs are more commonly shared throughout larger geographic scales than accented ending songs (Kroodsma 1981, Byers 1996, Beebee 2002). The populations of Mangrove Warblers that I studied show that repertoire sharing of both categories of songs, are most commonly shared between males of the same mangrove patch but only UES were also shared at a larger scale. In other Wood Warbler species, only the findings of Janes and Ryker (2011) for Black-throated Gray Warblers show that repertoires of Type I (AES) have considerable geographic variation providing dialect formation. This stands in contrast with Mangrove Warblers and most of the studied Wood Warblers. My results are more similar to those of Byers (1996) for Chestnut-sided Warblers, where unaccented song sharing is common in birds that have nearby territories. However, his findings on accented songs do not show this same pattern and although repertoire sharing of AES of Mangrove Warblers is less common than that of UES, when it occurs, it happens between birds whose territories are in the same mangrove patch. My findings where most similar to those of Beebee (2002) for Yellow Warblers, where even if Type I song sharing is infrequent, both categories of songs are shared between birds of neighboring territories and Type II songs (UES) are also shared at larger geographic scales. 


\section{Geographic vocal variation}

The overall vocal variation of the Mangrove Warbler is given by the introductory part of the song and geographic variation occurs mainly on UES. Local dialects within subspecies seem to be represented by UES, mostly because of differences in frequency characteristics of the introductory parts of the songs. Although, also differences in frequency of the terminal note of UES were found on two nearby northern locations of the distribution of the subspecies. The only occasion where AES played a role in geographic differentiation was in the southernmost population of the S. p. castaneiceps subspecies where the frequency of the introductory part of the song could be distinguished from those of the northern populations. This could be due to the large geographical gap between these populations.

It is unclear why this was the only occasion in which AES provided geographic variation. Byers and Kroodsma (1992) have suggested that in general songs of Wood Warblers vary geographically mostly on Type II (UES) and that Type I (AES) seem to have a degree of genetic control. However, Moldenhauer (1992) found differences in type A (AES) in two allopatric populations of Northern Parula (Setophaga americana) song length, trill duration and trill rate, where no genetic difference had been detected. I believe that further studies on AES and genetics with an increased number of sampled individuals and a wider range of the distribution of the mangrove warblers in these areas should be used to evaluate geographic variation.

Dialects in Mangrove Warblers were mostly distinct in frequency on the introductory part of the song. Such characteristics have also been found in other Wood Warblers. For instance, Janes and Ryker (2006) found that dialect formation in Hermit Warblers (Setophaga occidentalis) is based on distinctions by the first phrase of the song, particularly its length and frequency. The general variation in frequency characteristics of the songs, which provides dialect formation, could be the product of differences in the acoustic environment. Slabbekoorn and Smith (2002) suggested that habitat type and density could influence song transmission; 
therefore the frequency of the song may vary through different habitats to improve transmission. Although Mangrove warblers are habitat specific, the frequency of the songs of the different locations could be related to differences in density between Mangrove patches. Further studies taking habitat density into account could be useful to clarify if dialect formation is related to habitat characteristics.

\section{Vocal differences between subspecies}

Although differentiation among subspecies is generally based on morphological traits, some behavioral studies have shown that song can also vary between subspecies. Song differences among subspecies have been found on spectral and temporal characteristics of the songs (Slabekoorn and Smith 2002). In the populations of Mangrove Warblers that I studied, while spectral characteristics of song provided dialect distinction within subspecies, the most important distinction among subspecies was based on temporal characteristics. The fact that temporal differences in the song were found only between subspecies and not among the locations within these subspecies suggests that these characteristics may be a strong indicator of subspecific differentiation.

Temporal song characteristics have been known to be a distinctive feature in species recognition among Warblers. For instance Badyaev and Leaf (1997) found that differences among species of Phylloscopus and Hippolais Warblers are mostly related to temporal aspects of the song and that these could be correlated with body mass and habitat structure. Smaller species or species that live in open areas tend to have shorter intervals between notes and use shorter notes than larger species or the ones that live in closed habitats. My findings on the distinction in temporal characteristics of the songs between subspecies could be related to such associations described by Badyaev and Leaf (1997). Individuals of S. p. castaneiceps are larger than individuals of S. p. rhizophorae (Schweizer, 2011) and temporal characteristics of the 
songs of S. p. castaneiceps are longer than those of S. p. rhizophorae. However habitat relationships are still to be determined.

Overall, such temporal differences in song of the Mangrove Warbler subspecies are consistent with other studies comparing song features between subspecies. For instance, Sedgwick (2001) found differences among subspecies of the Willow Flycatcher (Empidonax traillii) based on temporal characteristics of the song, notes, internote and interphrase and Bay (1999) found that vocal variation among subspecies of the Northern Parula can be distinguished mainly by length of song of Type B songs (UES). Nelson and Poesel (2011) found that characteristics related to song length in the White-crowned Sparrows (Zonotrichia leucophrys) may vary according to the context of singing throughout the breeding season, where males tend to sing longer trills prior to pairing and shorter trills after pair formation during the female fertility and incubation periods. Patten had similar findings on where females respond to males who sing at faster rates, but in the end mate selection is based on plumage. The temporal differences between subspecies of the mangrove warbler could be related to the different stages of the breeding season when I recorded the different subspecies. However, although I was not able to sample simultaneously both subspecies throughout the breeding season, I sampled first the S. p. rhizophorae subspecies which had shorter songs lengths than those of the S. p. castaneiceps subspecies which was sampled later throughout the breeding season. This would stand in contrast with Nelson and Poesel (2011) findings, however I have vague information about the breeding stages and context in which songs were delivered in the populations I studied, thus, I believe further research with behavioral data during the breading season should be considered when comparing populations.

The relationship between these temporal characteristics suggested also a difference in note rate in the introductory part of the song between S. p. castaneiceps and S. p. rhizophorae In Wood Warblers repetition rate of note seem to be related to evolutionary changes associated 
to habitats, where rapid note repetition is more common in Wood Warbler species that occupy dense habitats (van Buskirk 1997). Patten et al. (2004) found similar results on song sparrows, where birds in increased vegetation cover, shrub height and variation in shrub height and shrub spacing exhibited higher levels of cadence of introductory notes and main trill. Differences in note rate between the Mangrove Warblers subspecies could be associated to different habitat characteristics as well, but further studies on habitat density are needed to test this association.

Assuming that both subspecies are geographically and reproductively isolated and that the local populations among them are reproductively isolated due to sedentary behavior of the Mangrove warbler, it could be inferred that populations are highly endogamic, due to the lack of genetic flow. However, it is probable that individuals among populations maintain a high genetic variability, which keeps populations reproductively isolated without threatening them to extinction. This last scenario could be possible due to the adaptative radiation which gave origin to Dendroica genus (Lovette and Bermingham 1999). The lineage from which the Mangrove warbler comes from is highly diverse and such variability could also be encountered in the interior of local populations. The fact that the mangrove Warbler songs are so diverse within mangrove patches, local populations and subspecies, could be related to the great variability of its lineage. Although songs of Oscines are a learned behavior, there is a degree in which genetics also intervene, particularly in the way in which a birds' morphology and physiology may be shaped delimiting the sound characteristics that can be produced.

In recent radiations the cause of variability may be linked to ecological and environmental factors (Shluter 1996). Interestingly such adaptive radiation in Dendroica (now Setophaga) warblers is quite different from others because their species lack conspicuous morphometric differentiation (Lovette and Bermingham 1999). Most distinctions are given by their plumage coloration (Browning 1994) and songs (Spector 1992) which probably arose by sexual selection The unusual combination of poor morphological variety along with high local 
diversity is interesting, especially when noticing that behavioral differences can be pronounced (Lovette and Bermingham 1999).

The high vocal variation encountered in The Mangrove warbler, appears to be related to several factors. The life history of its genus seems to be reflected on the variability of the species at different population levels, there is a high vocal diversity within subspecies, local populations and mangrove patches populations and even among individuals which prevent a clear understanding on how and which traits are determined to distinguish populations. Although the introductory part of the song seems to be a cue in providing song differentiations, the lack of a clear pattern among all populations could be related to the specific ecological factors of each of them. However, if UES vary more than AES and such variation seems to be related to ecological factors, both categories of songs should be equally affected. This suggest, that AES have more basal traits that provide a clue in species recognition, while UES have derived characters which allow variation. If differences between subspecies were related mostly to a gradual process of speciation more than to ecological factors, it would be expected to find differences between AES also. 


\section{LITERATURE CITED}

BADYAEV, A. V., AND E. S. LeAF. 1997. Habitat associations of song characteristics in Phylloscopus and Hippolais Warblers. Auk 114:40-46.

BAY, M. D. 1999. The type B Song of the Northern Parula: structure and geographic variation along proposed sub-species boundaries. Wilson Bulletin 111:505-514.

BEEBEE, M. D. 2002. Song sharing by Yellow Warblers differs between two modes of singing: implications for song function. Condor 104:146-155.

BUSKIRK, J. V. 1997. Independent evolution of song structure and note structure in American Wood Warblers. Proceedings: Biological Sciences 264:755-761.

BYERS, B. E., AND D. E. KROOdSMA. 1992. Development of two song categories by Chestnutsided Warblers. Animal Behaviour 44:799-810.

BYERS, B. E. 1996. Geographic variation of song form within and among Chestnut-sided Warbler populations. Auk 113:288-299.

CATChPOle, C. K AND P. J. B. Slater. 2008. Bird song: biological themes and variations. Cambridge University Press, Cambridge.

Dussourd, N., AND G. RITCHISON. 2003. Singing behavior of male Yellow-Breasted Chats: repertoires, rates, reproductive success, and a comparison with other WoodWarblers. Wilson Bulletin 115:52-57.

KROODSMA, D. E. 1981. Geographical variation and functions of song types in Warblers (Parulidae). Auk 98:743-751.

KREBS, J. R., AND D. E. KROODSMA. 1980. Repertoires and geographical variation in bird song. Pages 143-177 in Advances in the study of behavior.(J. Rosenblatt, R. Hinde, C. Beer, and M.C. Busnel, Eds.). Academic Press, New York.

JANES, S. W., AND L. RYKER. 2006. Singing of Hermit Warblers: Dialects of type I songs. Condor 108:336-347. 
JANES, S. W., AND L. RYKER. 2011. Geographic variation in type I songs of the Black-throated Gray Warblers. The Wilson Journal of Ornithology 123:339-346.

LEMON, R. E., J. StRugeR, AND M. J. LECHOWICZ. 1983. Song features as species discriminants in American Warblers (Parulidae).Condor 85:308-322.

Lovette, I. J. ANd E. Bermingham. 1999. Explosive speciation in the New World Dendroica Warblers. Proceedings: Biological Sciences 266:1929-1636.

MARLER, P AND M. TAMURA. 1964. Culturally transmitted patterns of vocal behavior in sparrows. Science 146:1483-14-86.

MAYR, E. 1963. Animal species and evolution. Harvard University Press. Cambridge.

MoldenhaueR, R. R. 1992. Two song populations of the Northern Parula. Auk 109:215-222.

NELSON, D. A. 2000. Song overproduction, selective attrition and song dialects in the Whitecrowned Sparrow. Animal Behaviour 60:887-898.

Nelson, D. A., AND A. PoEsel. 2011. Song length variation serves multiple functions in the White-crowned Sparrow. Behavioral Ecology and Sociobiology 65:1103-1111.

Patten, M. A., J. T. RotenberRy, AND M. ZUK. 2004. Habitat selection, acoustic adaptation, and the evolution of reproductive isolation. Evolution 58:2144-2155.

Peters, S., W. A. Searcy, M. D. Beecher, AND S. NoWickI. 2000. Geographic variation in the organization of Song Sparrow repertoires. Auk 117:936-942.

Podos, J., S. HUBER, AND B. TAFT. 2004. Bird song: The interface of evolution and mechanism. Annual review of Ecology, Evolution and Systematics 35:55-87.

SCHLUTER, D. 1996. Ecological causes of adaptative radiation. American Naturalist 148:40-64.

SCHWEIZER, C. L. 2011.Biometric variation among two Mangrove Warbler Setophaga petechia populations of northwestern Mexico. Master Thesis. Davis College of Agriculture, Forestry, and Consumer Sciences, West Virginia University.

SEDGWICK, J. A. 2001. Geographic variation in the song of Willow Flycatchers: differentiation between Empidonax traillii adastus and E. t. extimus. Auk 118:366-379. 
SLABBEKOORN, H., AND T. SMITH. 2002. Birdsong, ecology and speciation. Philosophical Transactions of the Royal Society 357:493-503.

SPECTOR, D. 1992. Wood-warbler song systems: a review of Parulinae singing behaviors. Current Ornithology 9:199-292. 
Table 1. Variables used to assess vocal variation. See the sample spectrogram in figure 19 Chapter I for identification of song parts.

\begin{tabular}{ll}
\hline \multicolumn{1}{c}{ Variable } & \multicolumn{1}{c}{ Description } \\
\hline Song & Number of notes in all the song \\
NNS & Number of different notes in all the song \\
NNTS & Song duration (ms) \\
LS $^{\text {AU }}$ & Minimum frequency of song $(\mathrm{Hz})$ \\
MinFS & Maximum frequency of song $(\mathrm{Hz})$ \\
MaxFS & \\
Introductory phrase & \\
NNI $^{U}$ & Number of notes of introductory part \\
LI & Duration of introductory part (ms) \\
NRI & Note rate of introductory part \\
NLI & Duration of note of introductory part (ms) \\
IFNI & Initial frequency of note of introductory part $(\mathrm{Hz})$ \\
EFNI & Final frequency of note of introductory part $(\mathrm{Hz})$ \\
MinFNI & Minimum frequency of note of introductory part $(\mathrm{Hz})$ \\
MaxFNI & Maximum frequency of note of introductory part $(\mathrm{Hz})$ \\
Terminal note & \\
LTN & Duration of terminal note (ms) \\
MinFTN & Minimum frequency of terminal note $(\mathrm{Hz})$ \\
MaxFTN & Maximum frequency of terminal note $(\mathrm{Hz})$ \\
\hline
\end{tabular}

${ }^{*}$ Calculated variables

A Square-root transformed variables for AES

$\checkmark$ Square-root transformed variables for UES 
Table 2. Loading scores of PCA of all songs.

\begin{tabular}{lcccc}
\hline Variable & PC1 & PC2 & PC3 & PC4 \\
\hline MinFNI & .882 & -.100 & .207 & -.203 \\
EFNI & .849 & -.150 & .224 & -.190 \\
MaxFNI & .830 & .401 & .072 & .023 \\
IFNI & .774 & .440 & .047 & .094 \\
MinFS & .480 & -.094 & .407 & .207 \\
LI & -.056 & .964 & -.058 & -.009 \\
NNI & .086 & .884 & -.085 & -.180 \\
LS & -.412 & .703 & .287 & -.304 \\
NLI & -.393 & .531 & -.080 & .429 \\
MaxFTN & -.262 & -.007 & .674 & .441 \\
MaxFS & -.074 & -.010 & .663 & .079 \\
NNTS & -.406 & -.463 & .543 & -.341 \\
LTN & -.129 & .035 & -.459 & .178 \\
NNS & -.352 & .340 & .516 & -.620 \\
MinFTN & -.008 & .209 & .565 & .596 \\
\hline
\end{tabular}


Table 3. Loading scores of PCA of UES.

\begin{tabular}{lcccc}
\hline Variable & PC1 & PC2 & PC3 & PC4 \\
\hline MinFNI & .933 & .222 & .043 & -.133 \\
EFNI & .915 & .206 & .042 & -.129 \\
IFNI & .788 & .427 & .057 & .125 \\
MaxFNI & .774 & .375 & -.062 & .200 \\
NLI & -.713 & .170 & -.051 & .241 \\
NNI & -.251 & .837 & -.051 & .149 \\
LI & -.401 & .809 & -.127 & .247 \\
LS & -.429 & .733 & .125 & -.293 \\
MaxFTN & -.301 & -.117 & .811 & .119 \\
MinFTN & -.082 & -.039 & .752 & .402 \\
MinFS & .207 & -.210 & .708 & .112 \\
MaxFS & -.154 & -.369 & -.655 & -.077 \\
NNTS & -.076 & -.296 & .202 & -.730 \\
NNS & -.251 & .521 & .218 & -.676 \\
LTN & -.032 & -.103 & -.211 & .612 \\
\hline
\end{tabular}


Table 4. Loading scores of PCA of AES

\begin{tabular}{lcccc}
\hline Variable & PC1 & PC2 & PC3 & PC4 \\
\hline MaxFNI & .827 & .171 & -.178 & .148 \\
IFNI & .822 & .061 & -.112 & .059 \\
LI & .812 & -.079 & .465 & -.051 \\
NNI & .803 & -.086 & .171 & .208 \\
NNTS & -.642 & .394 & .341 & .350 \\
MinFTN & .065 & .666 & .169 & -.504 \\
MaxFTN & .013 & .648 & .264 & -.472 \\
EFNI & .139 & .645 & -.633 & .164 \\
MaxFS & -.466 & .589 & .268 & -.051 \\
LTN & -.087 & -.486 & -.199 & .025 \\
LS & .280 & .244 & .753 & .238 \\
MinFNI & .167 & .624 & -.633 & .209 \\
MinFS & .357 & .329 & -.420 & -.012 \\
NNS & .012 & .329 & .559 & .698 \\
NLI & .377 & -.023 & .430 & -.485 \\
\hline
\end{tabular}




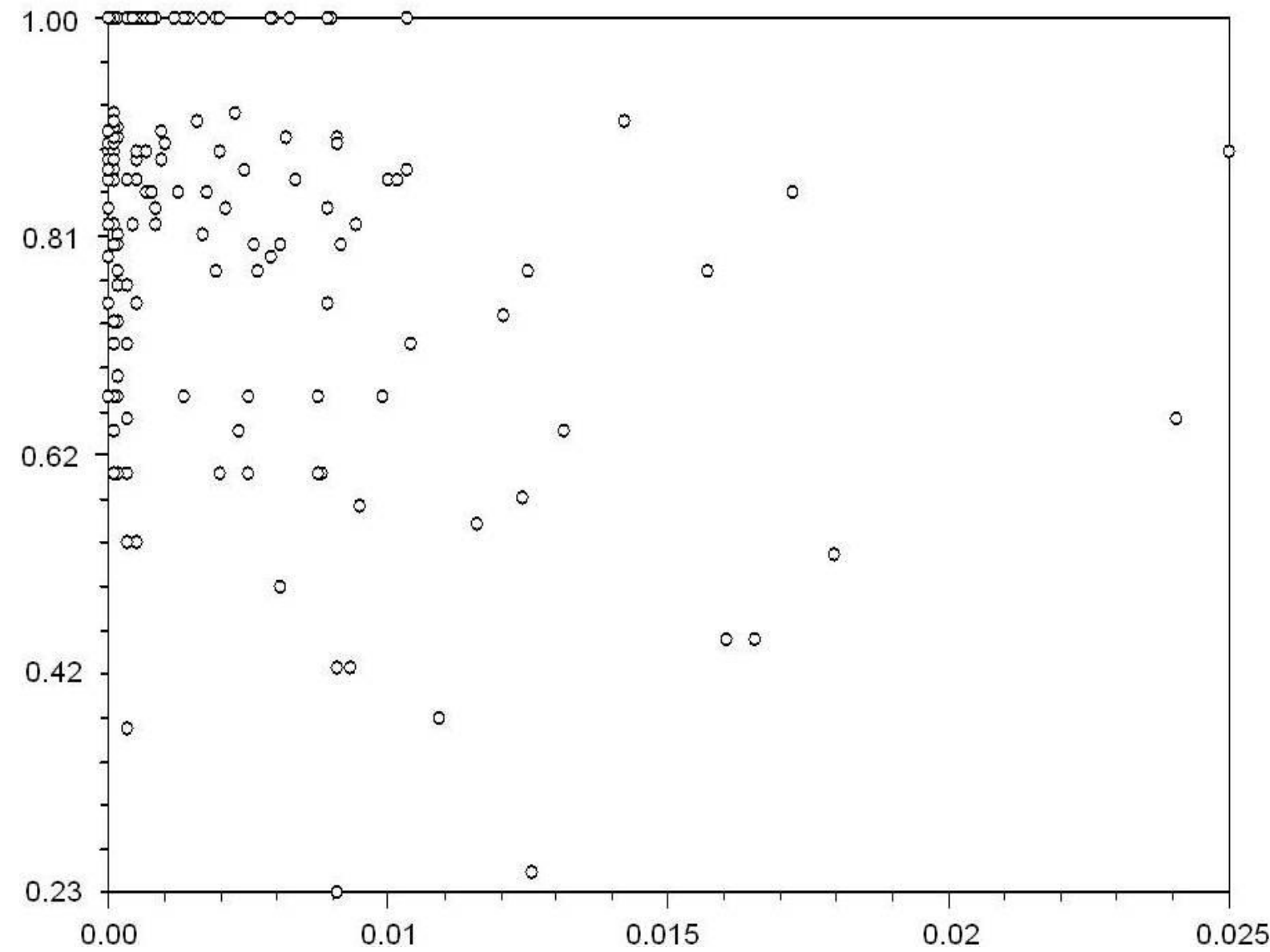

Figure 1. Correlation between distance and repertoire sharing when comparing entire repertoires. The $x$ axis represents reciprocal distance and the $y$ axis represents dissimilarity values the repertoire sharing index. 


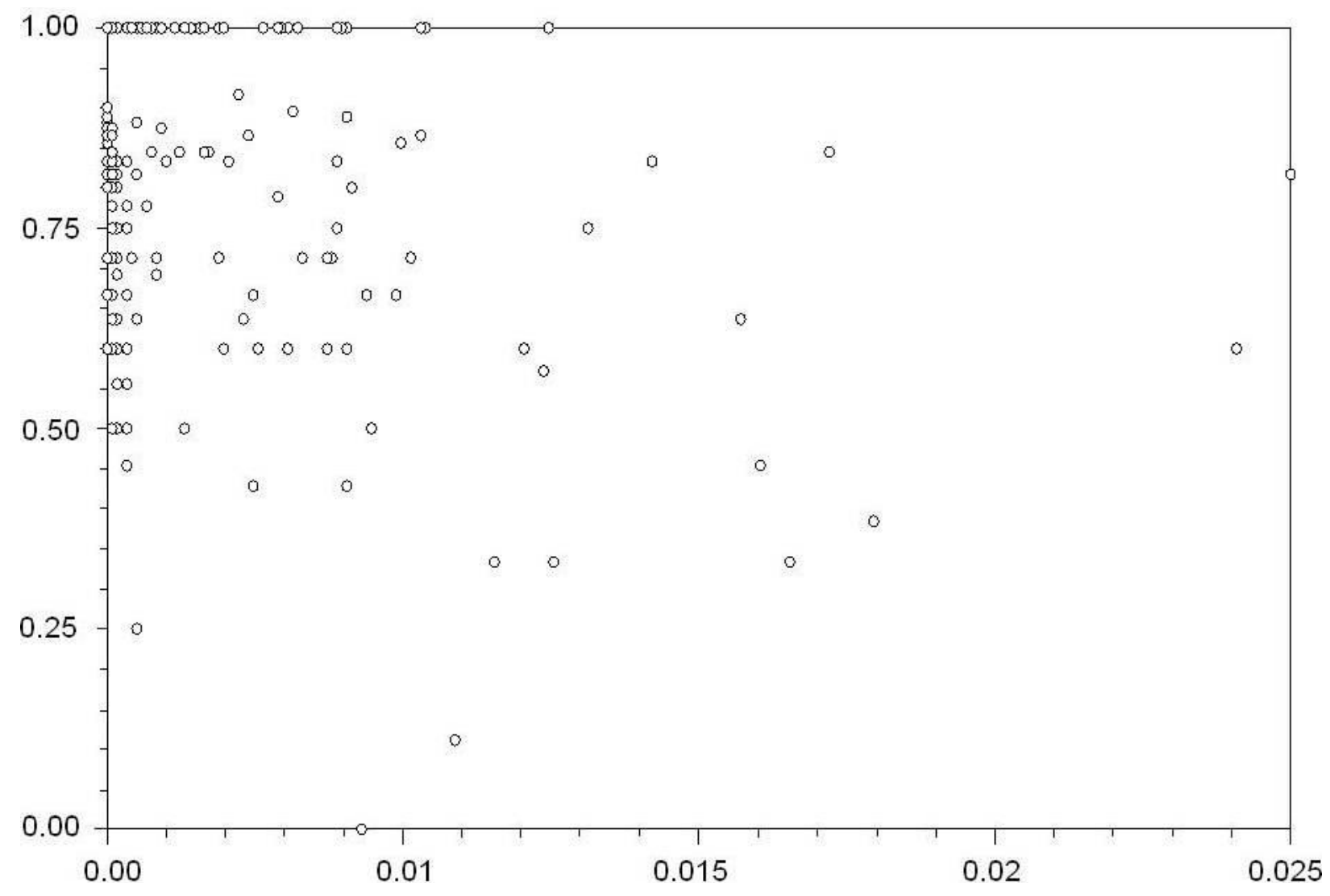

Figure 2. Correlation between distance and repertoire sharing of UES.

The $x$ axis represents reciprocal distance and the $y$ axis represents dissimilarity values the repertoire sharing index. 


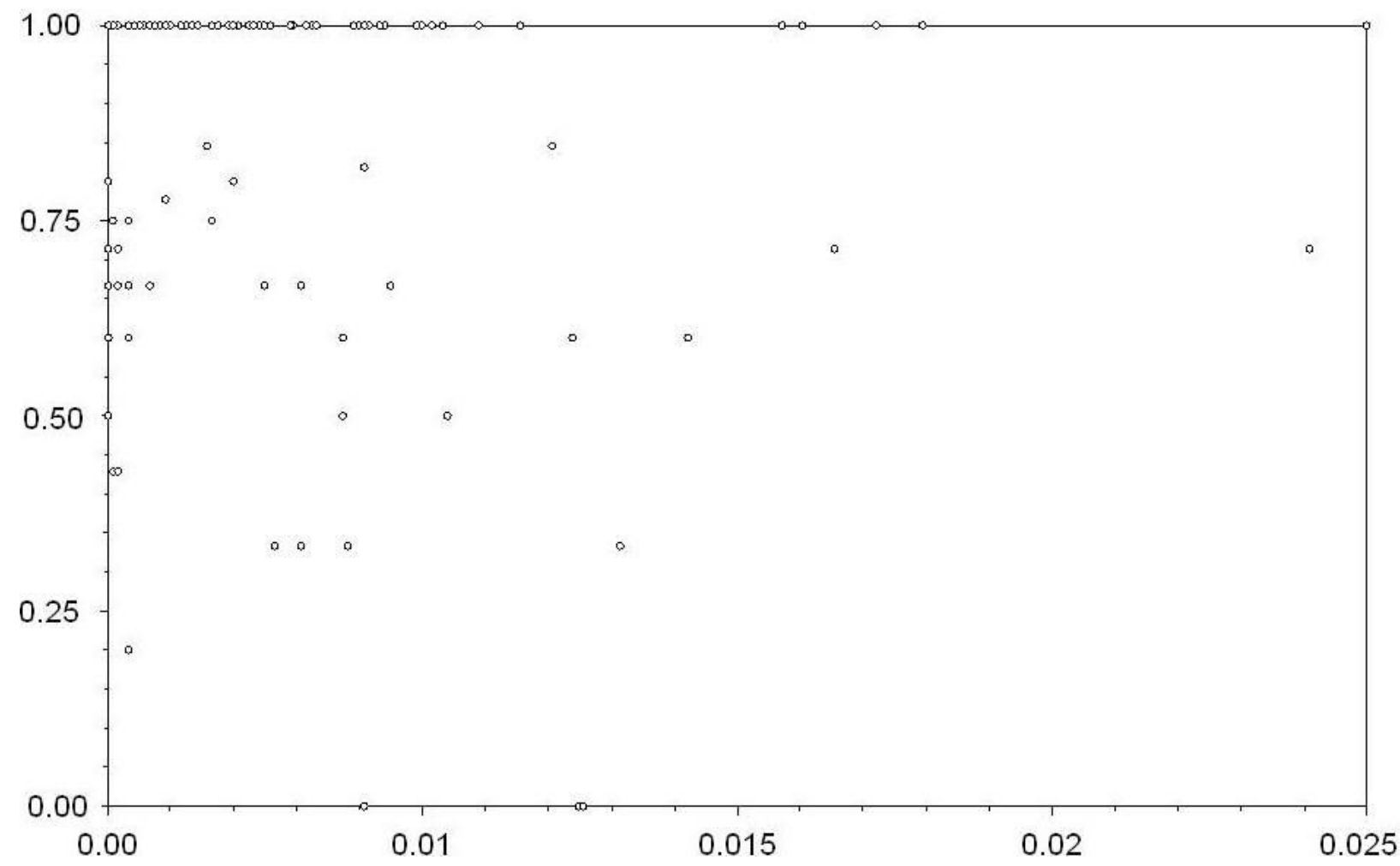

Figure 3. Correlation between distance and repertoire sharing of AES.

The $x$ axis represents reciprocal distance and the $y$ axis represents dissimilarity values the repertoire sharing index. 


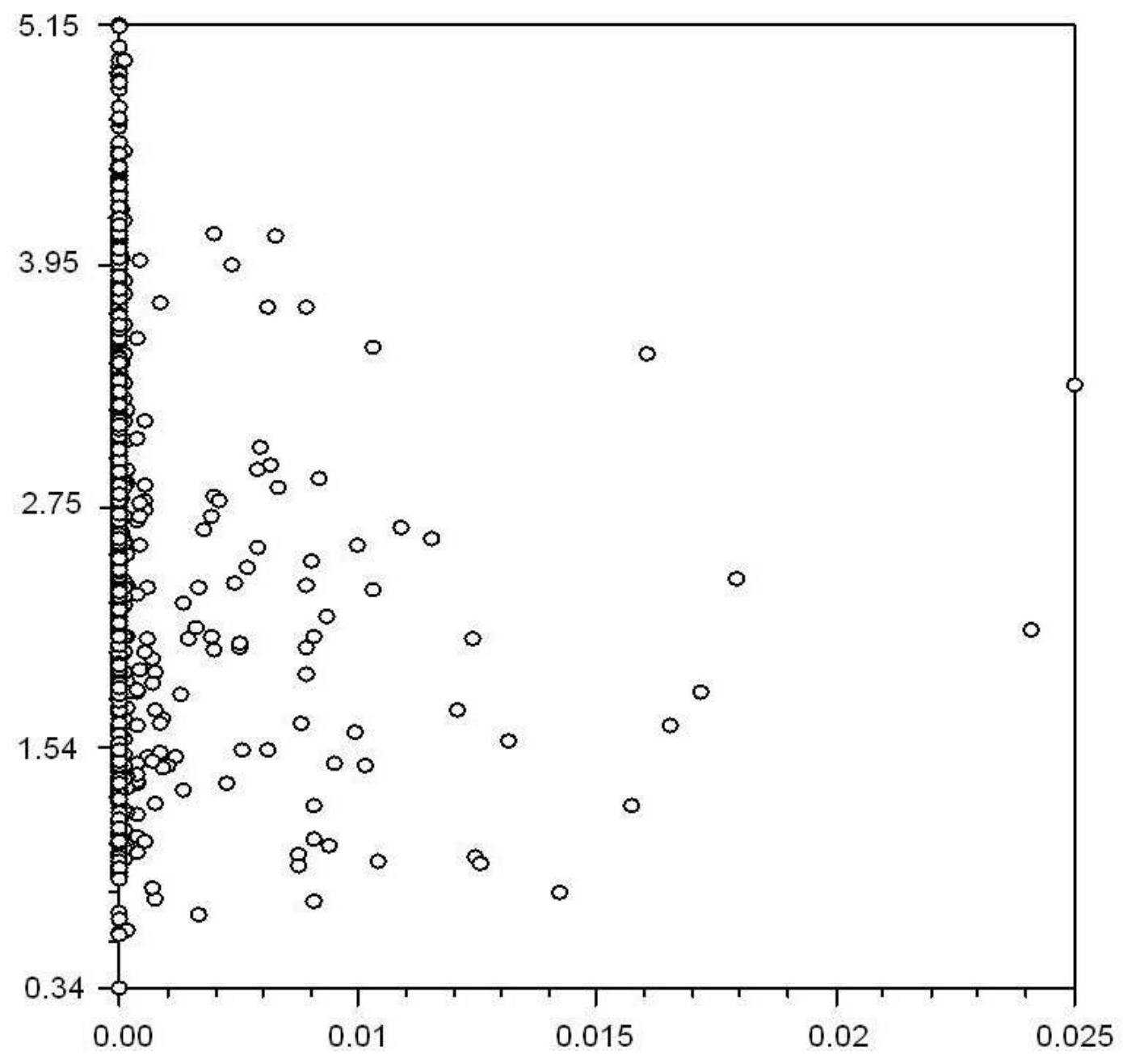

Figure 4. Correlation between distance and variation of vocal characteristics based on the entire repertoire. The $x$ axis represents reciprocal distance and the $y$ axis represents vocal variation. 


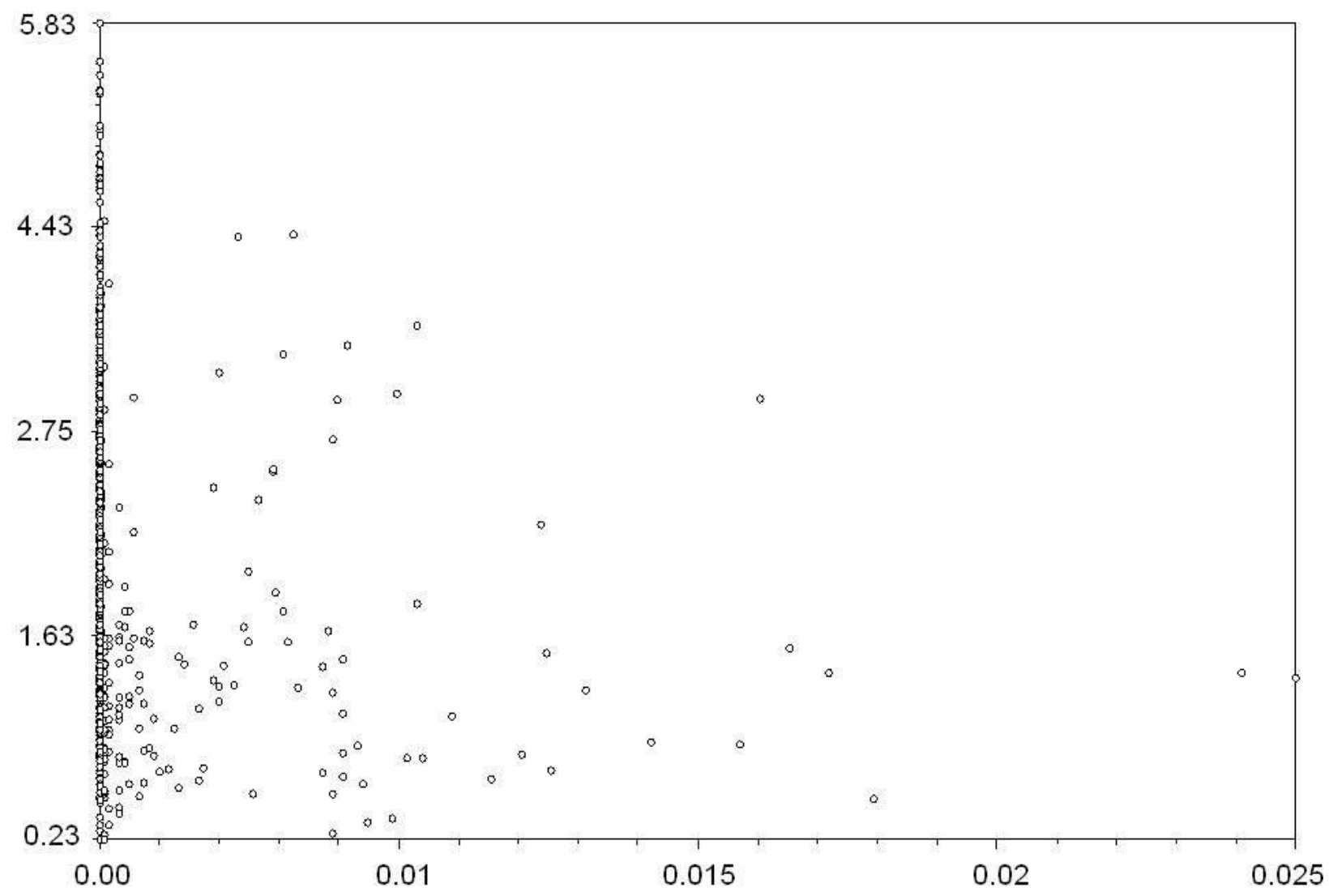

Figure 5. Correlation between distance and variation of vocal characteristics of UES.

The $x$ axis represents reciprocal distance and the $y$ axis represents vocal variation. 


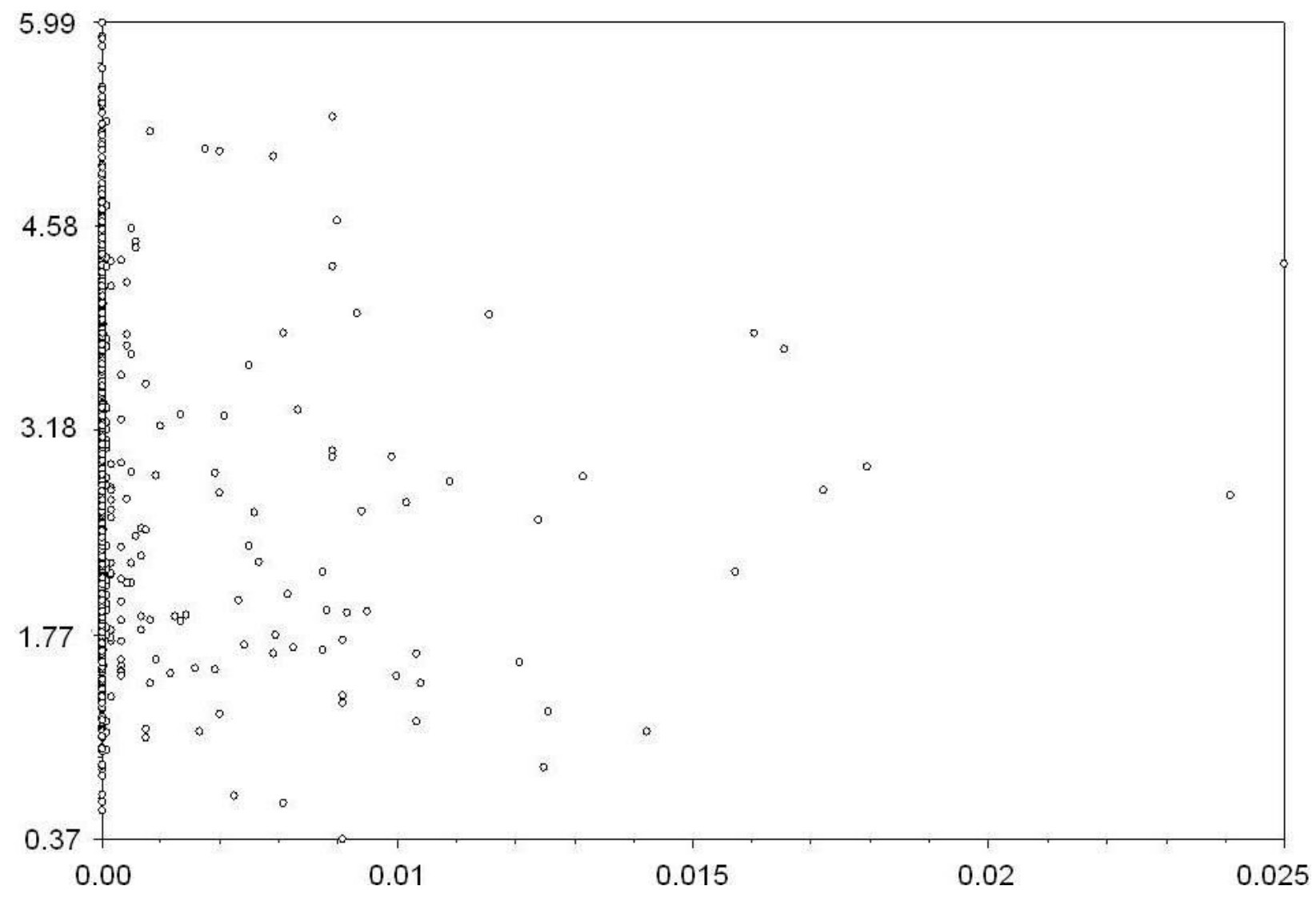

Figure 6. Correlation between distance and variation of vocal characteristics of AES. The $x$ axis represents reciprocal distance and the $y$ axis represents vocal variation. 


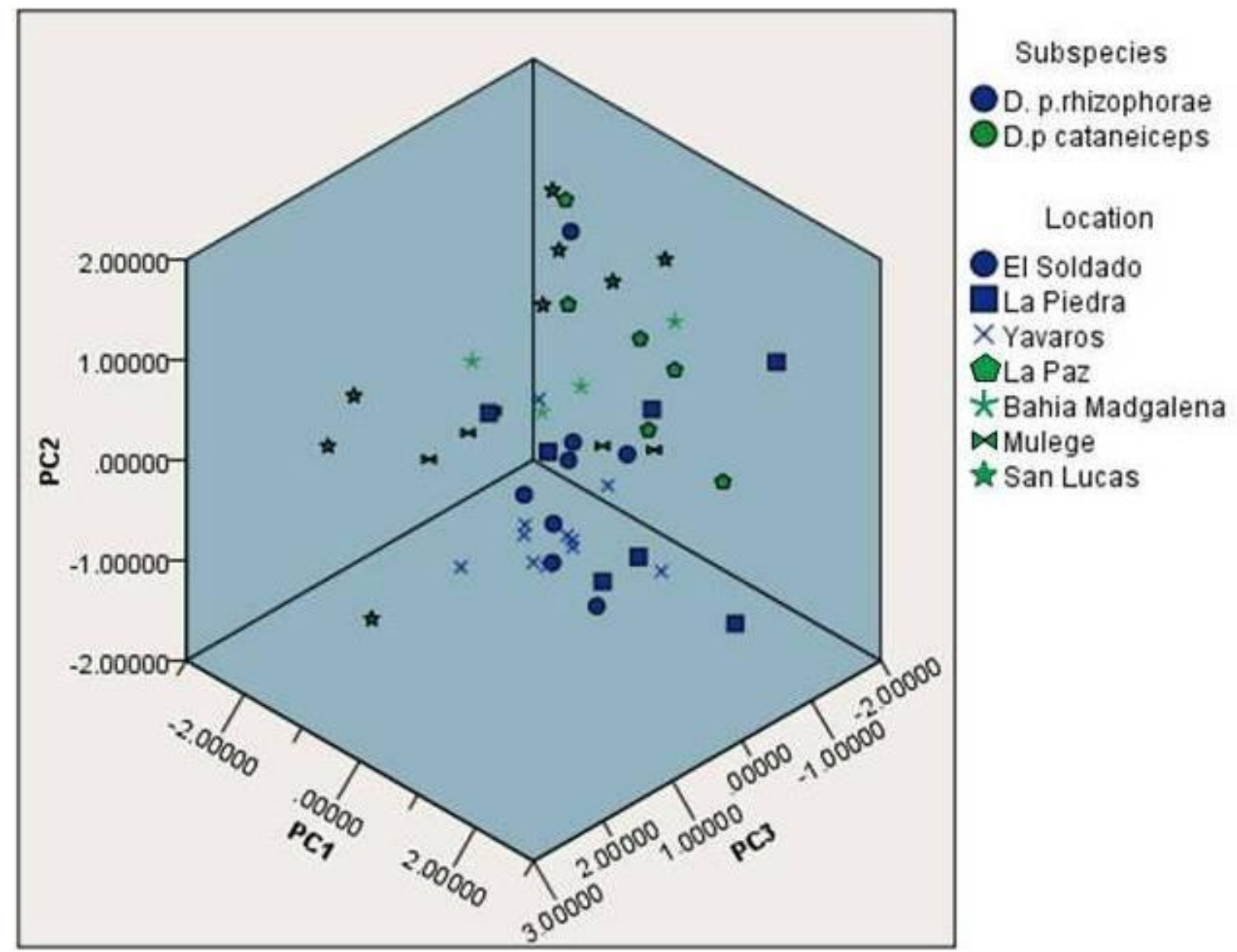

Figure 7. Vocal variation of all songs explained by the first 3 principal components. 


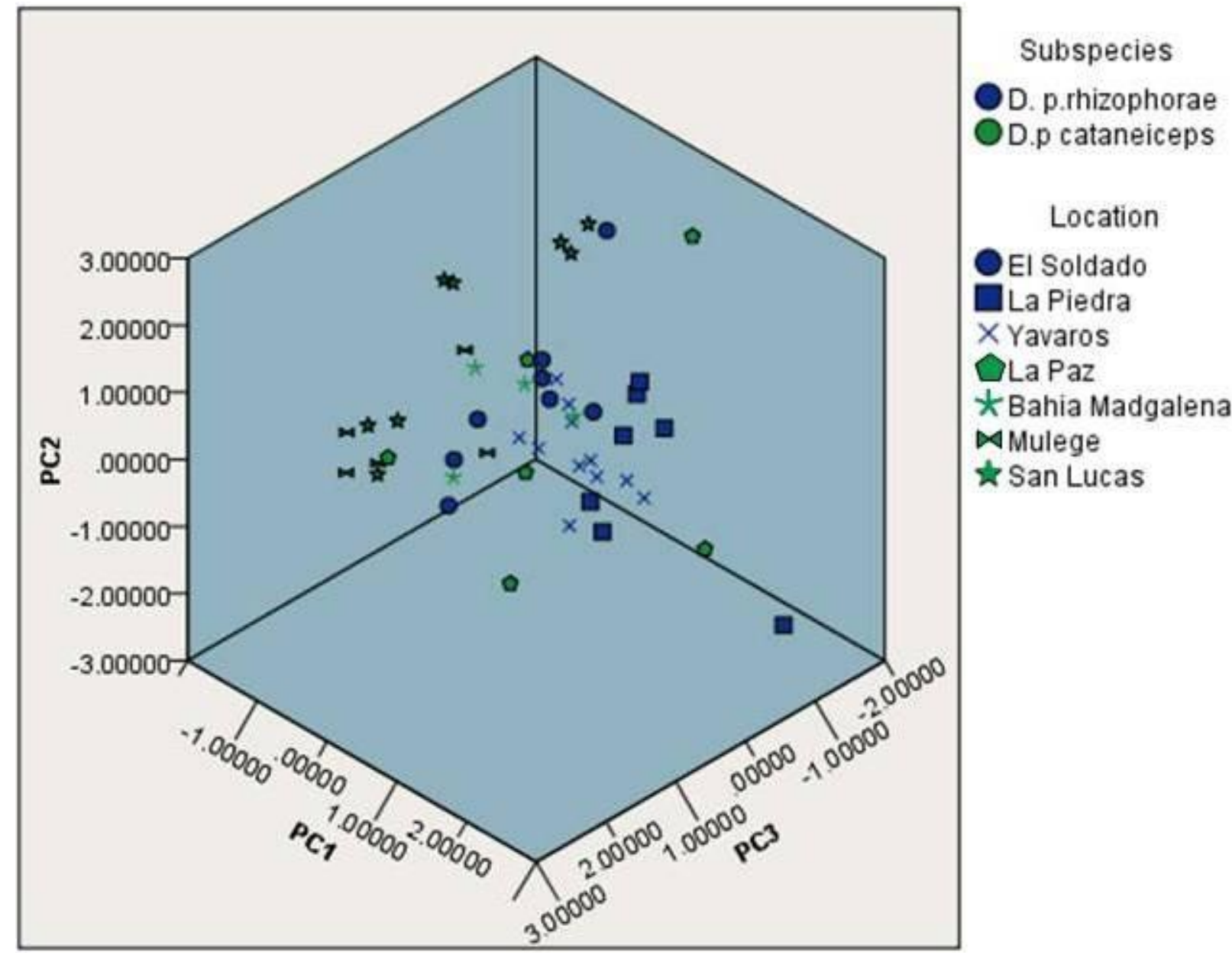

Figure 8. Vocal variation of UES explained by the first 3 principal components. 


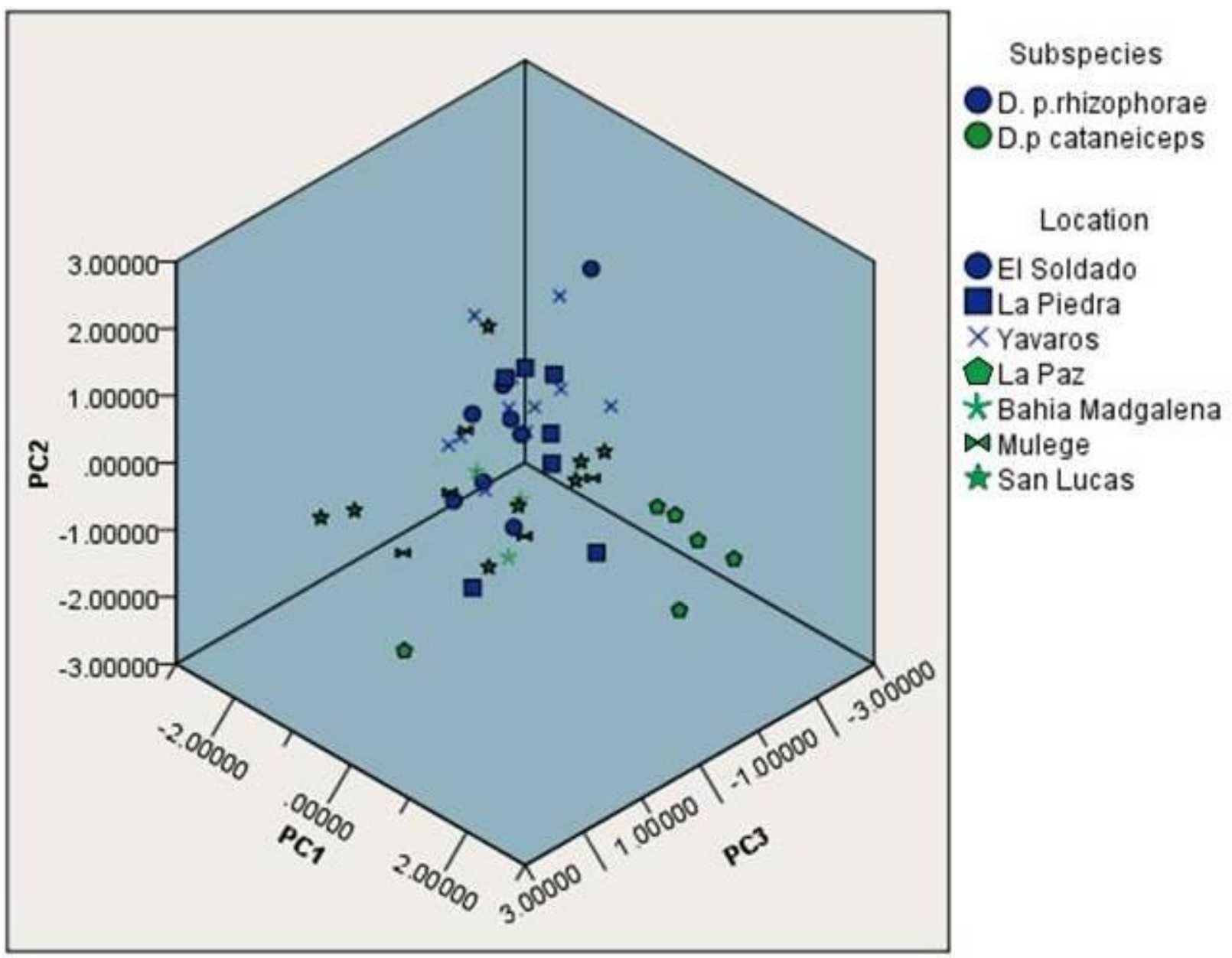

Figure 9. Vocal variation of AES explained by the first 3 principal components. 
Table 5. Nested ANOVA results for UES

\begin{tabular}{llll}
\hline Variable & \multicolumn{1}{c}{ Factor } & \multicolumn{1}{c}{ F } & \multicolumn{1}{c}{$\begin{array}{c}\text { P- } \\
\text { value }\end{array}$} \\
\hline PC1 & Subspecies & 0.241 & 0.644 \\
& Location within subspecies & 17.327 & 0.000 \\
PC2 & Subspecies & 16.154 & 0.010 \\
& Location within subspecies & 0.865 & 0.513 \\
PC3 & Subspecies & 5.978 & 0.058 \\
& Location within subspecies & 3.511 & 0.010 \\
PC4 & Subspecies & 0.060 & 0.816 \\
& Location within subspecies & 0.837 & 0.531 \\
\hline
\end{tabular}

Table 6. Nested ANOVA results for AES

\begin{tabular}{lllr}
\hline Variable & \multicolumn{1}{c}{ Factor } & F & $\begin{array}{c}\text { P- } \\
\text { value }\end{array}$ \\
\hline PC1 & Subspecies & 2.598 & 0.202 \\
& Locations within subspecies & 9.348 & 0.000 \\
PC2 & Subspecies & 0.023 & 0.174 \\
& Locations within subspecies & 0.428 & 0.326 \\
PC3 & Subspecies & 9.855 & 0.063 \\
& Locations within subspecies & 0.721 & 0.417 \\
PC4 & Subspecies & 0.000 & 0.604 \\
& Locations within subspecies & 2.287 & 0.135 \\
\hline
\end{tabular}




\section{APPENDIX}

SONOGRAMS OF SHARED SONGS 


\section{SHARED SONG TYPES}

When comparing songs between individuals some songs were found to be the same. However, because there could be individual variation, minor differences such as addition or deletion of few notes or minor changes in note frequencies and times were ignored when classifying shared song types. All shared song types were grouped under the same song type number. Each of the sonograms is labeled with the following information: ending of the song which can be "AES" for accentuated ending or "UES" for unaccetuated ending; birds' ID, according to its banding color code letters (unbanded individuals are labeled as "NB"); location; mangrove patch which is the number in parenthesis.

\section{Song Type: 2}
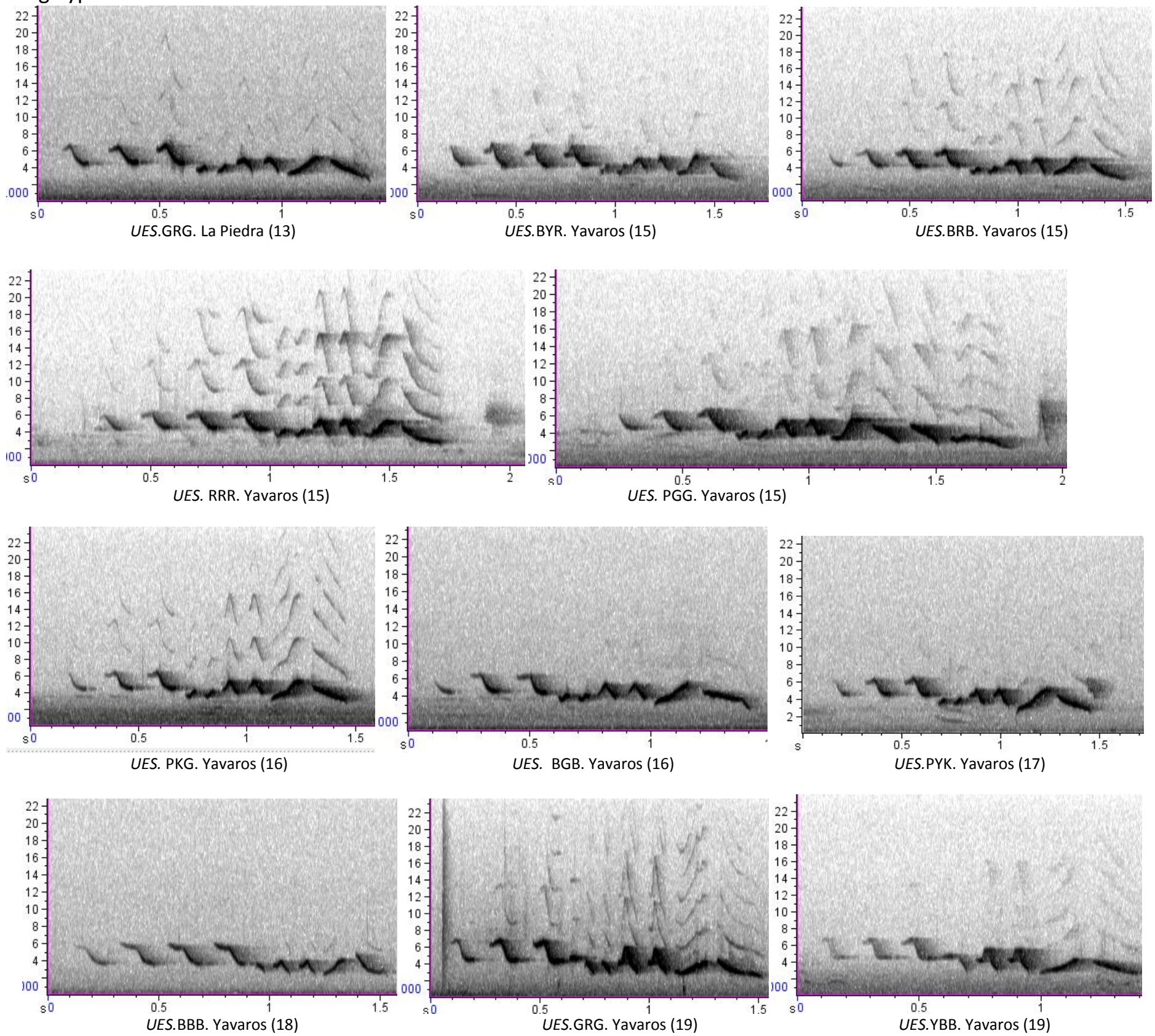
Song Type: 3
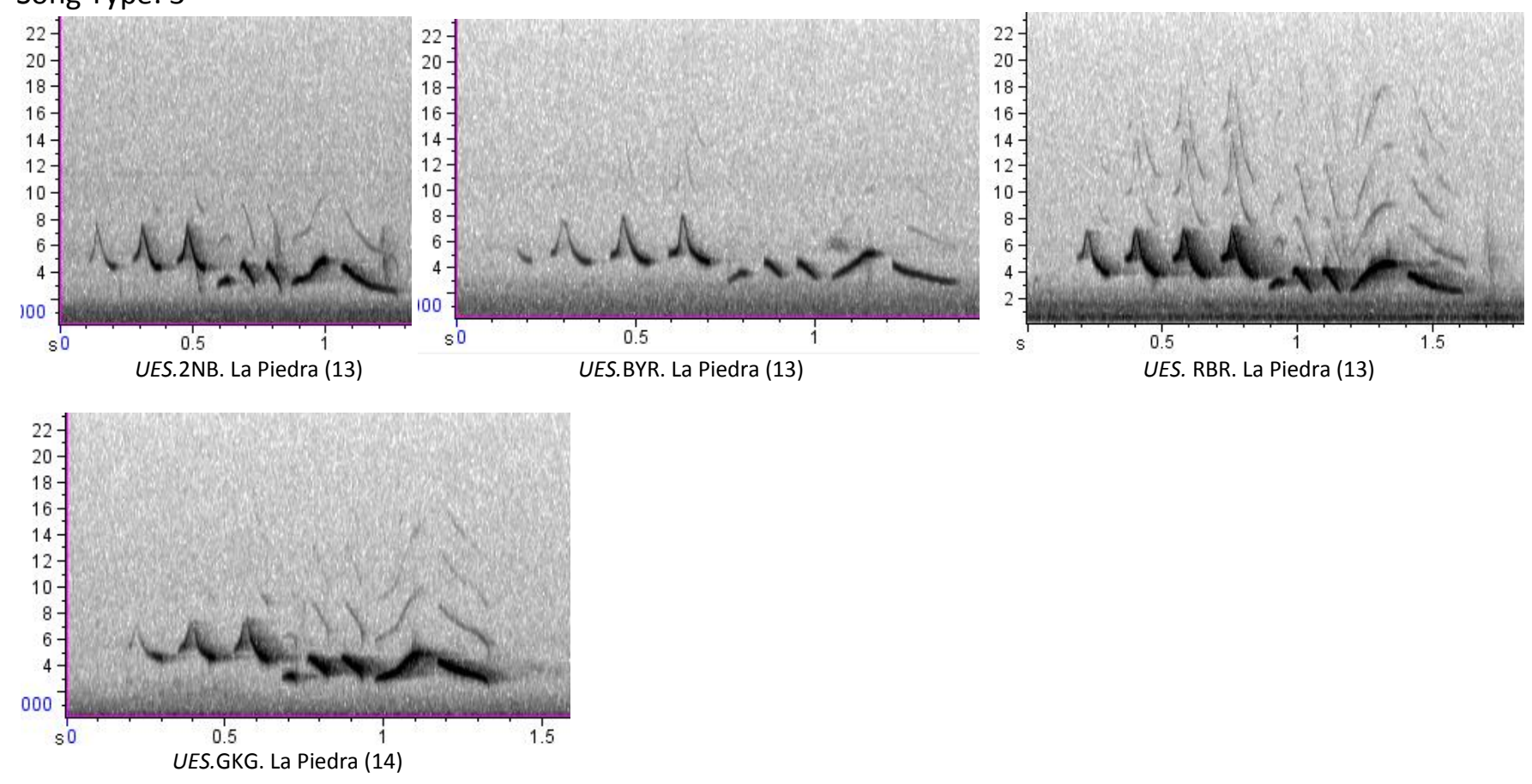

Song Type: 4
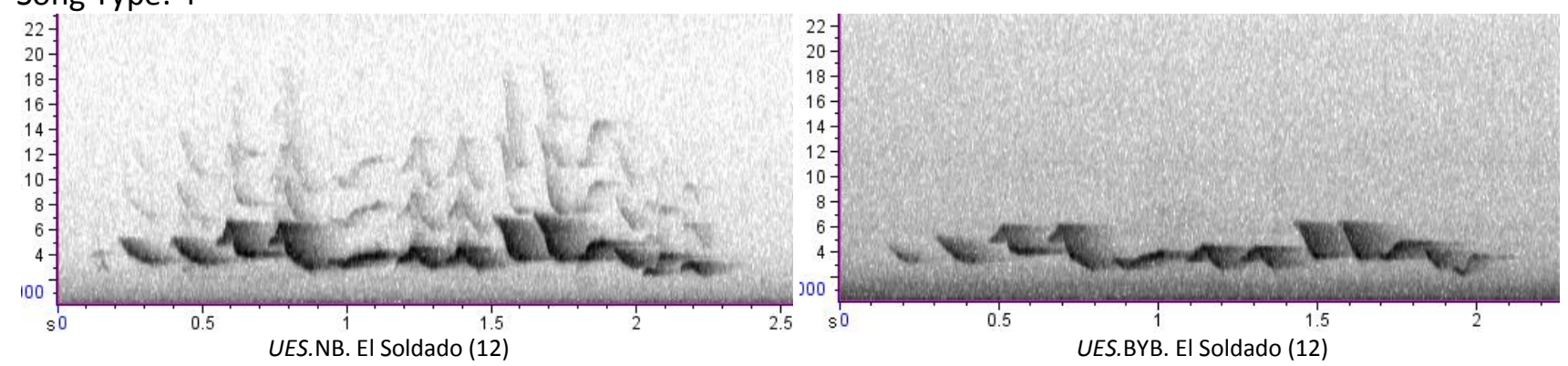

Song Type: 5
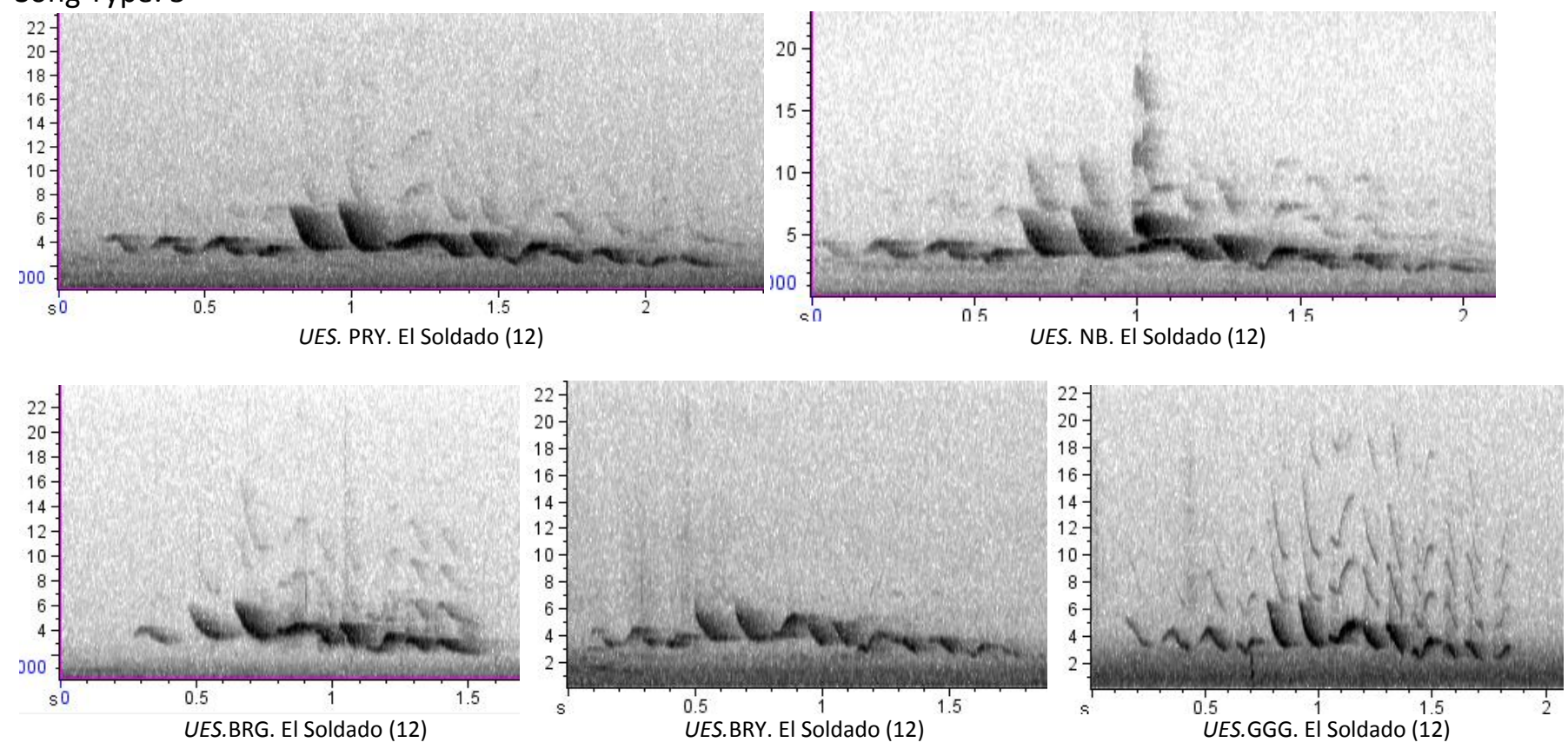
Song Type: 6
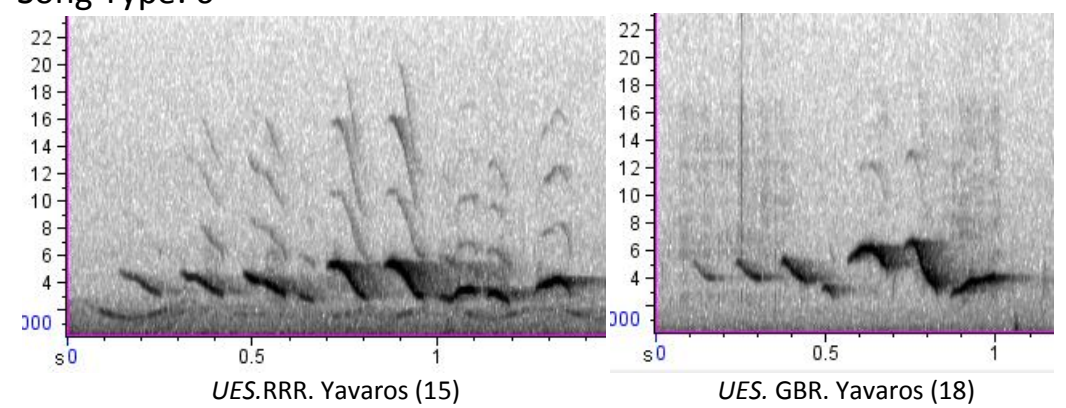

\section{Song Type: 7}
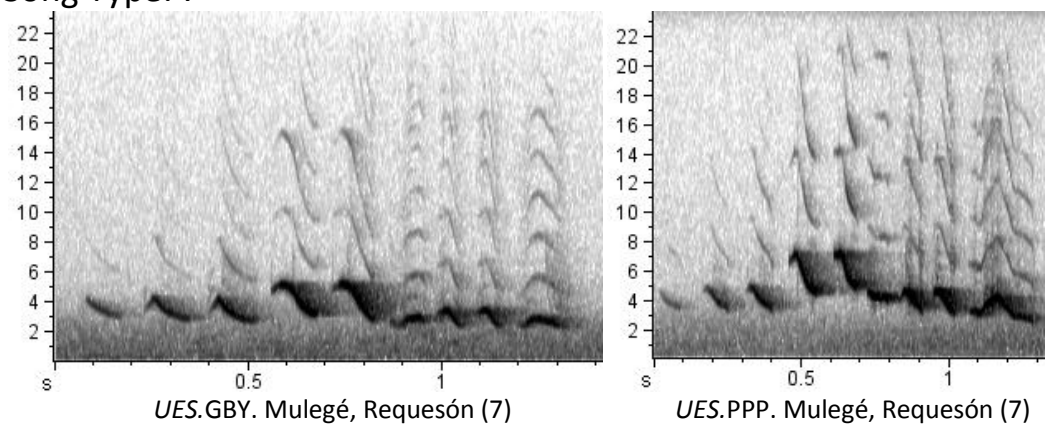

Song Type: 10
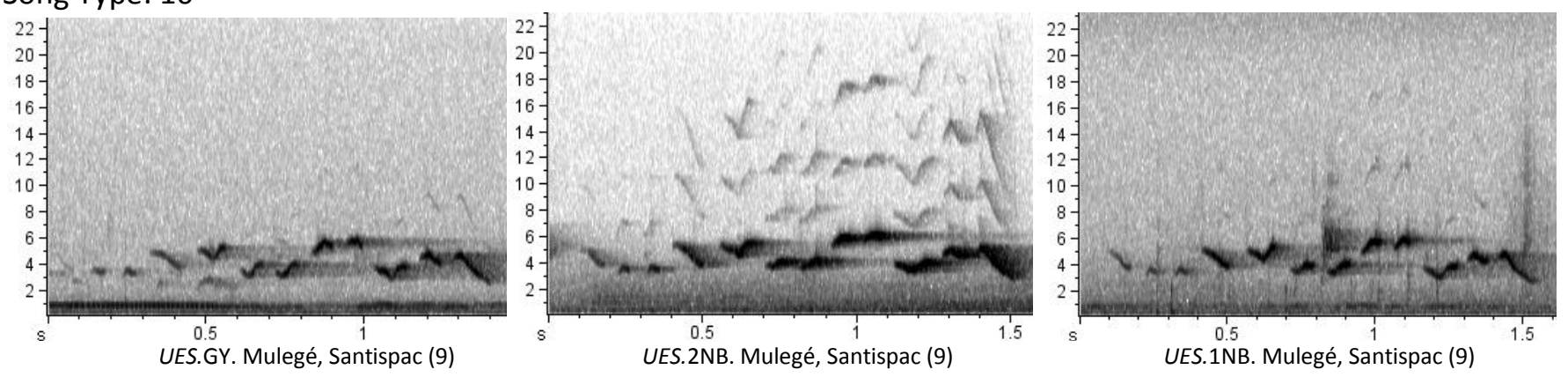

Song Type: 11
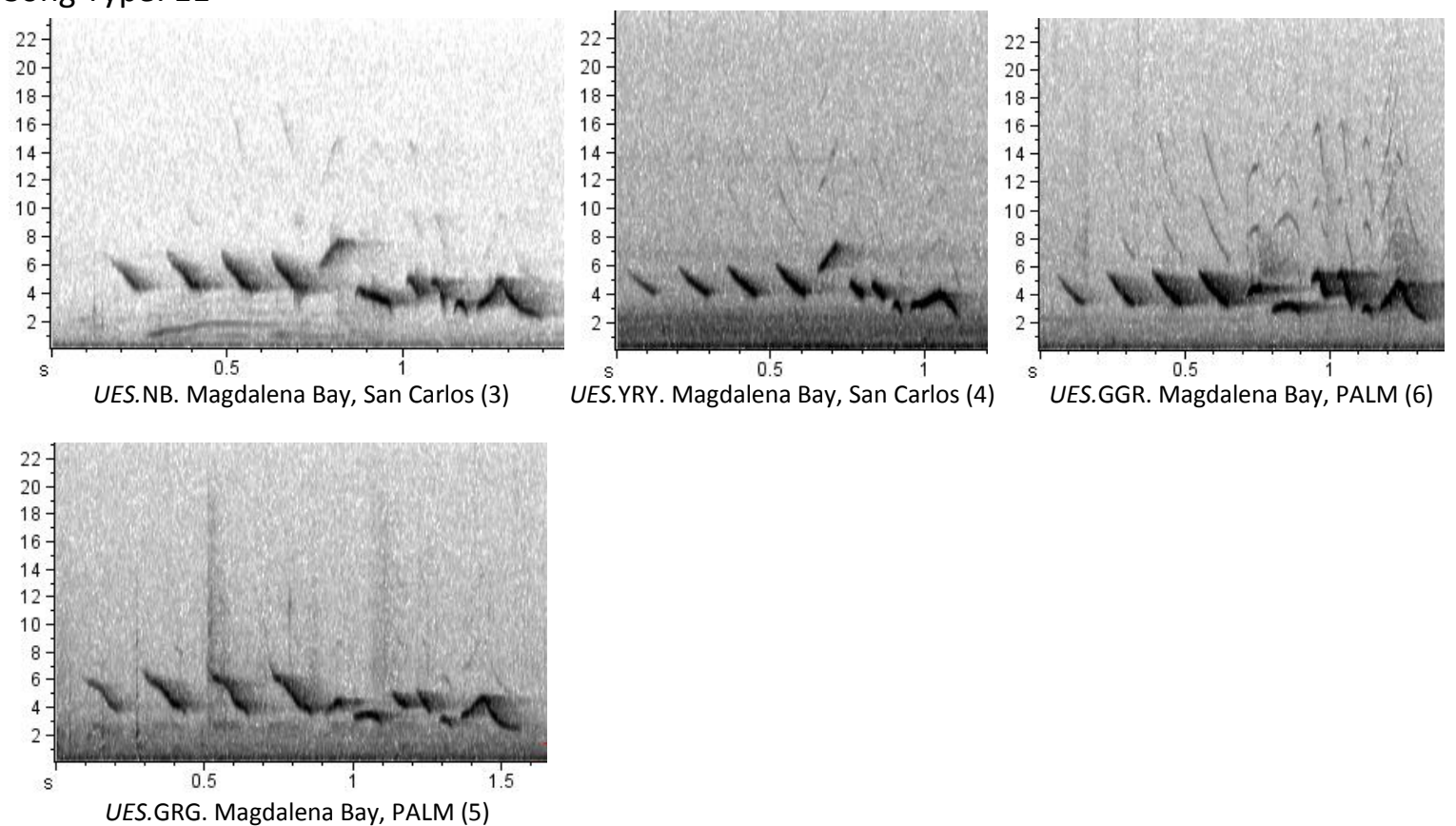
Song Type: 12
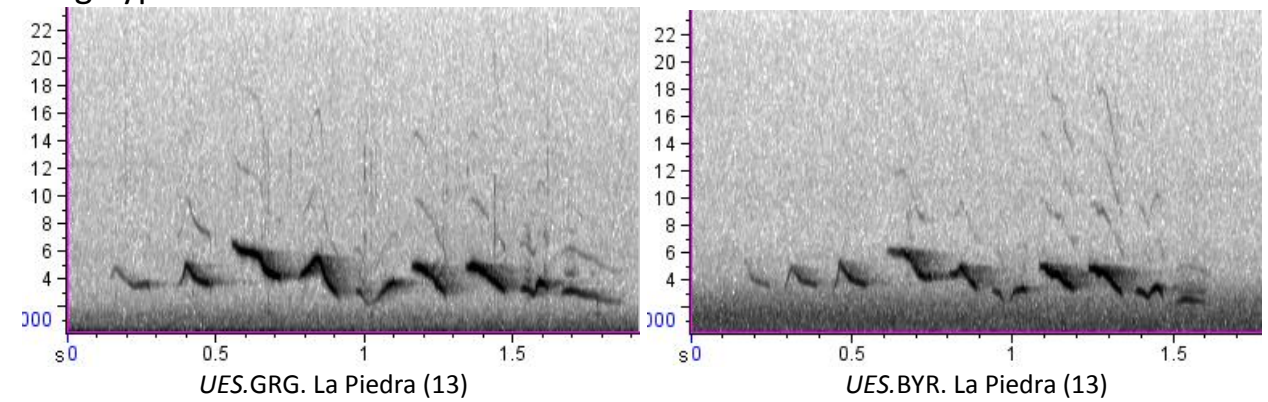

Song Type: 13
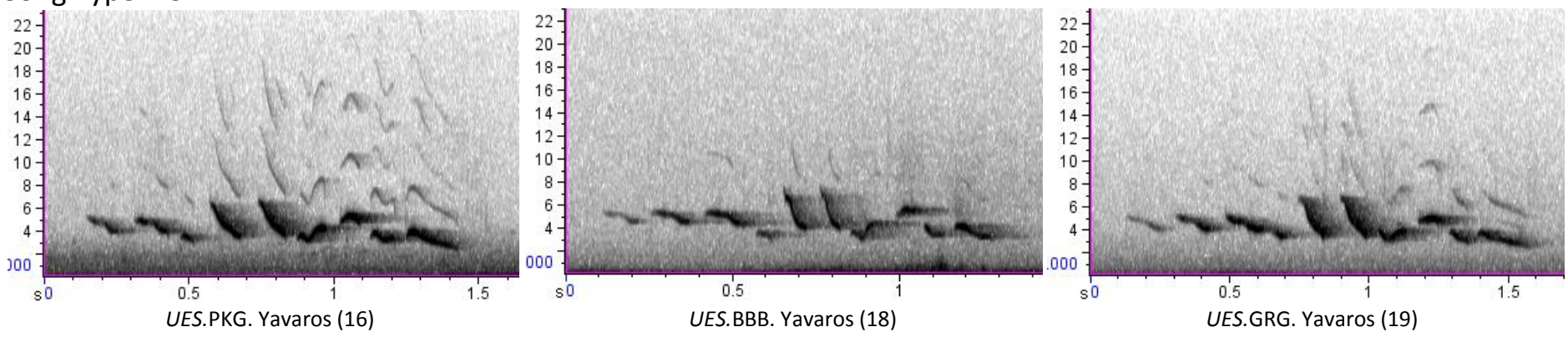

\section{Song Type: 14}
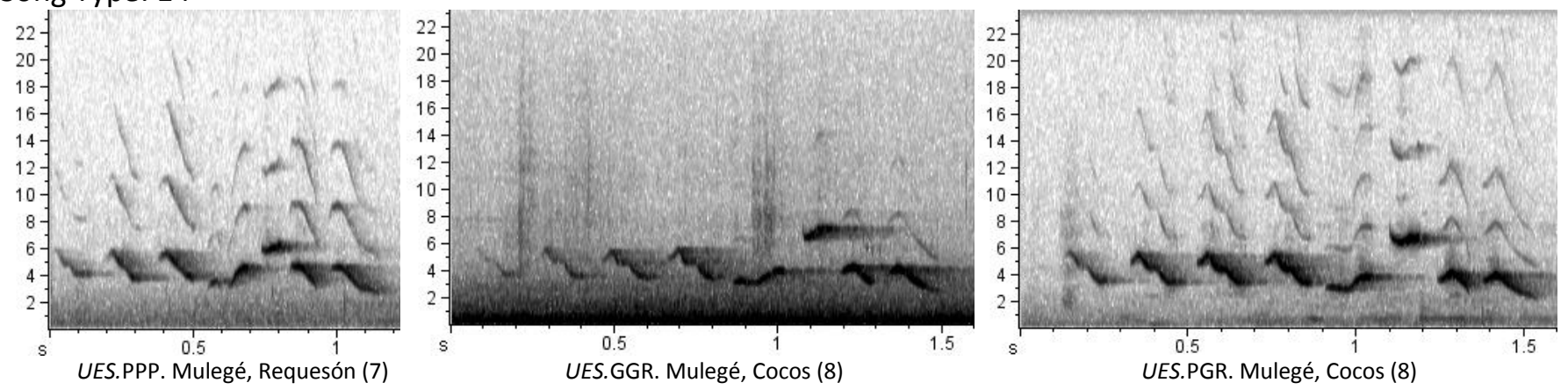

\section{Song Type: 16}
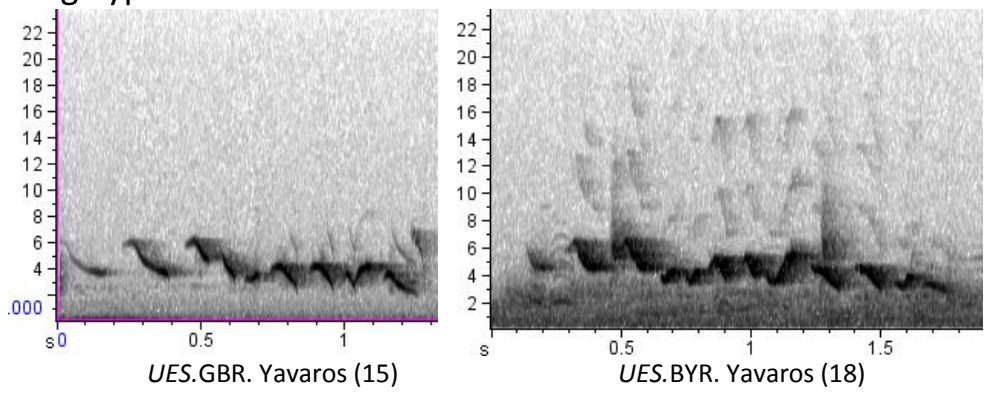

\section{Song Type: 22}
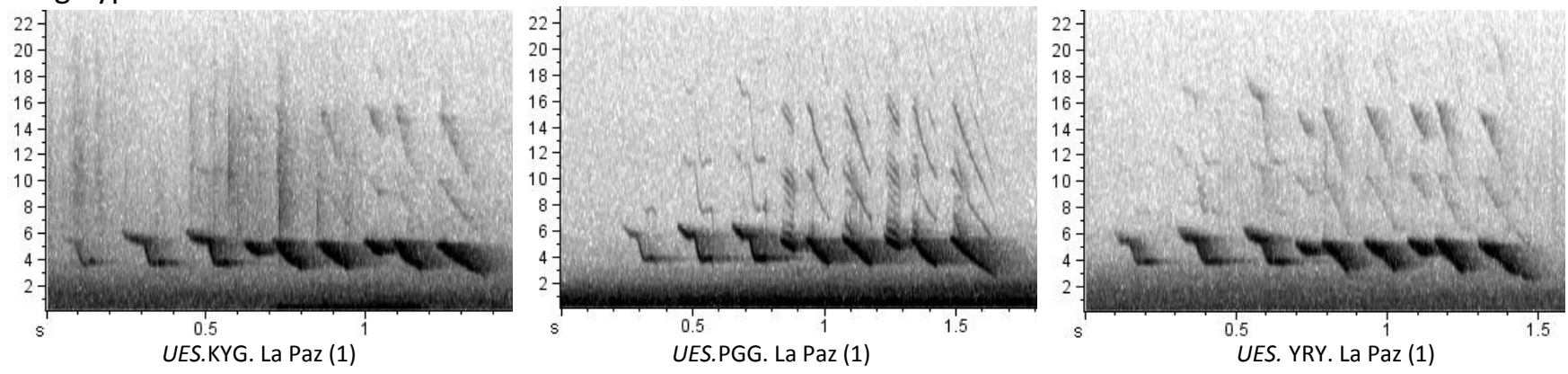


\section{Song Type: 25}
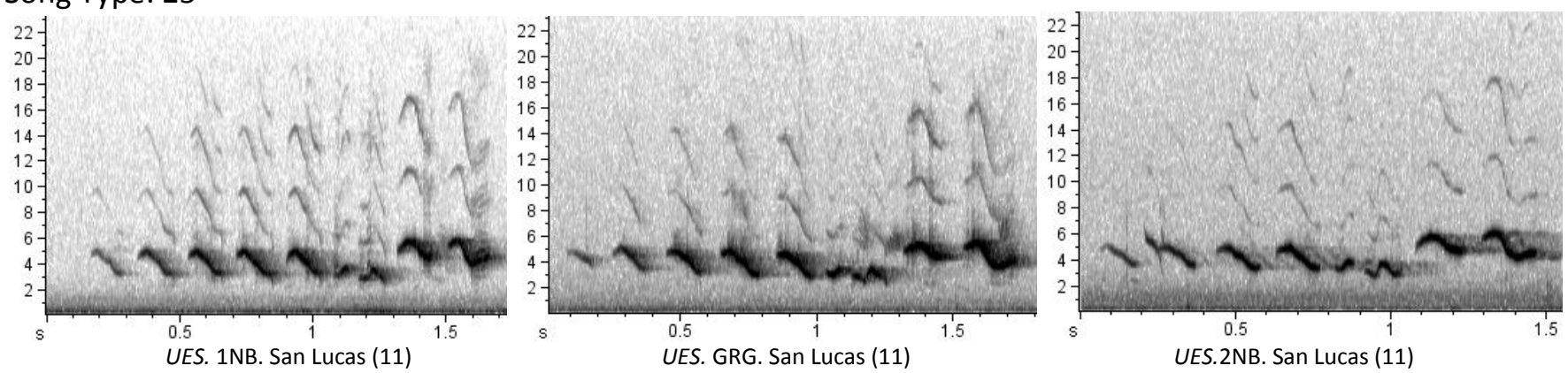

\section{Song Type: 26}
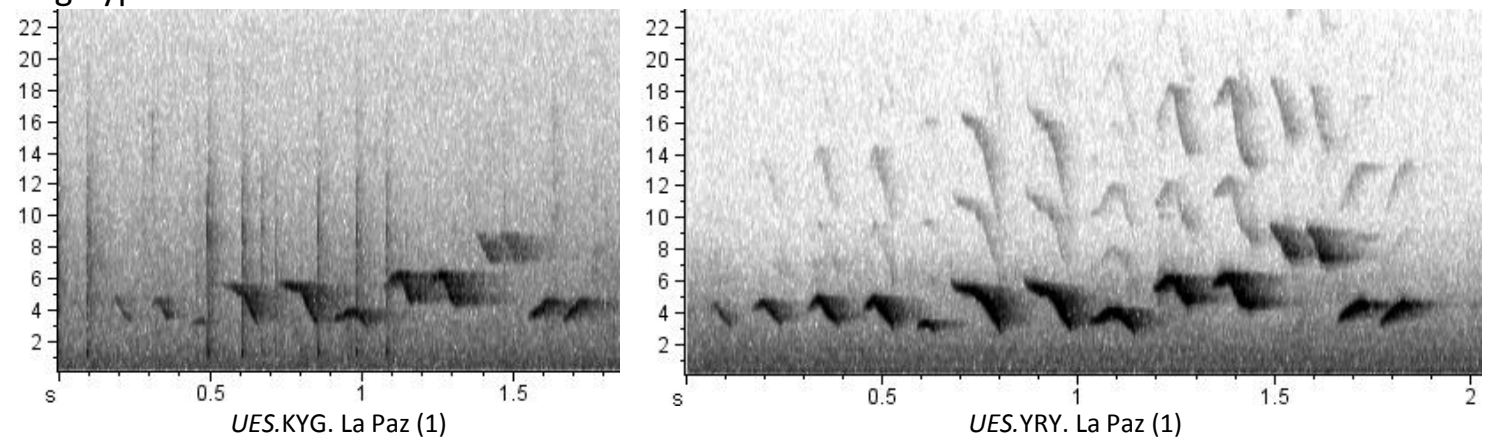

\section{Song Type: 27}
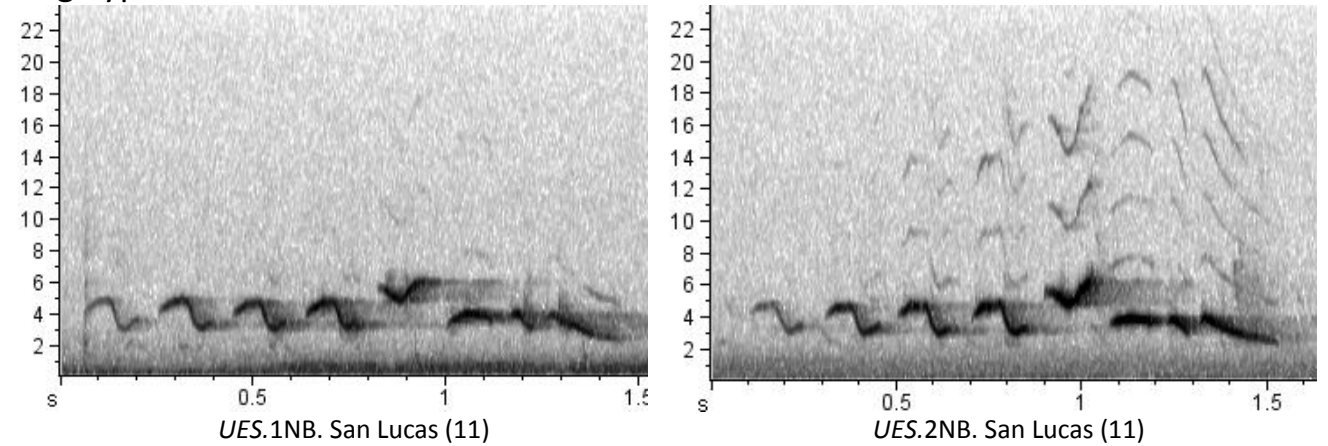

\section{Song Type: 30}
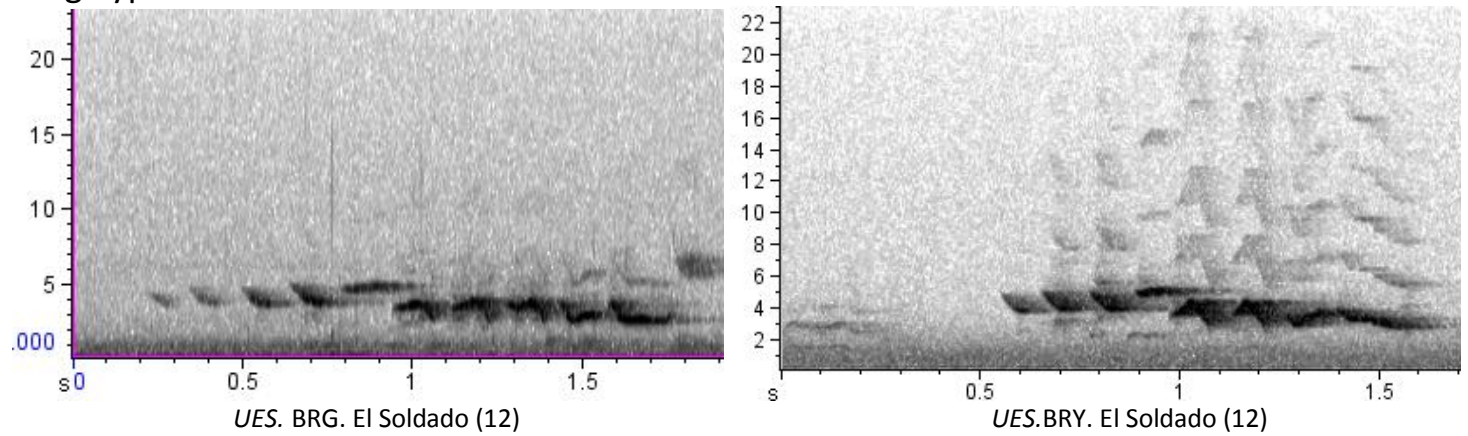
Song Type: 31
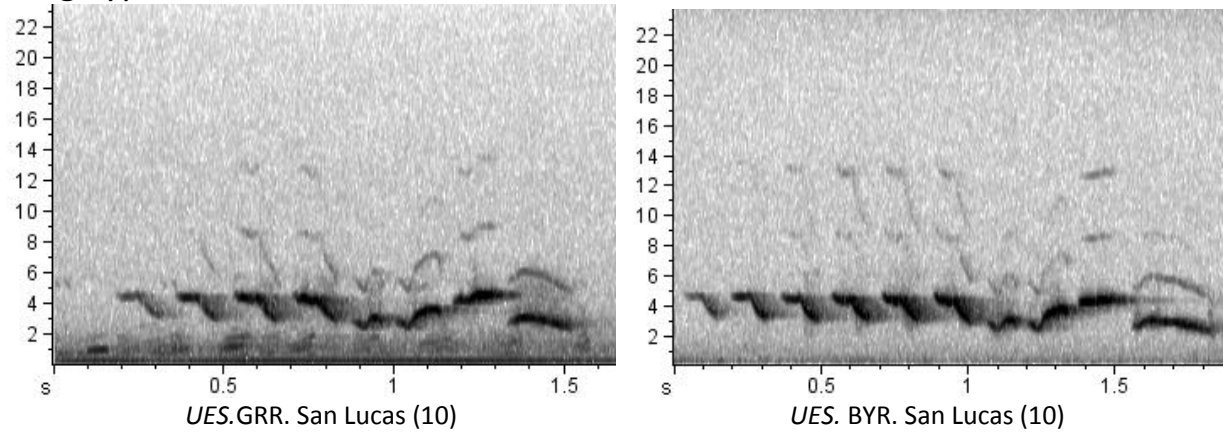

\section{Song Type: 33}
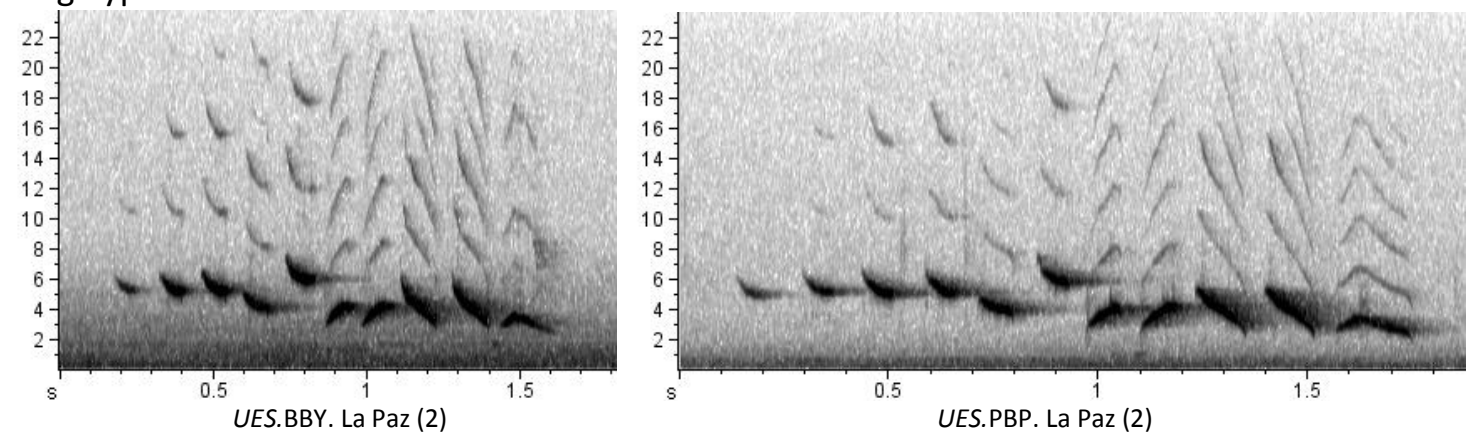

Song Type: 68
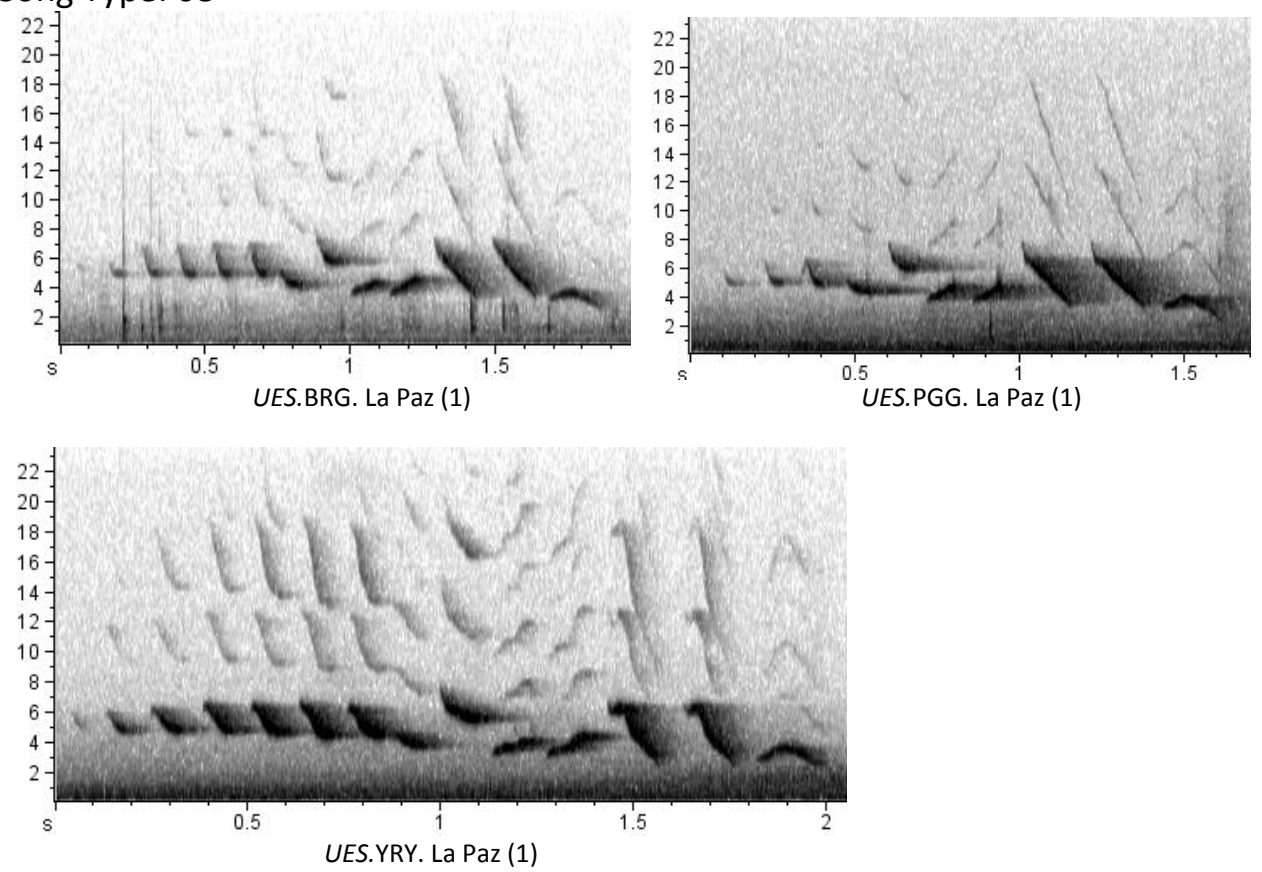
Song Type: 71
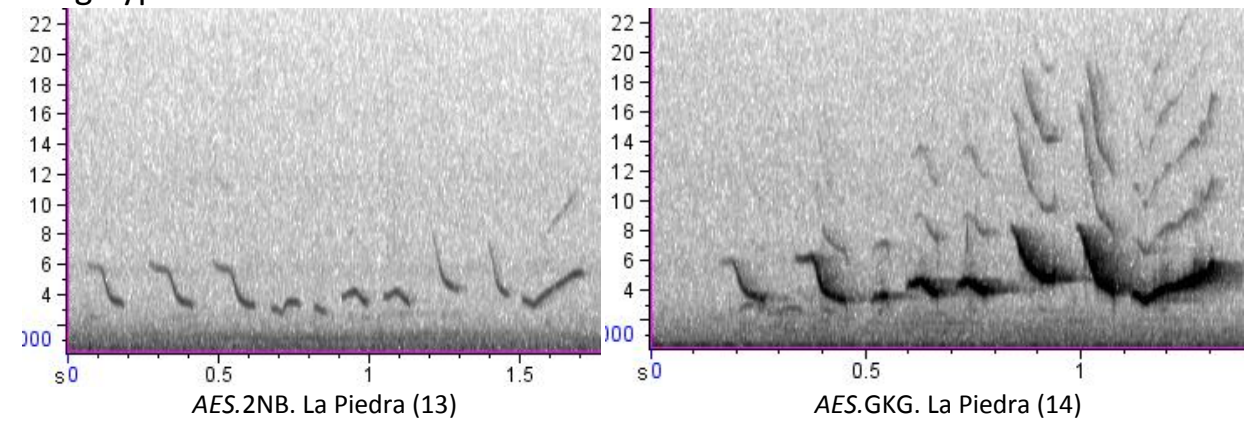

Song Type: 76
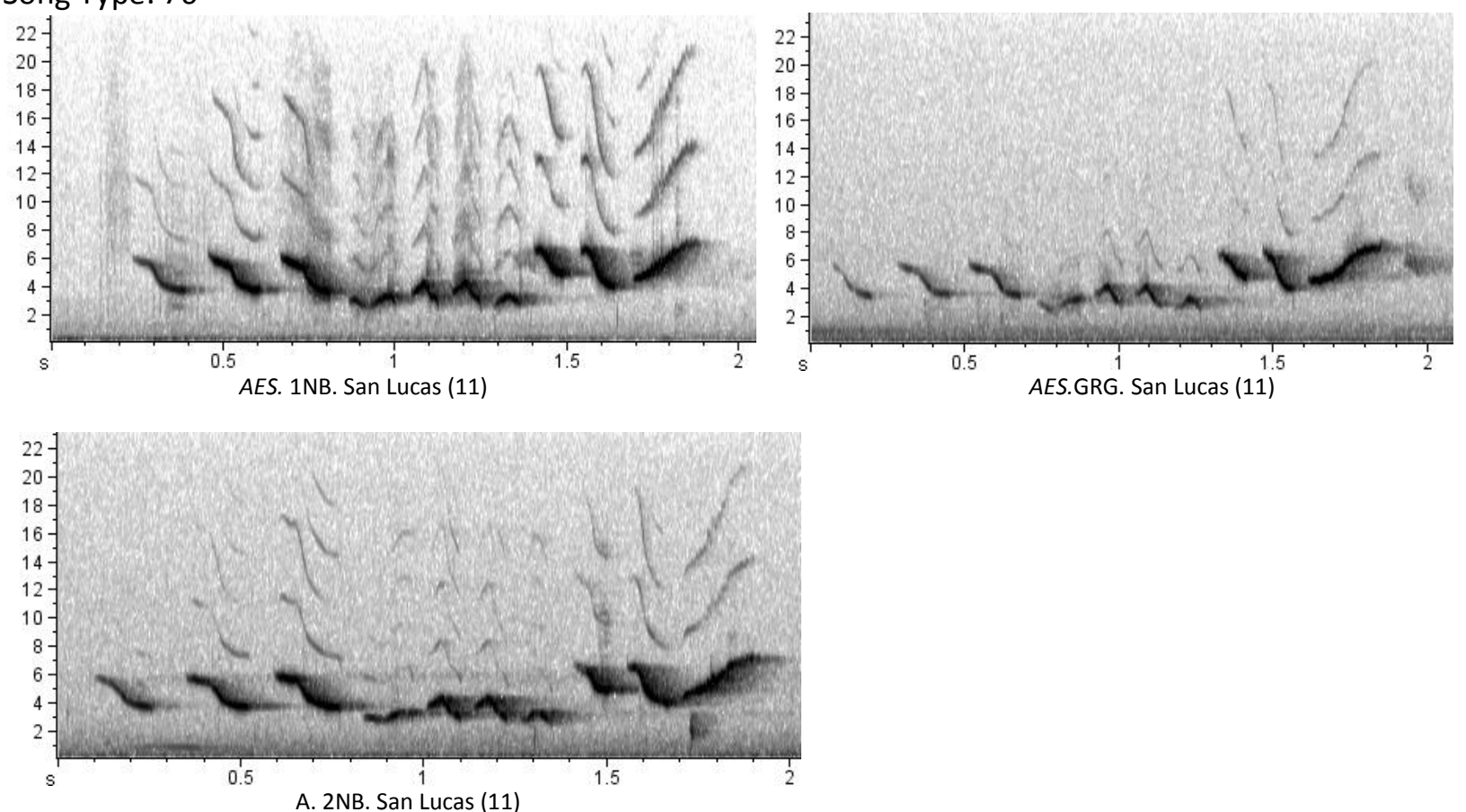

Song Type: 83
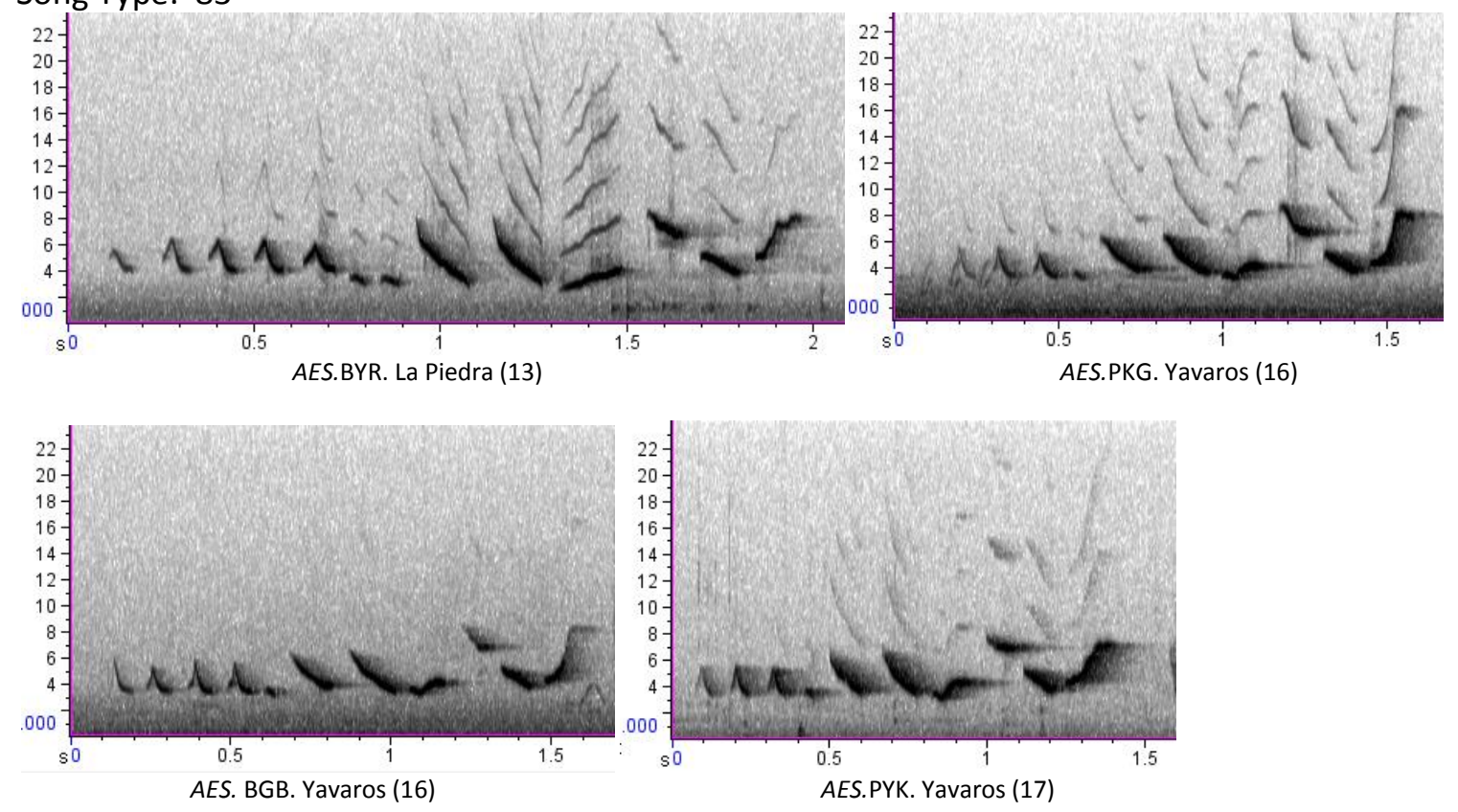
Song Type: 85

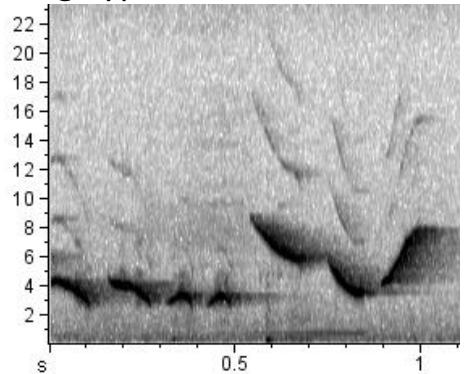

AES. PGR. Mulegé, Cocos (8)

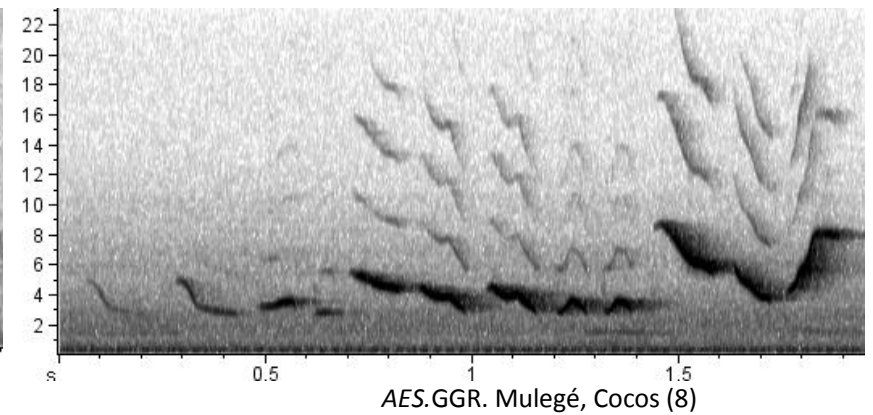

\section{Song Type: 87}
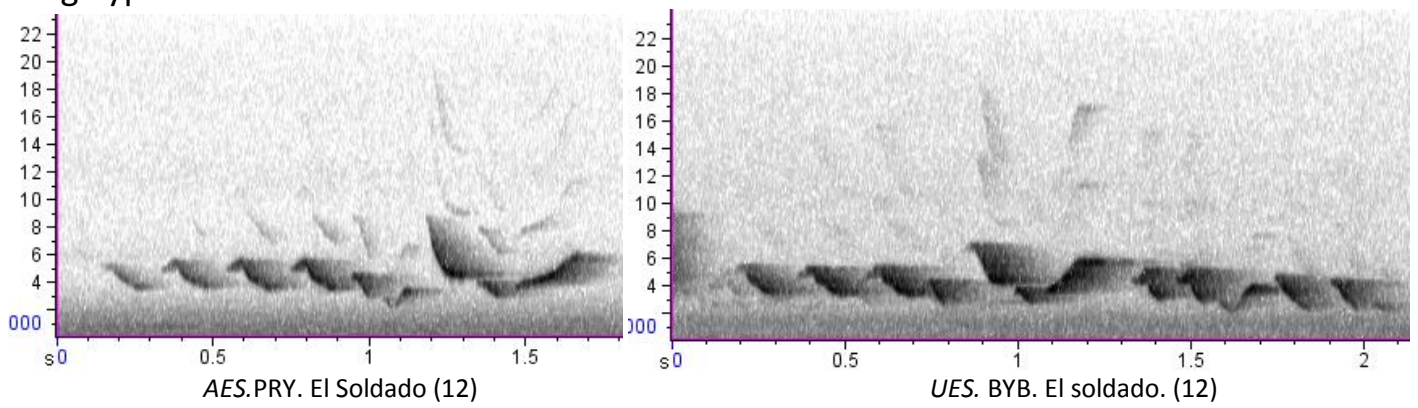

\section{Song Type: 88}
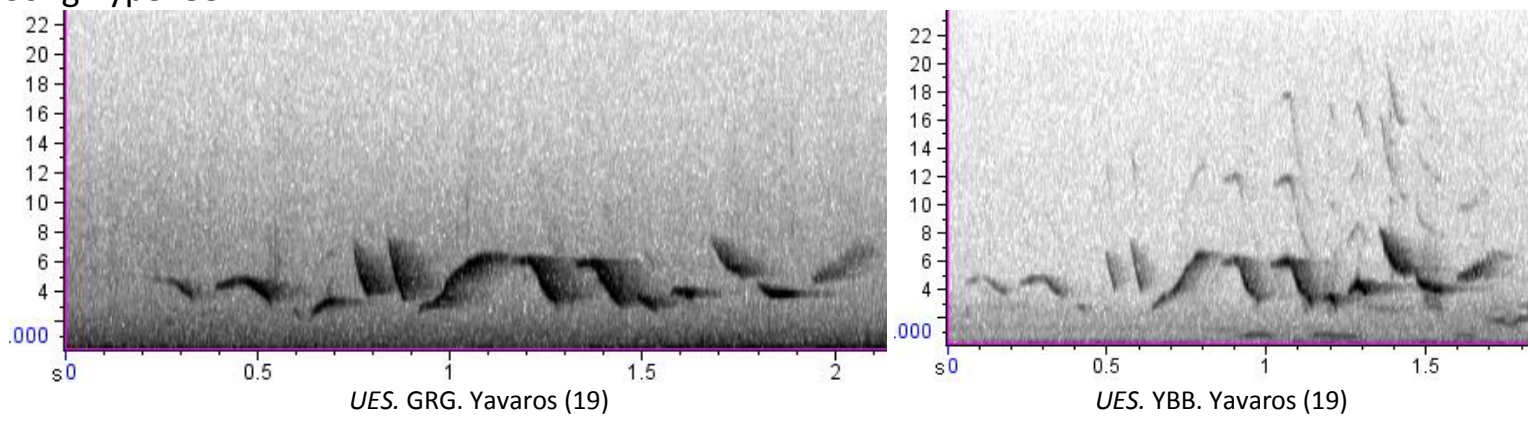

\section{Song Type: 90}
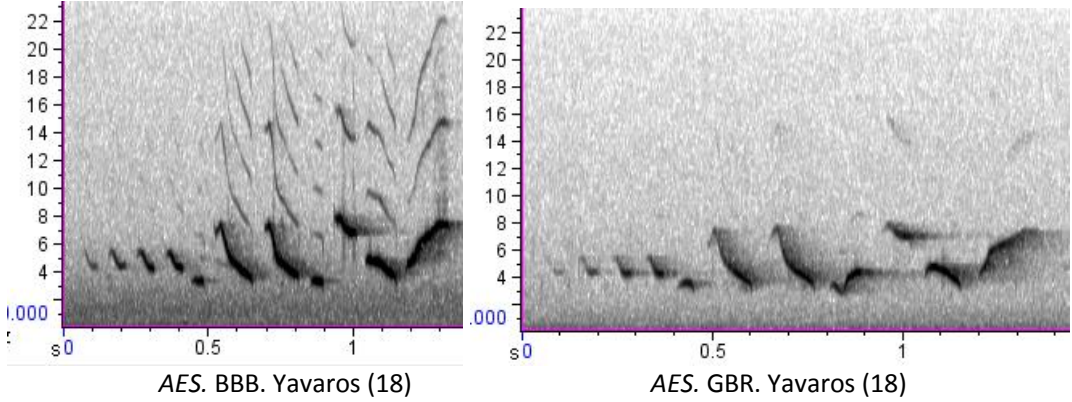


\section{Song Type: 91}
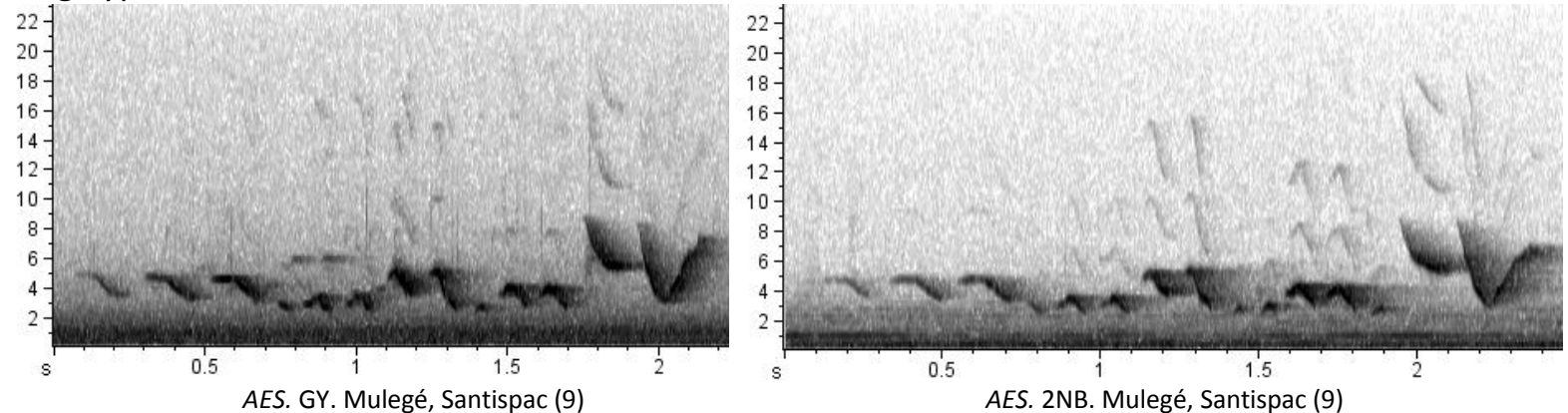

\section{Song Type: 92}
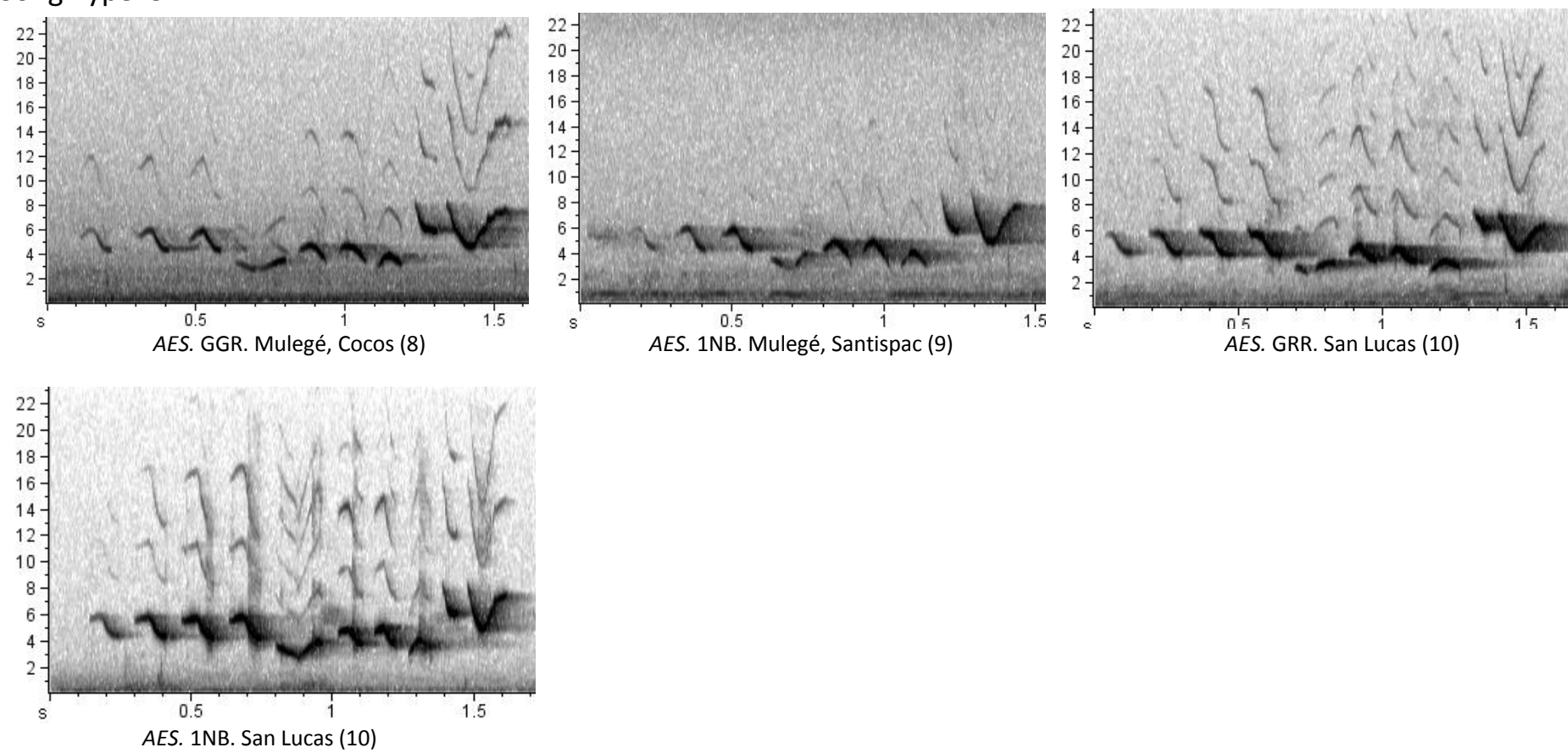

\section{Song Type: 93}
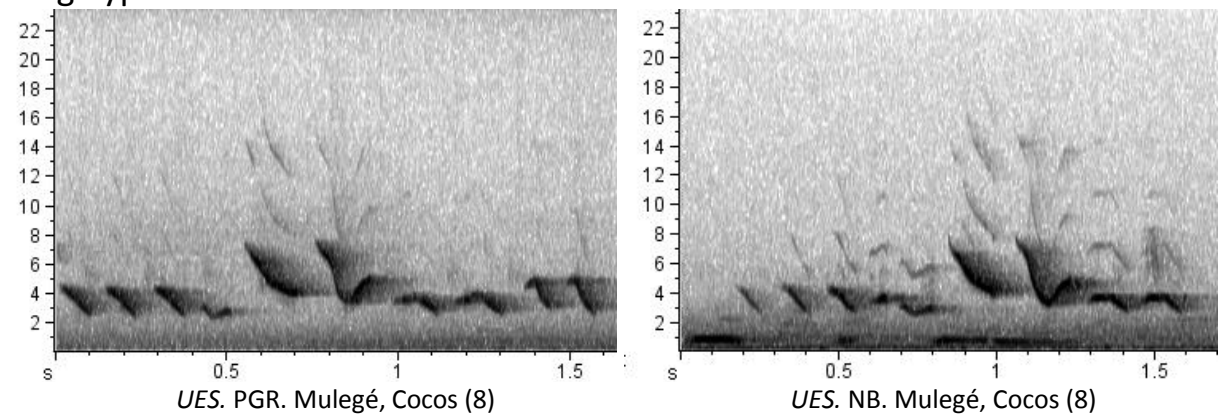


\section{Song Type: 94}
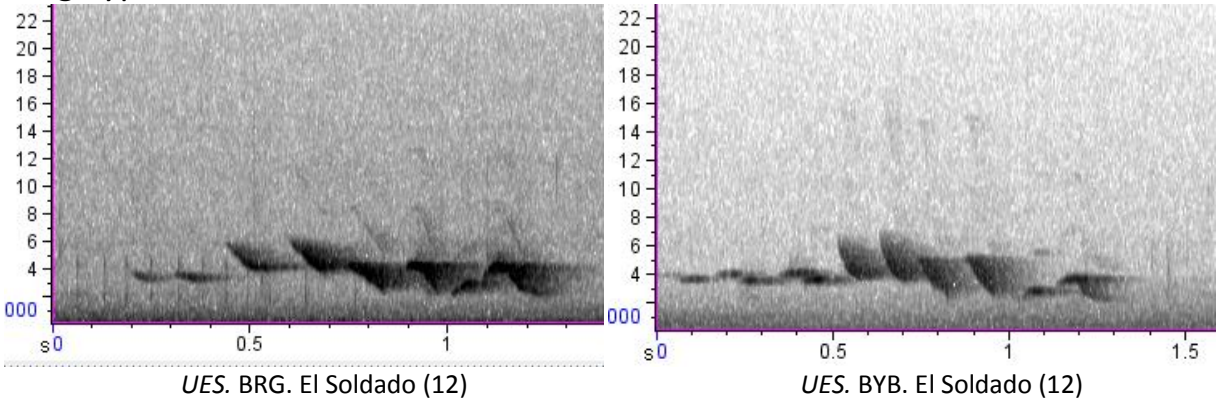

\section{Song Type: 96}
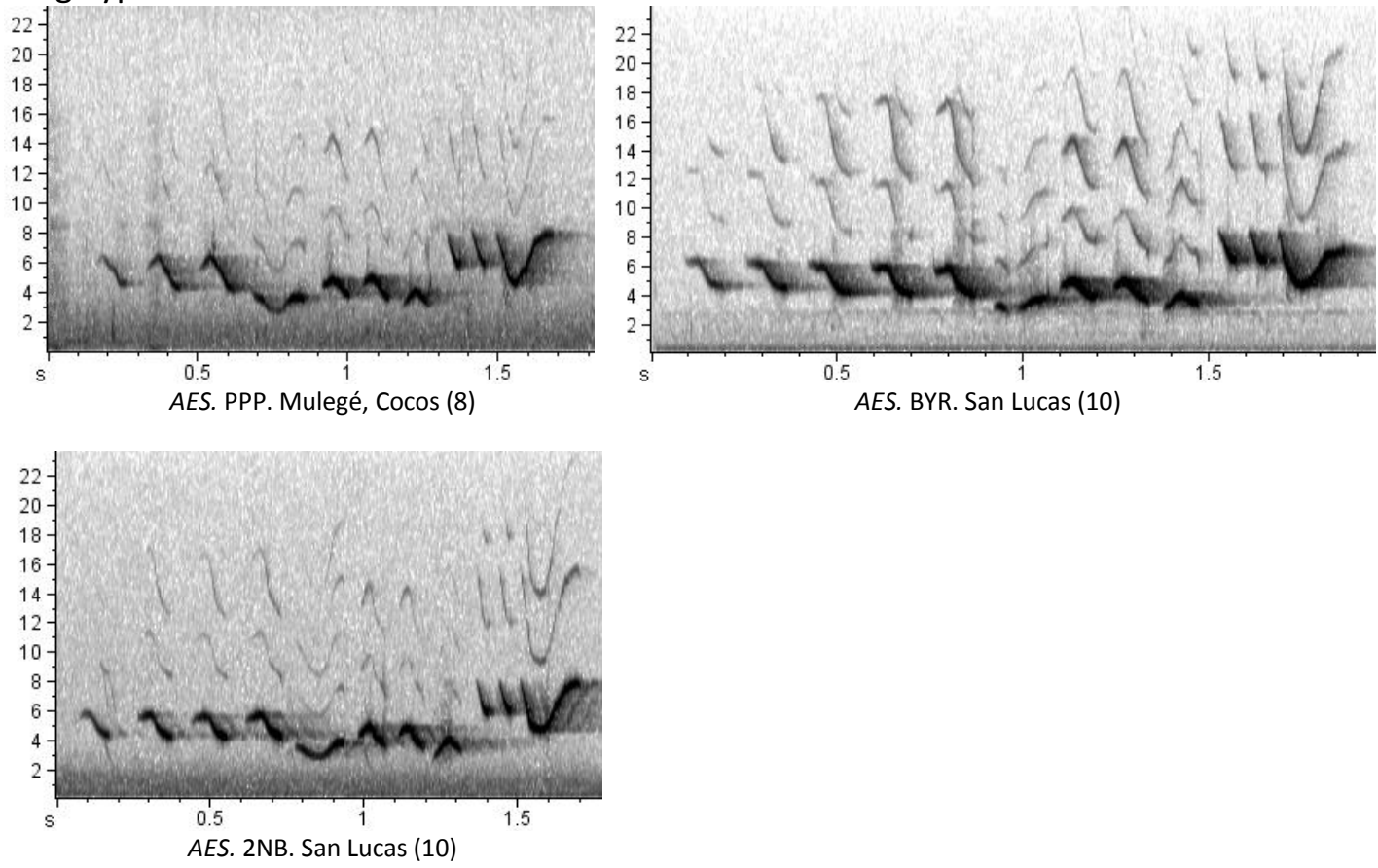

\section{Song Type: 97}
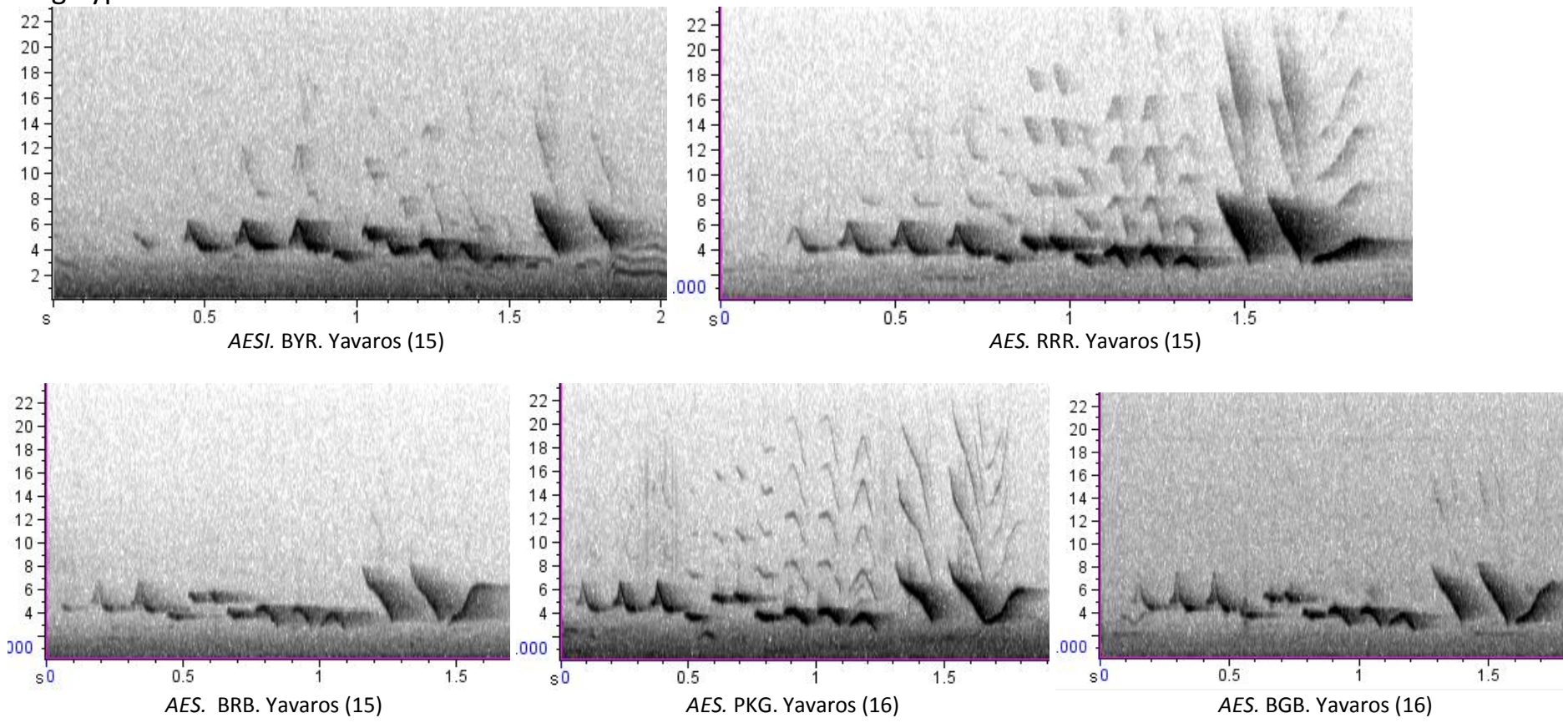

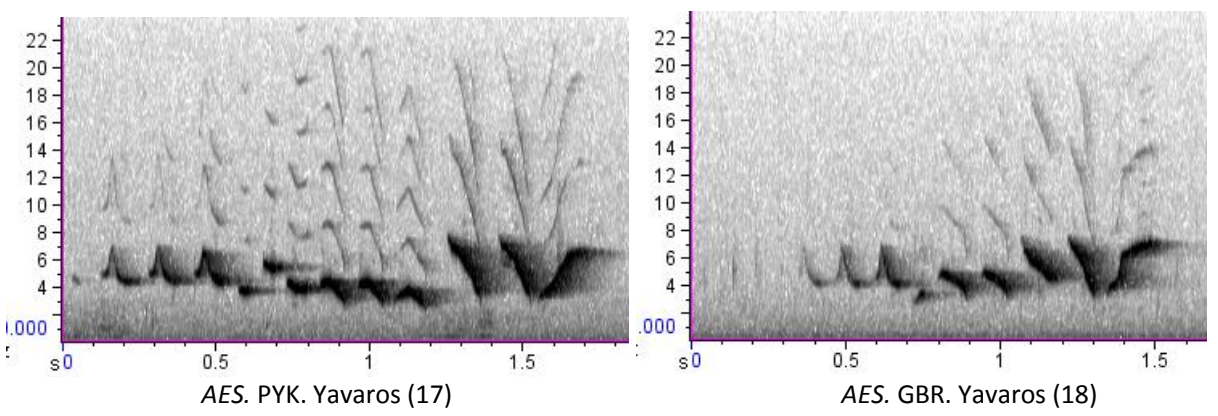

\section{Song Type: 99}
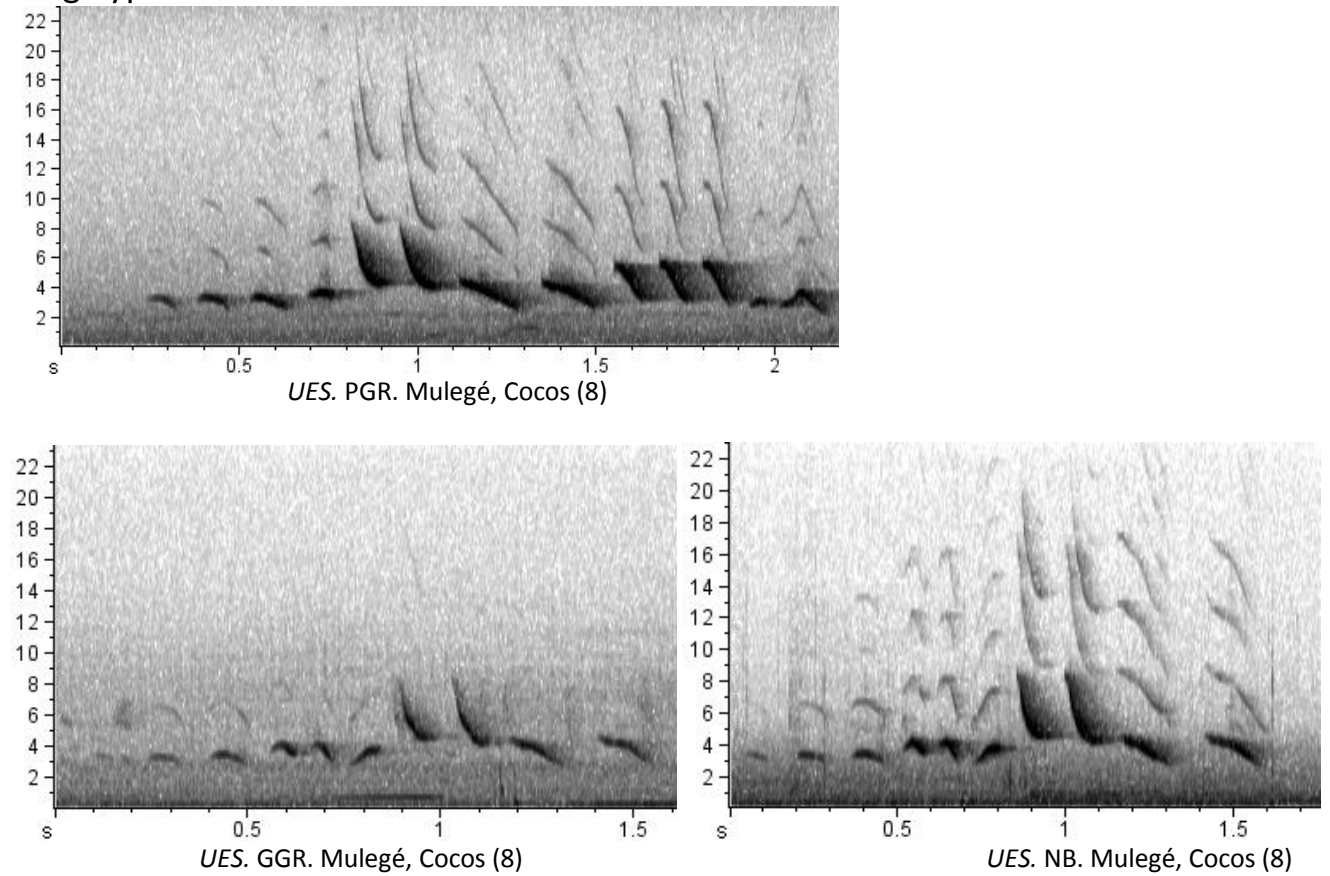

Song Type: 102
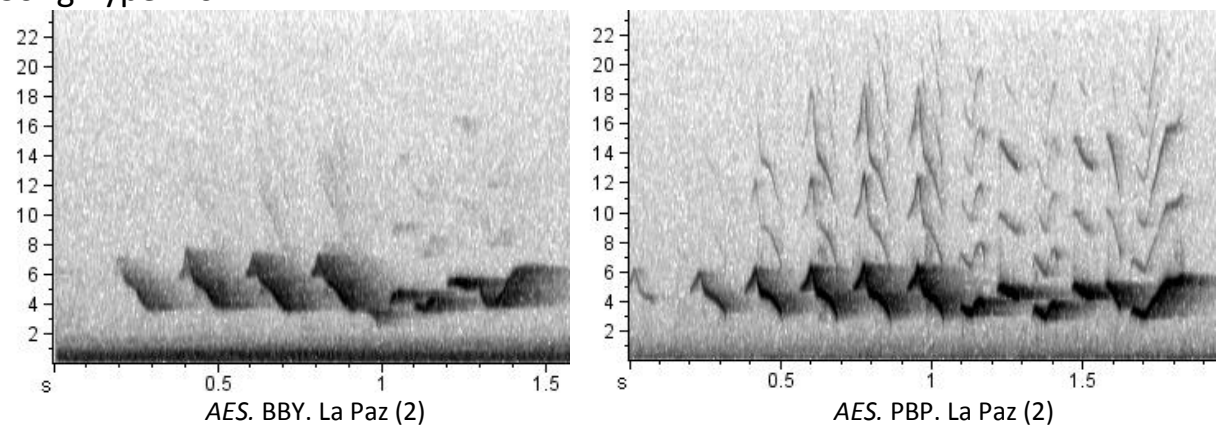

\section{Song Type: 103}
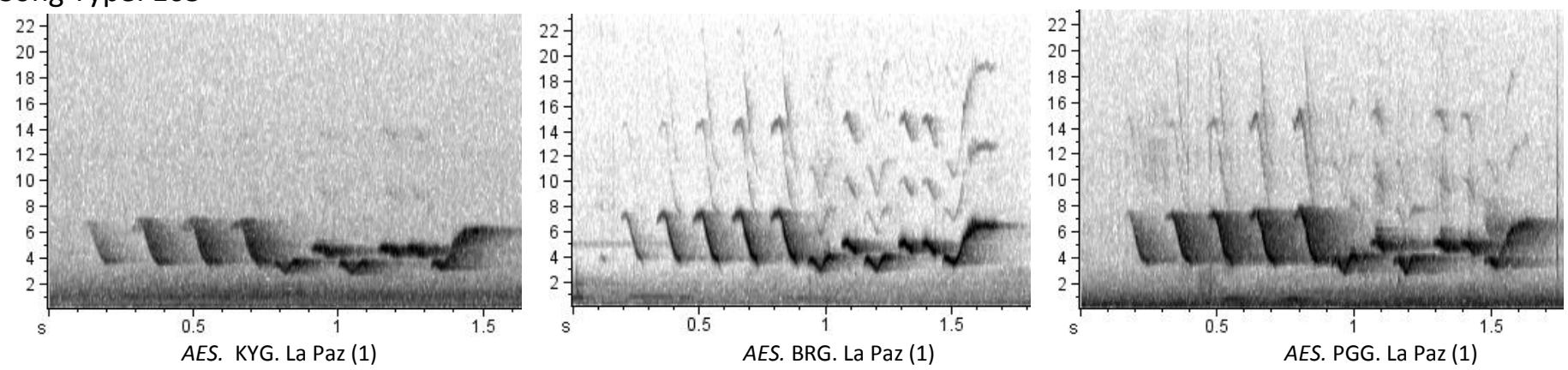
Song Type: 111
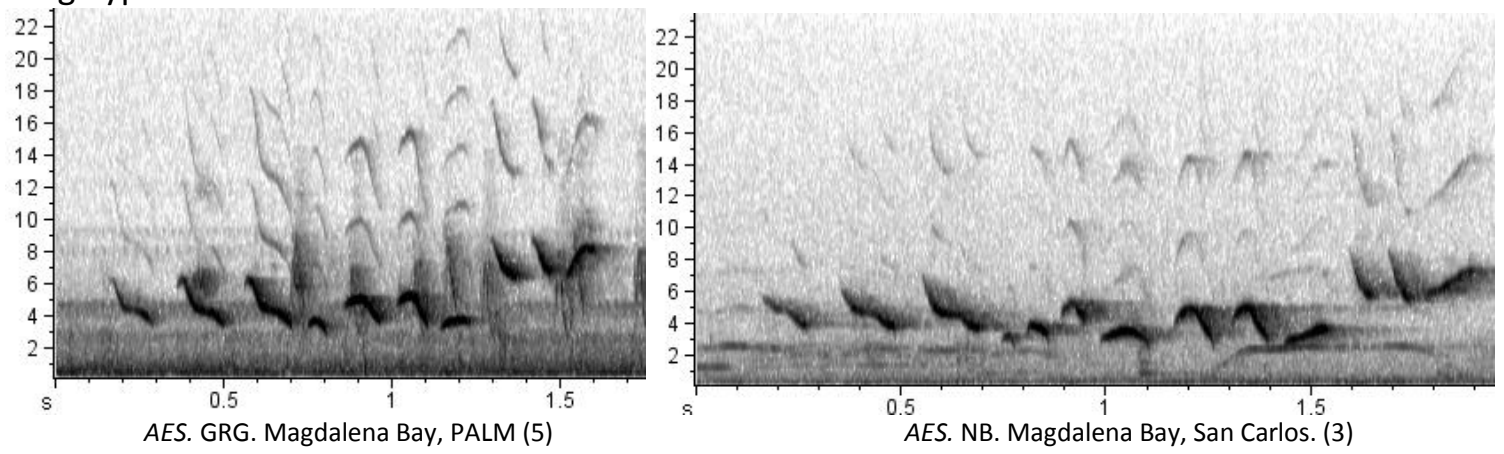

\section{Song Type: 112}
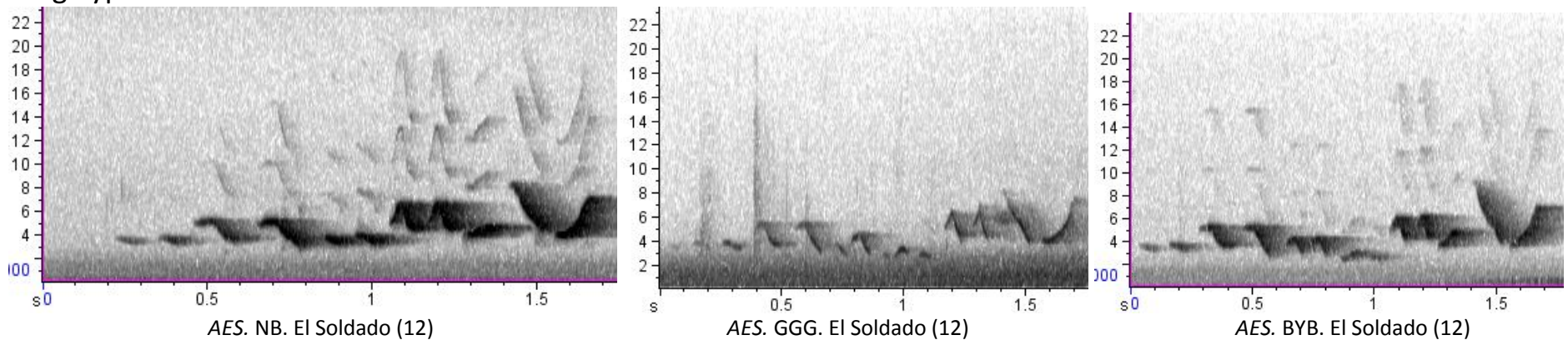

\section{Song Type: 116}
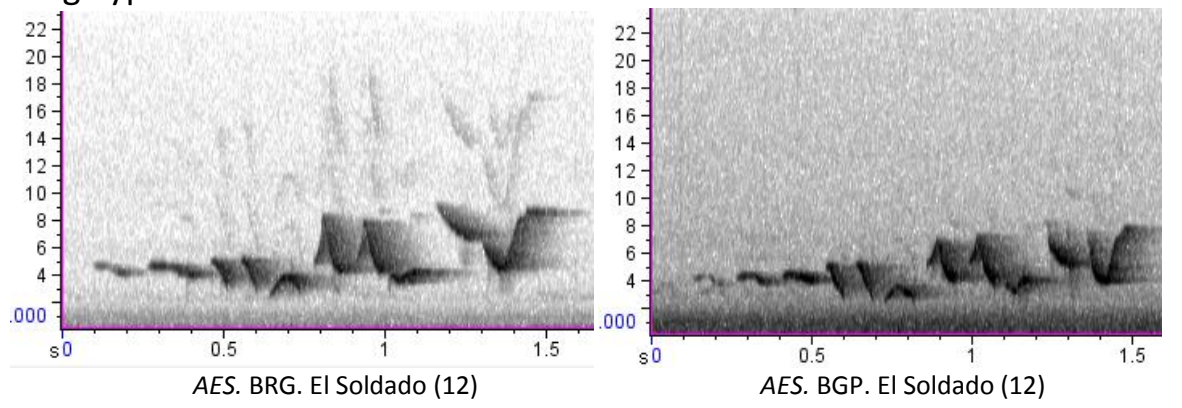

Song Type: 117
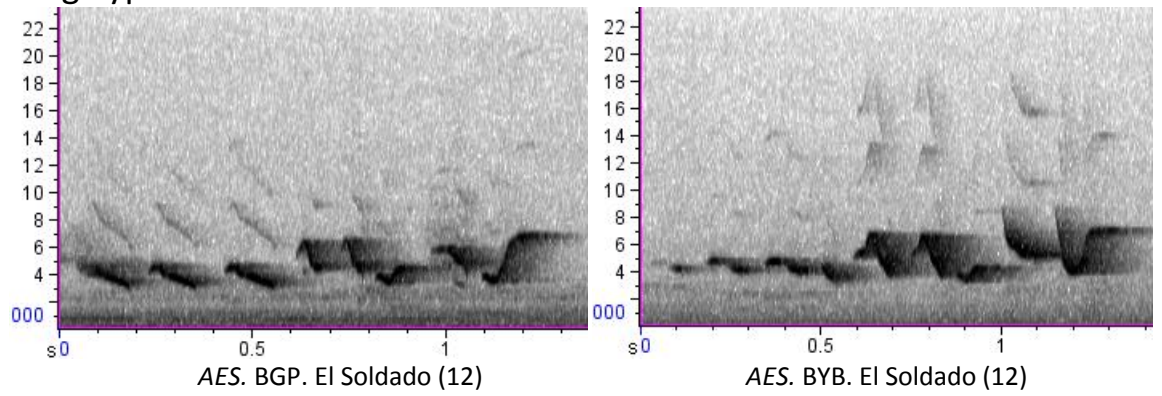
Song Type: 121
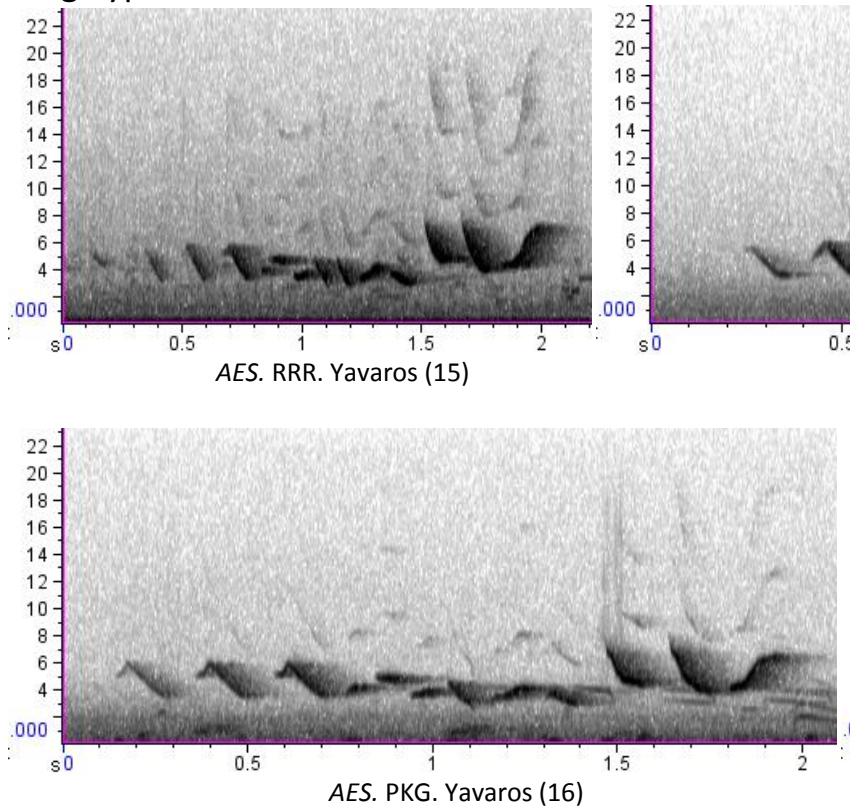
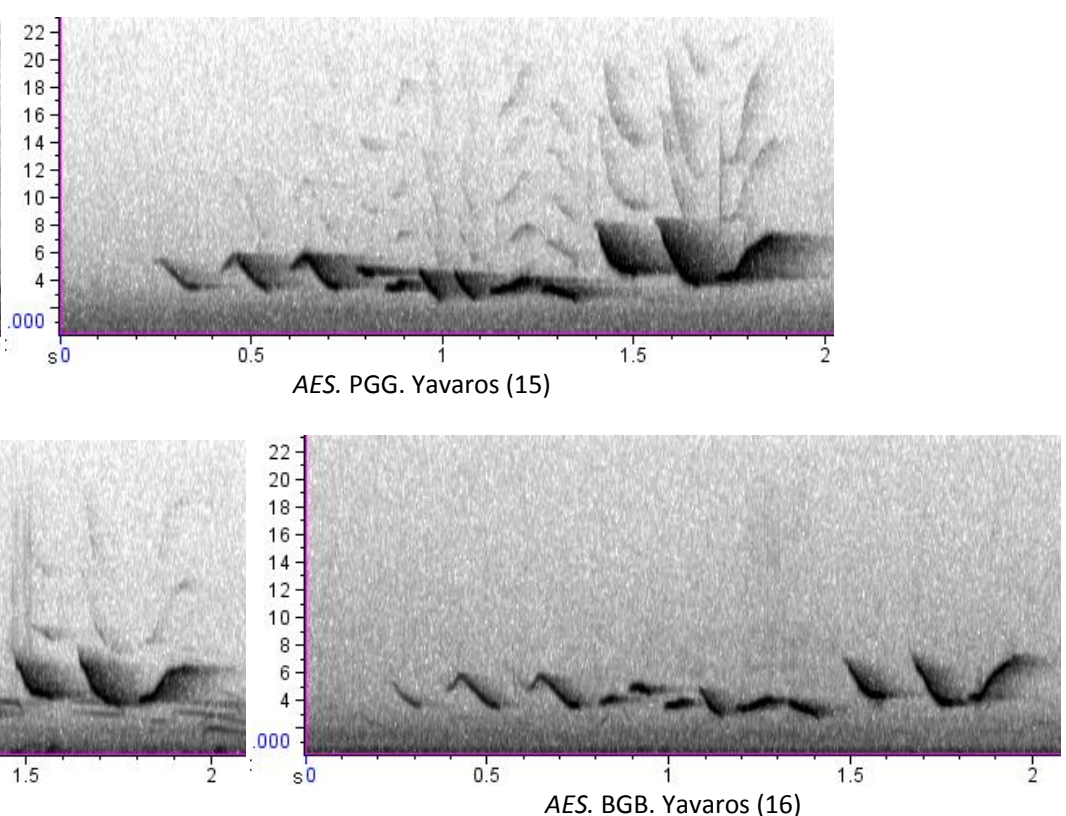

Song Type: 124
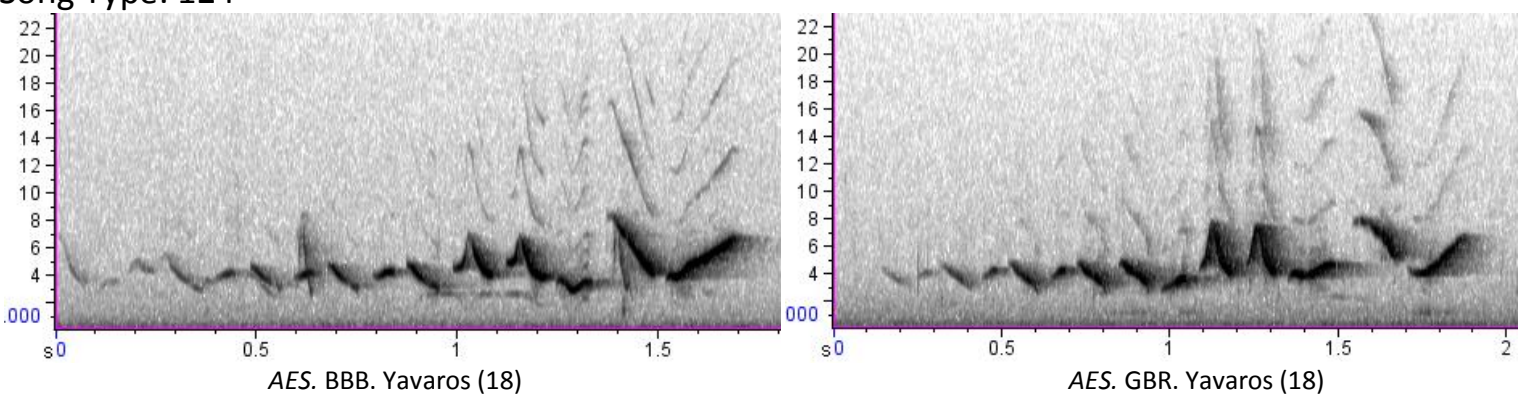

Song Type: 127
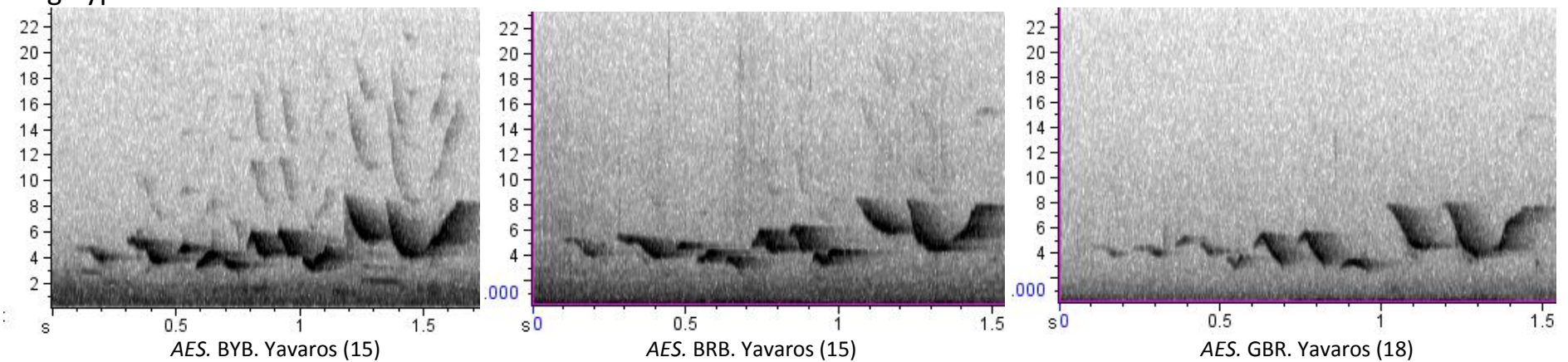

\section{Song Type: 133}
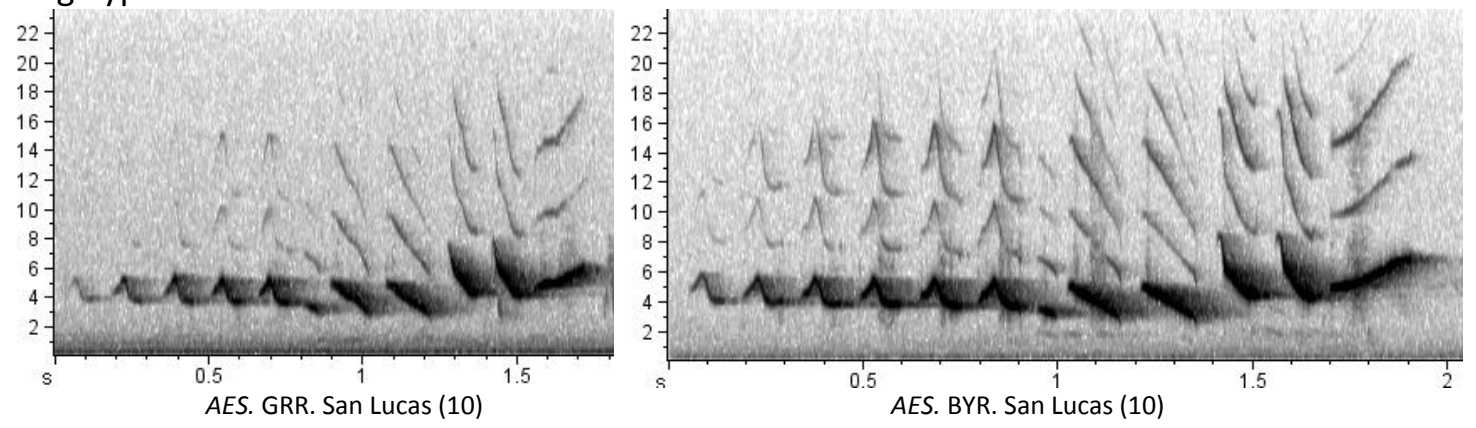
Song Type: 134
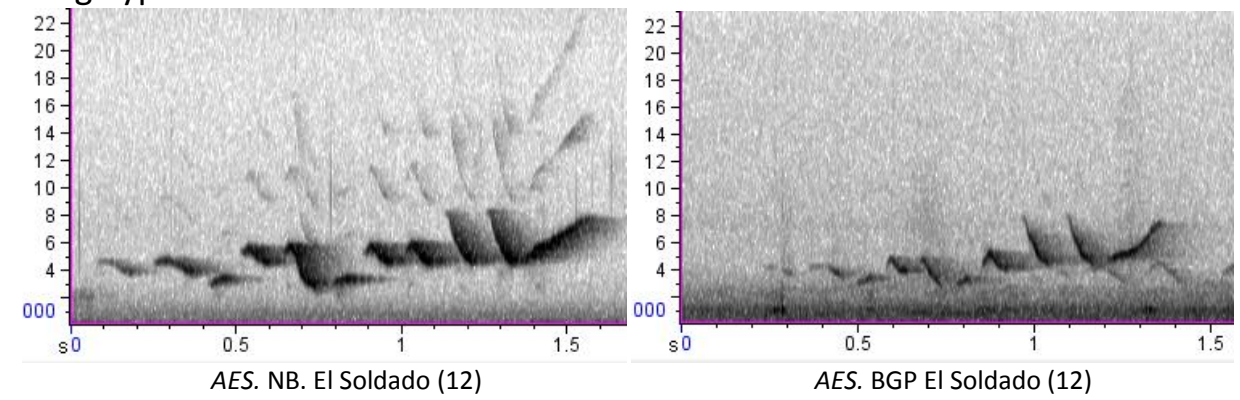

\section{Song Type: 137}
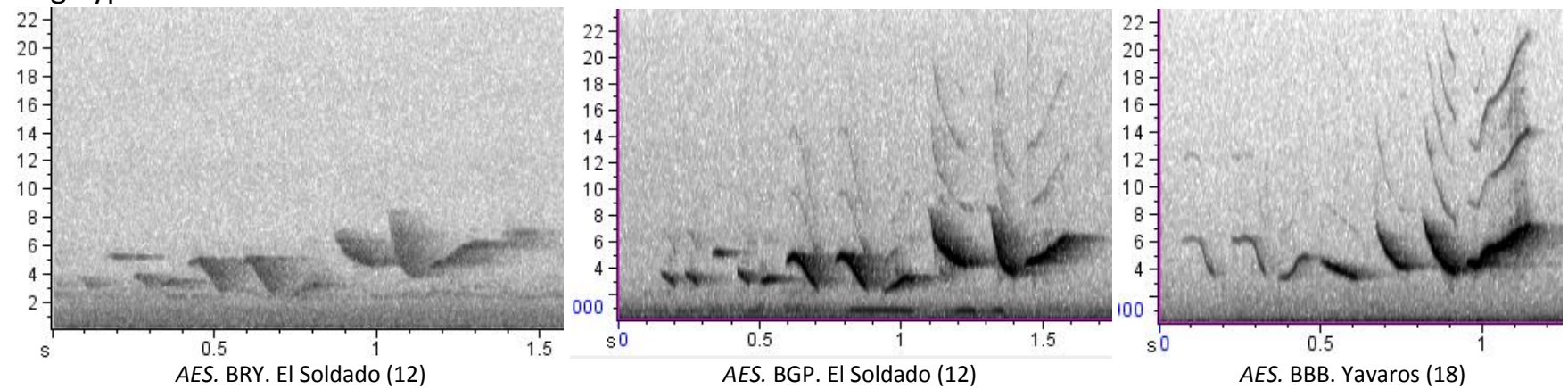

\section{Song Type: 139}
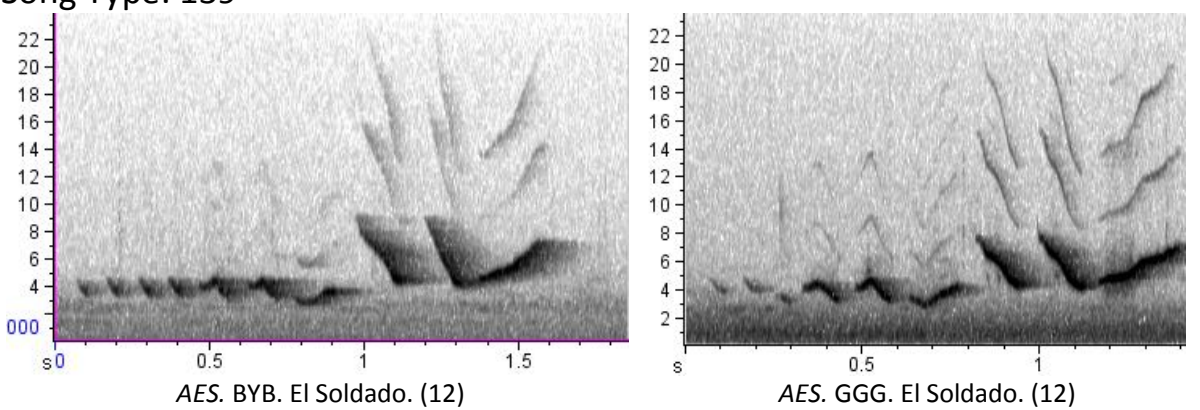

\section{Song Type: 144}

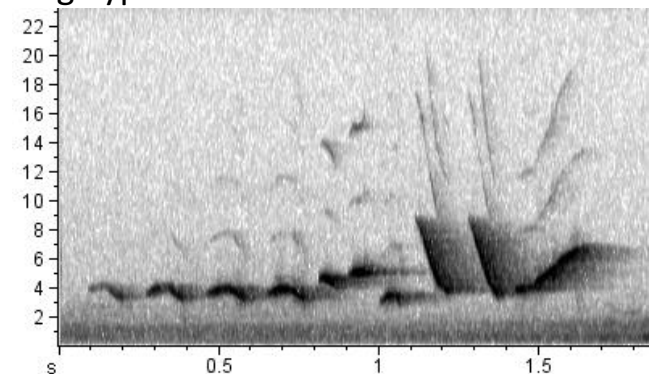

AES. PGR. Mulegé, Cocos. (8)

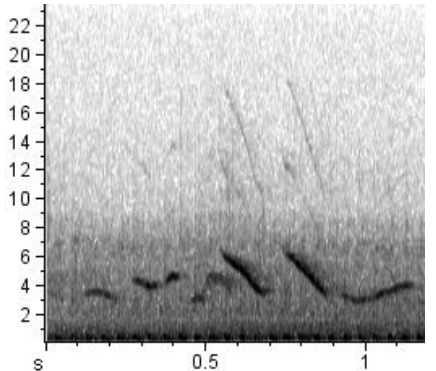

UES. NB. Mulegé, Cocos. (8) 
Song Type: 154
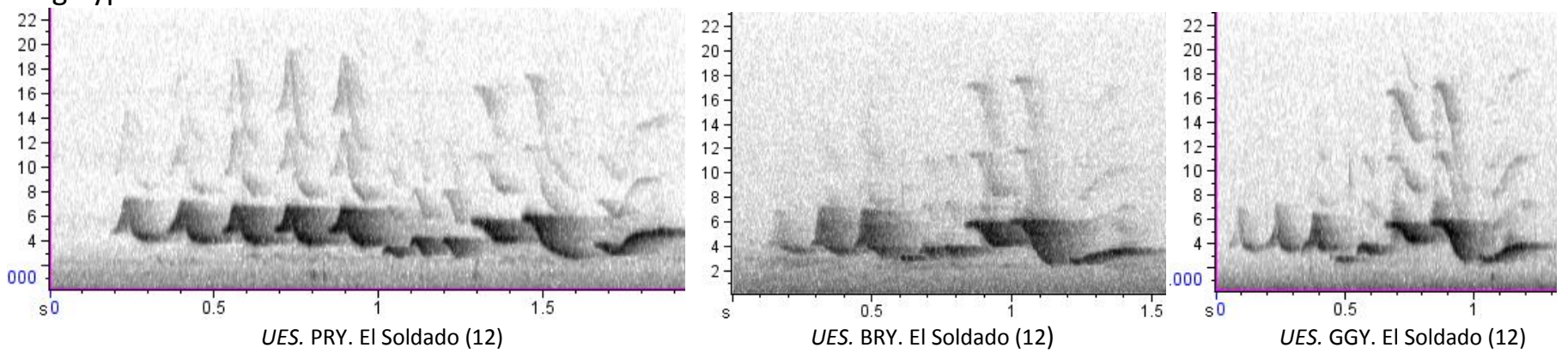

\section{Song Type: 156}
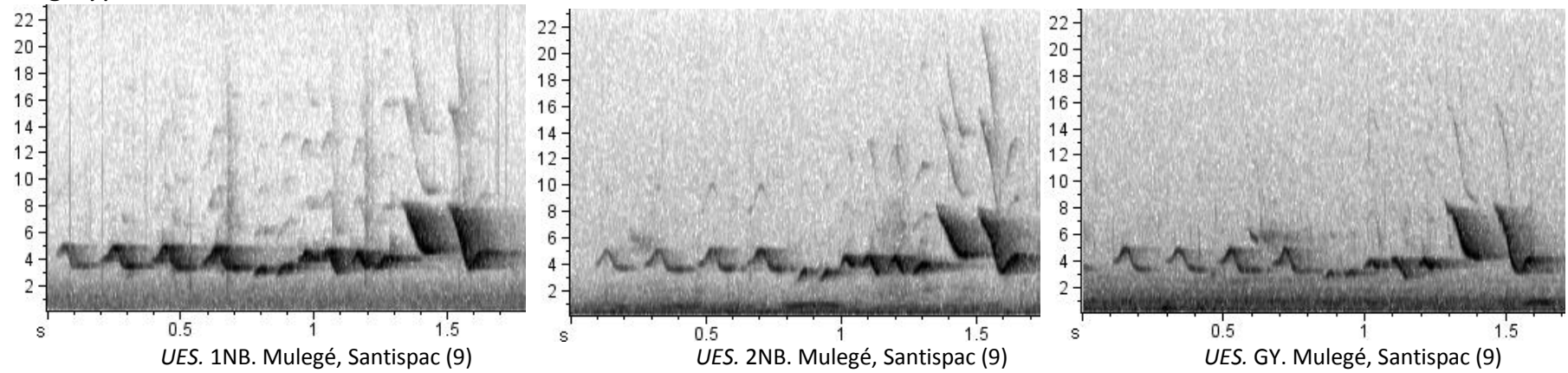

\section{Song Type: 157}
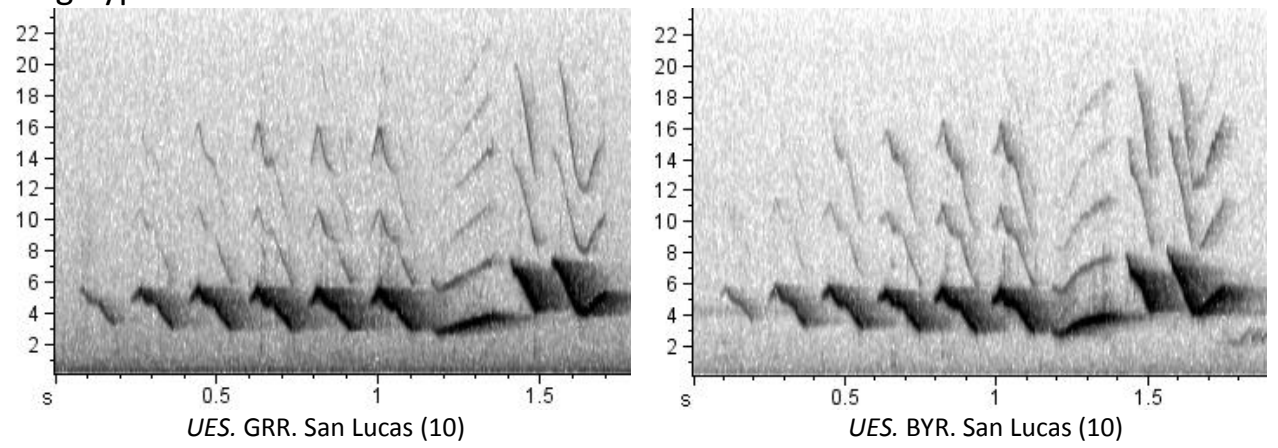

\section{Song Type: 162}
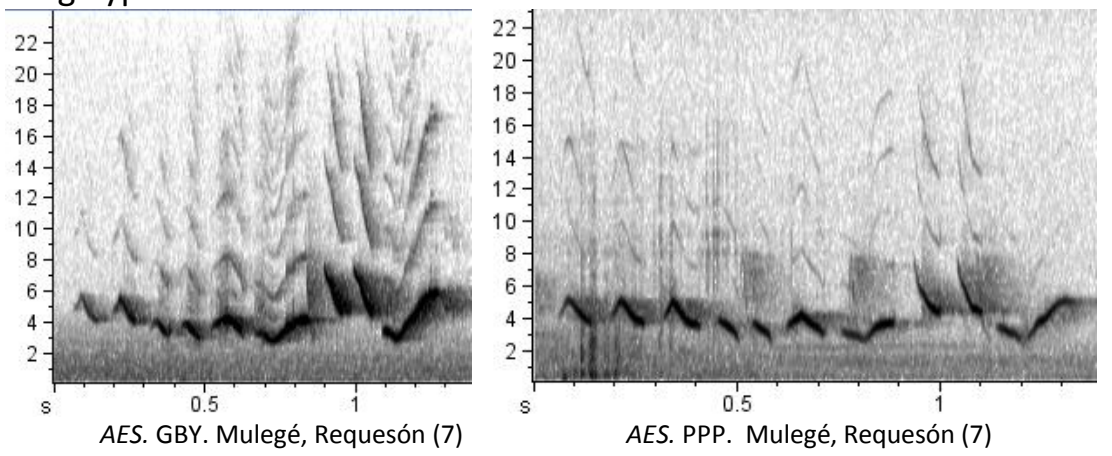

AES. PPP. Mulegé, Requesón (7) 
Song Type: 164
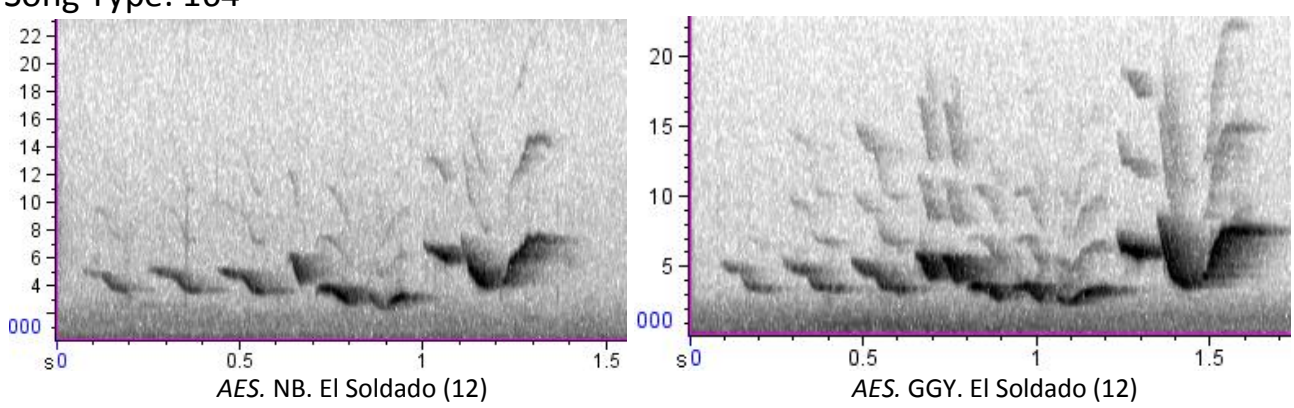

\section{Song Type: 170}
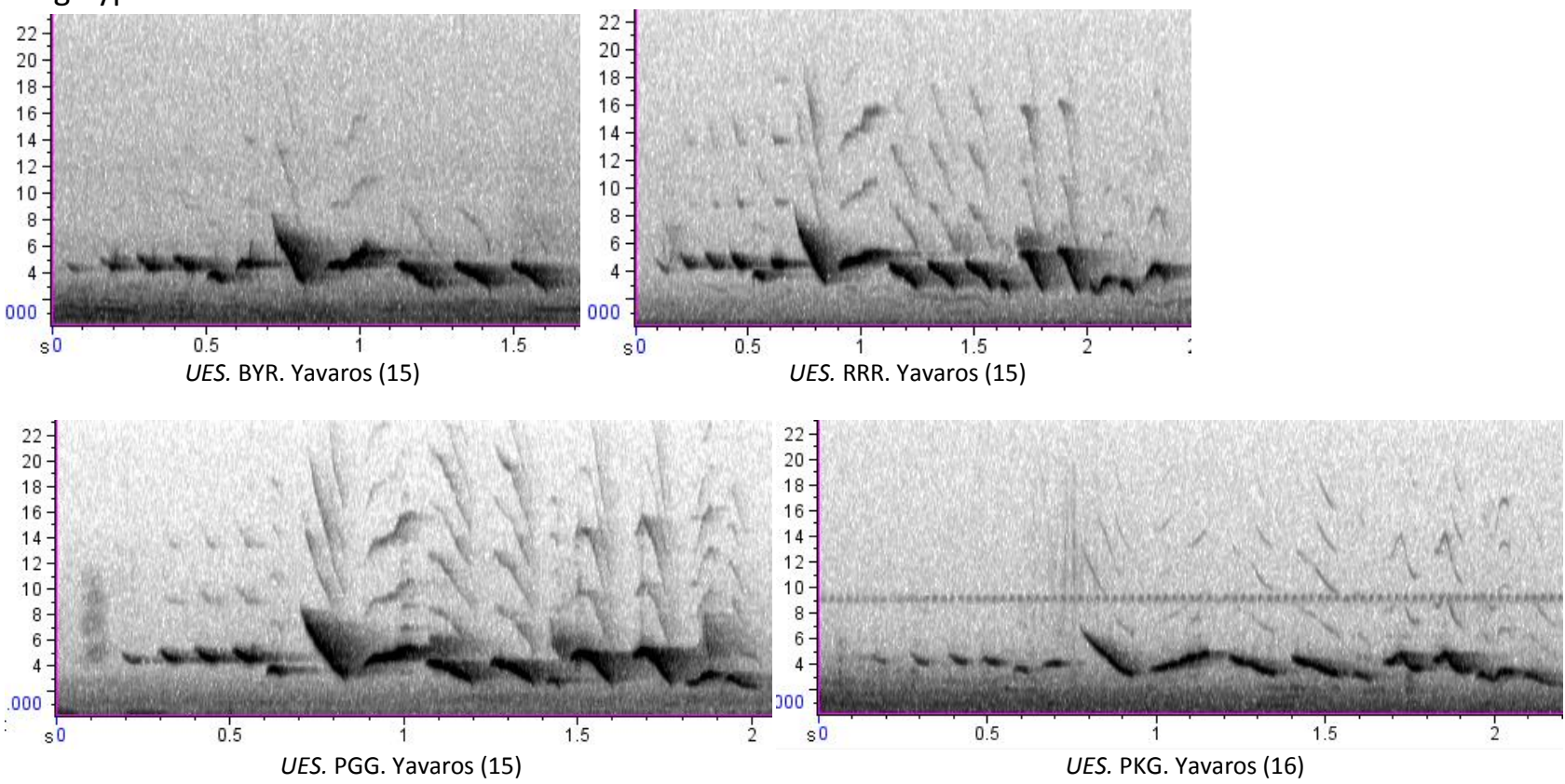

\section{Song Type: 174}

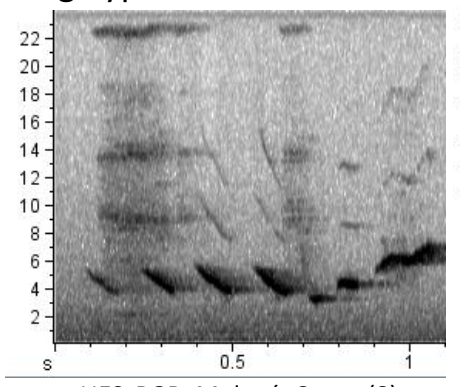

UES. PGR. Mulegé, Cocos (8)

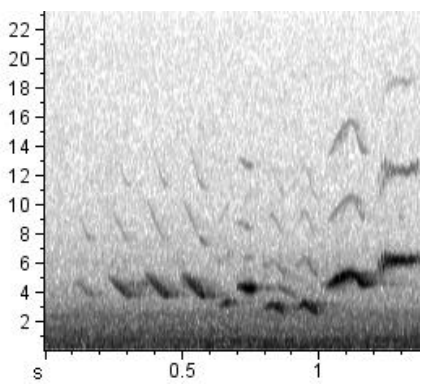

UES. NB. Mulegé, Cocos (8)

\section{Song Type: 176}
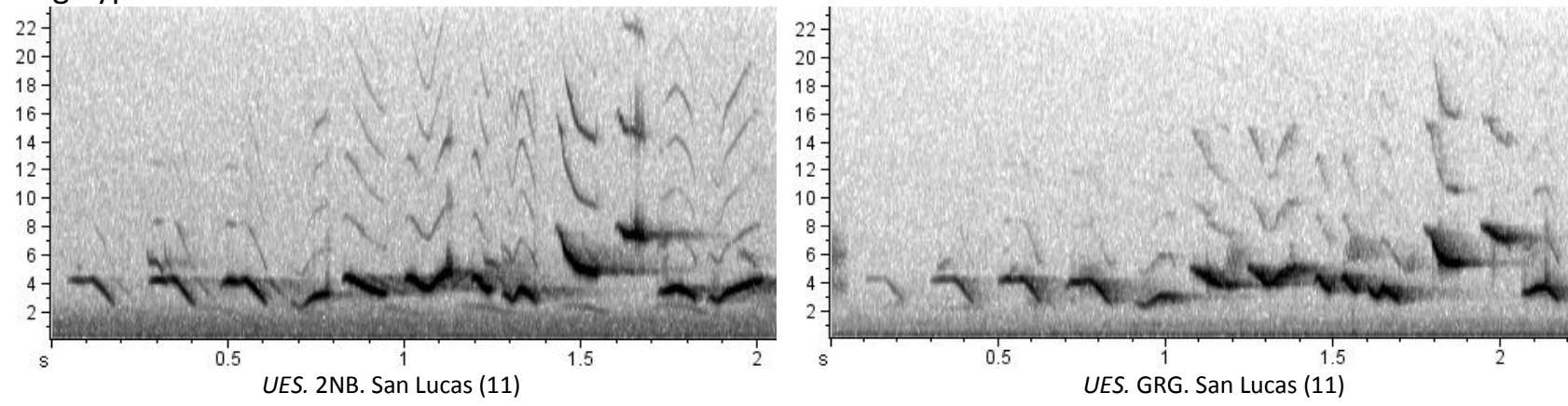


\section{Song Type: 180}
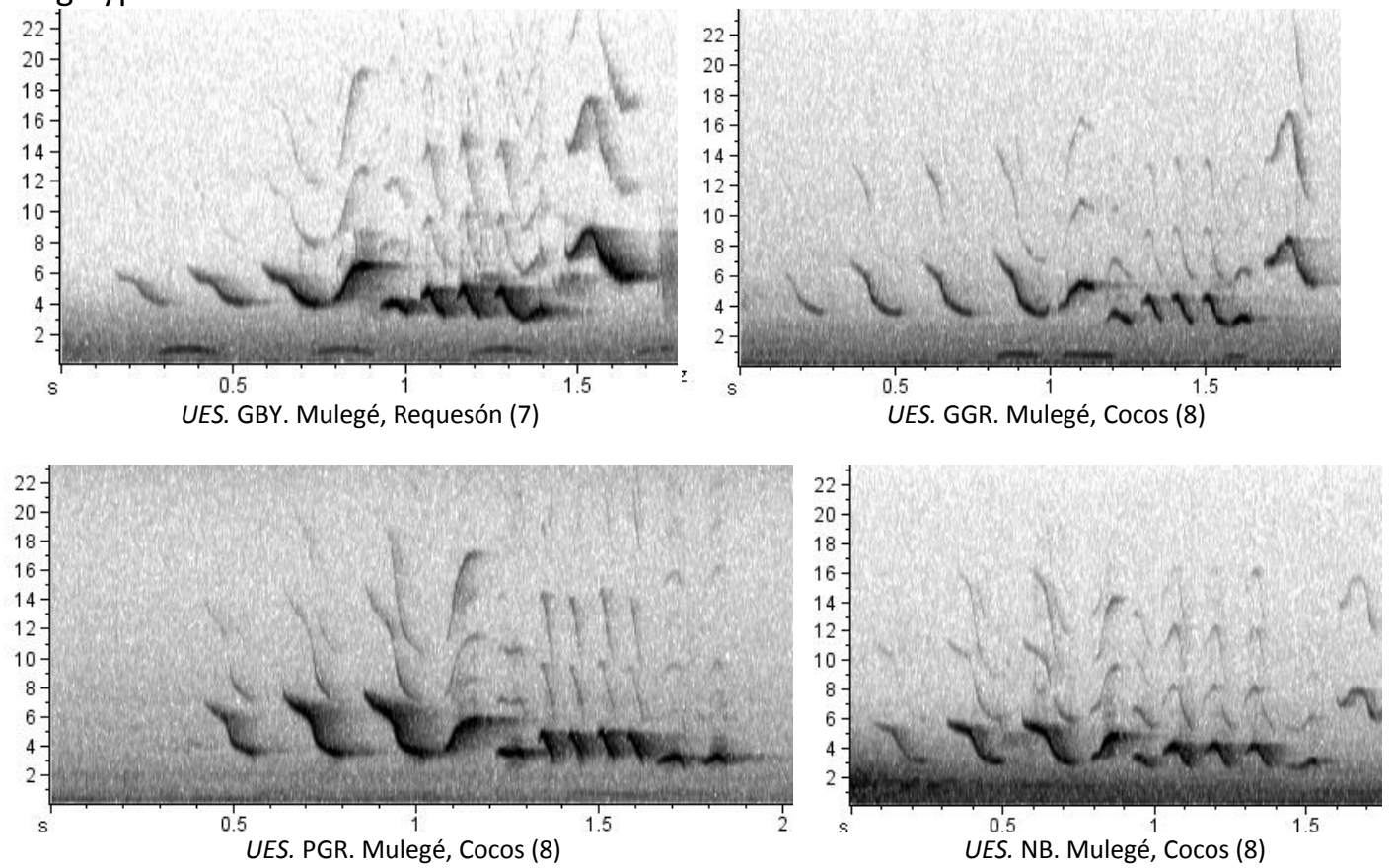

\section{Song Type: 195}
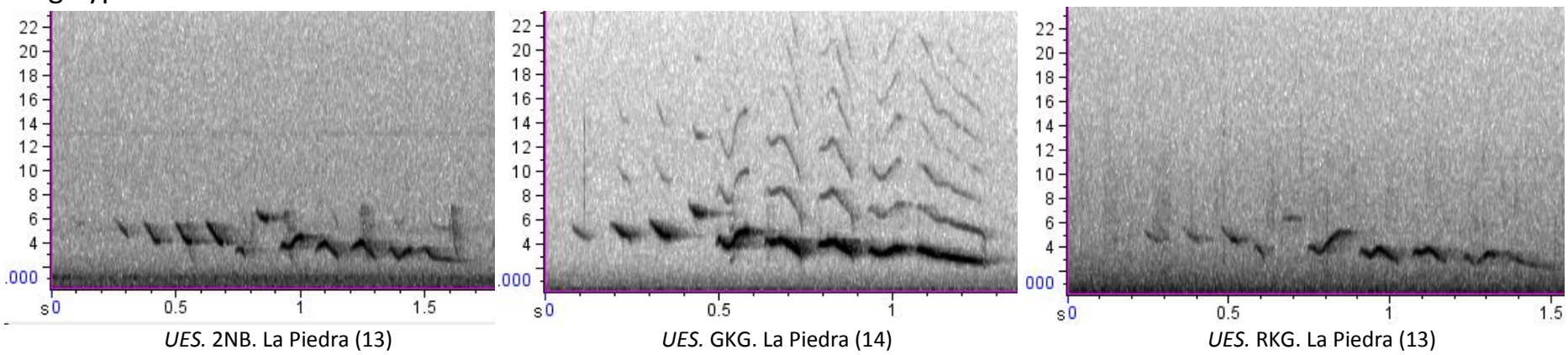

\section{Song Type: 196}
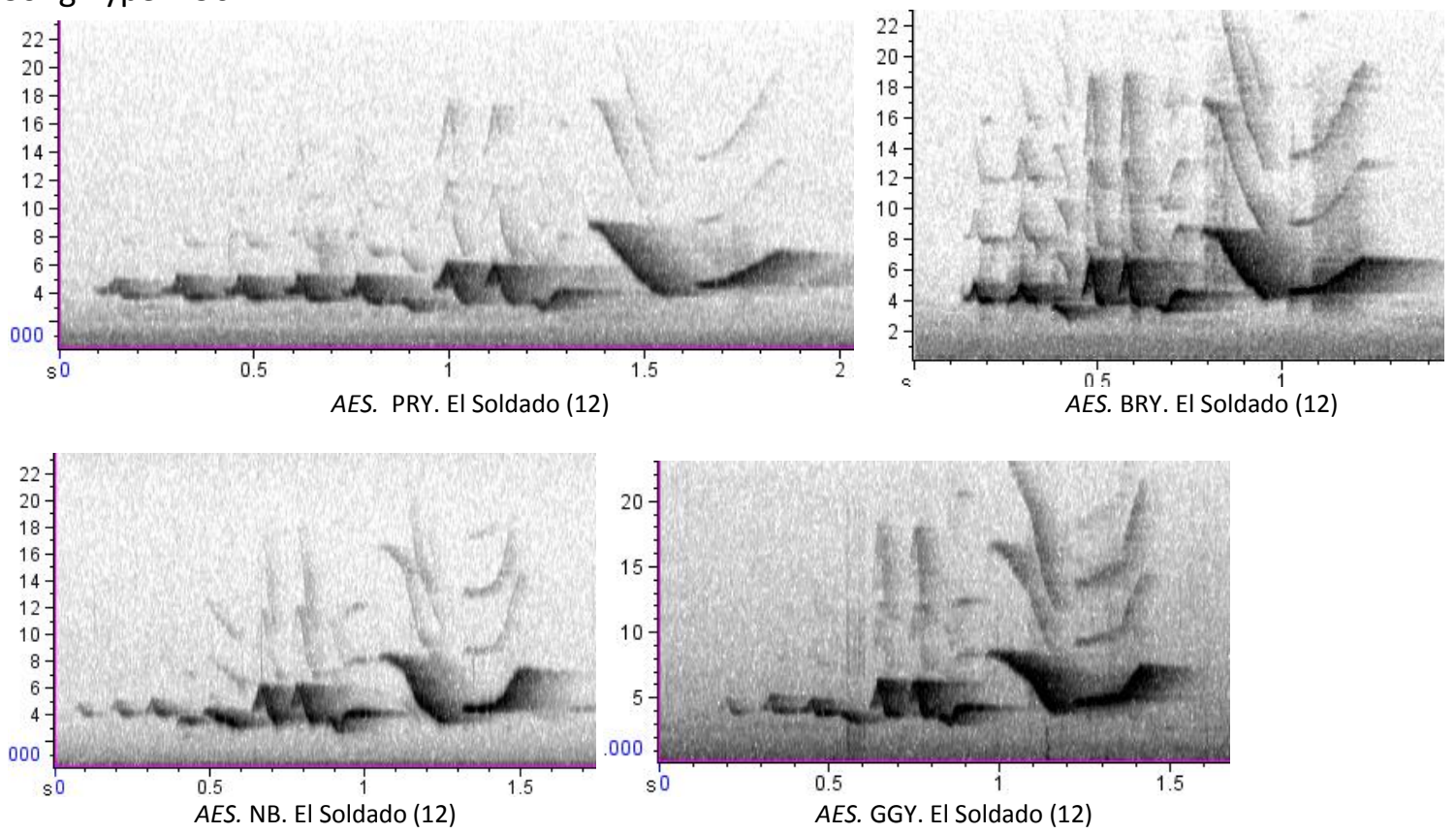
Song Type: 197
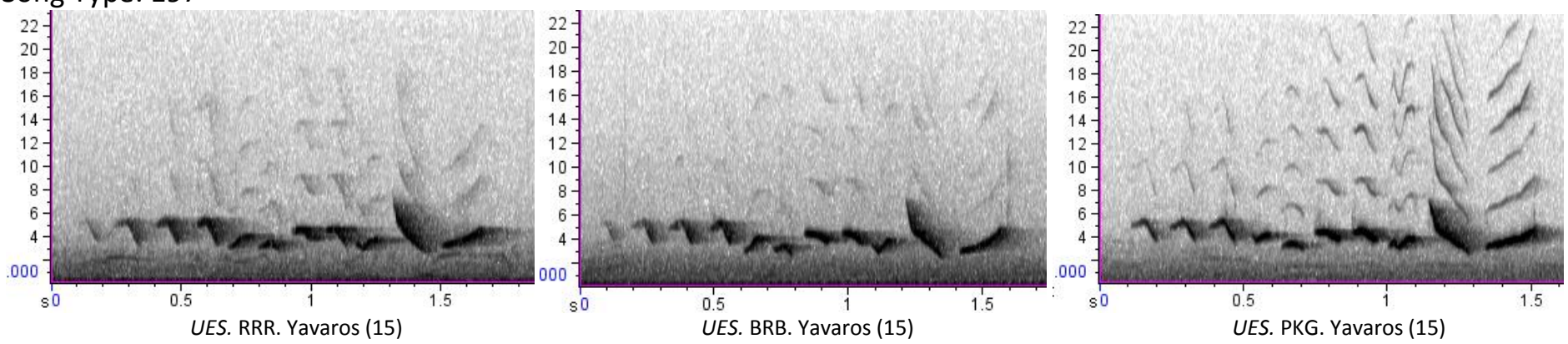

\section{Song Type: 199}
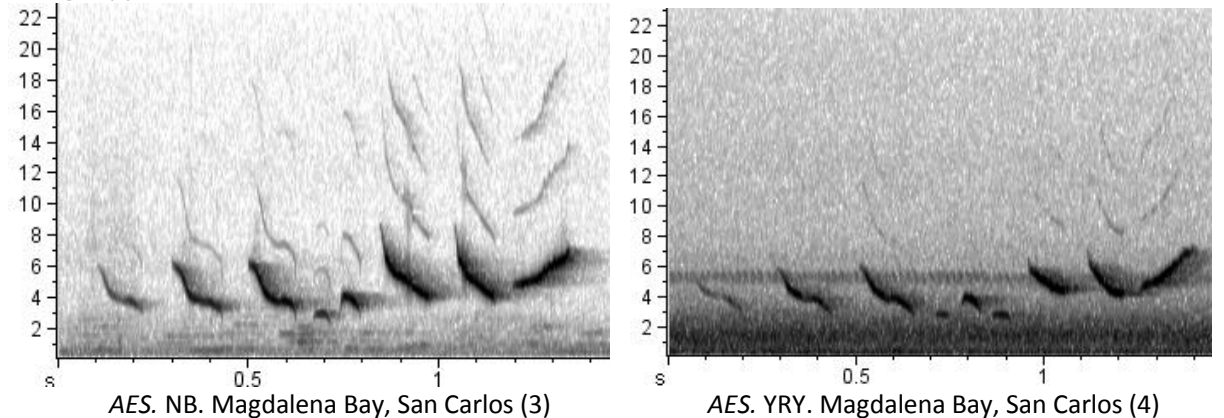

AES. NB. Magdalena Bay, San Carlos (3)

AES. YRY. Magdalena Bay, San Carlos (4)

\section{Song Type: 206}
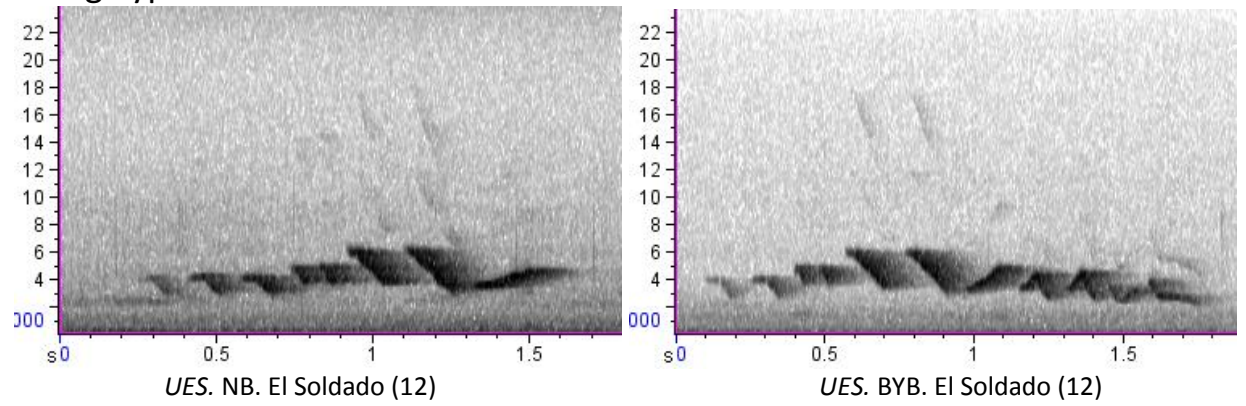

\section{Song Type: 208}
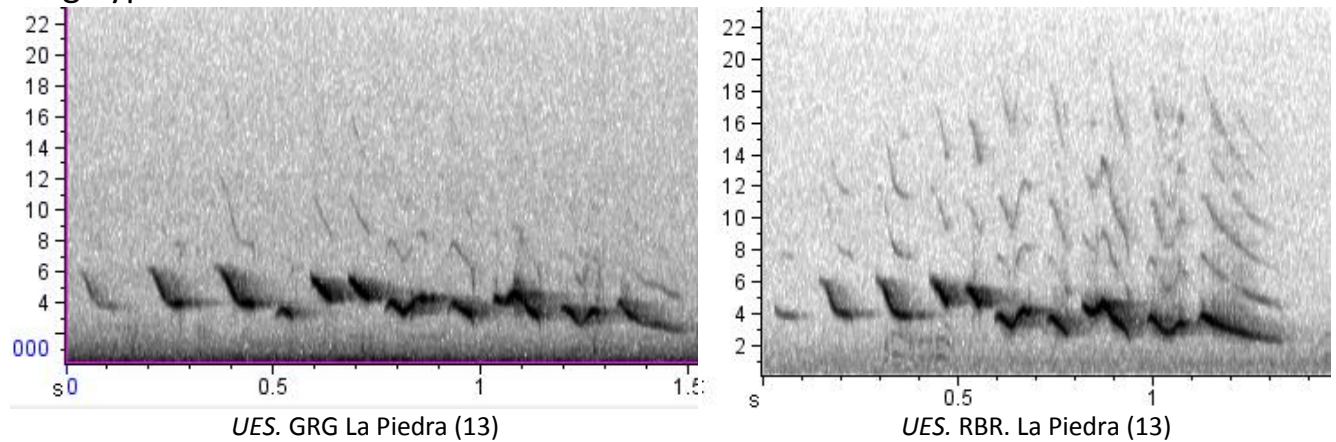
Song Type: 218
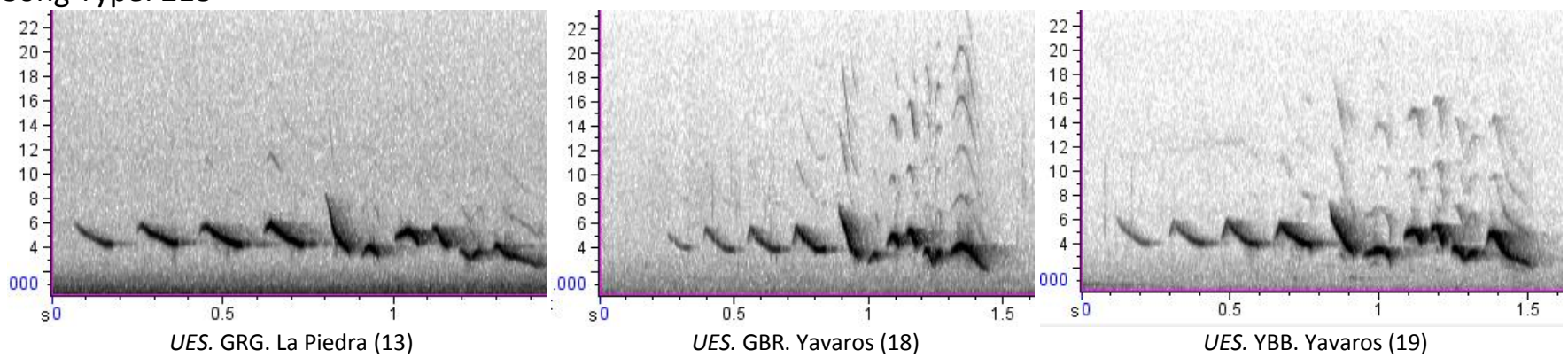

Song Type: 222
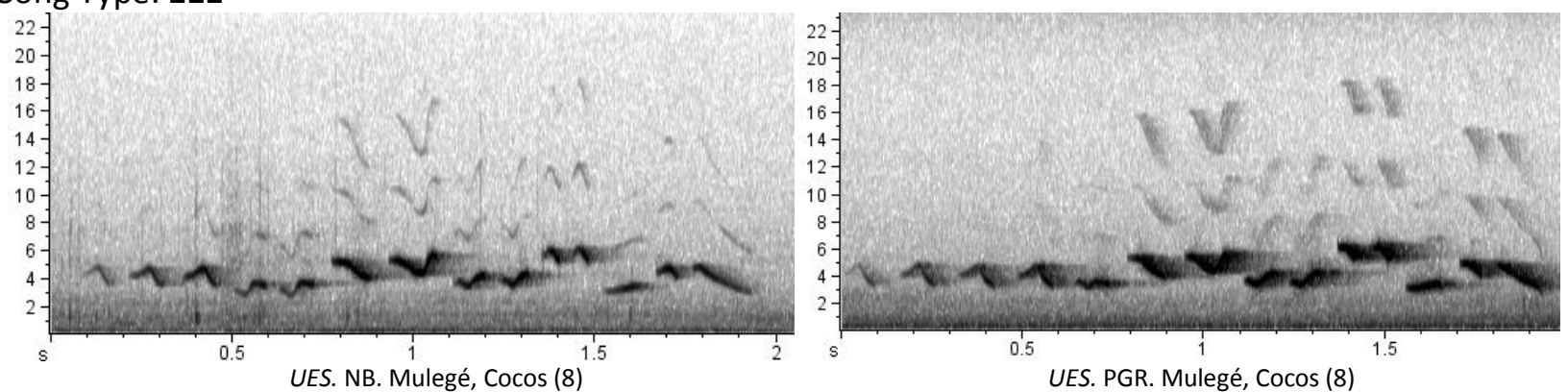

\section{Song Type: 224}
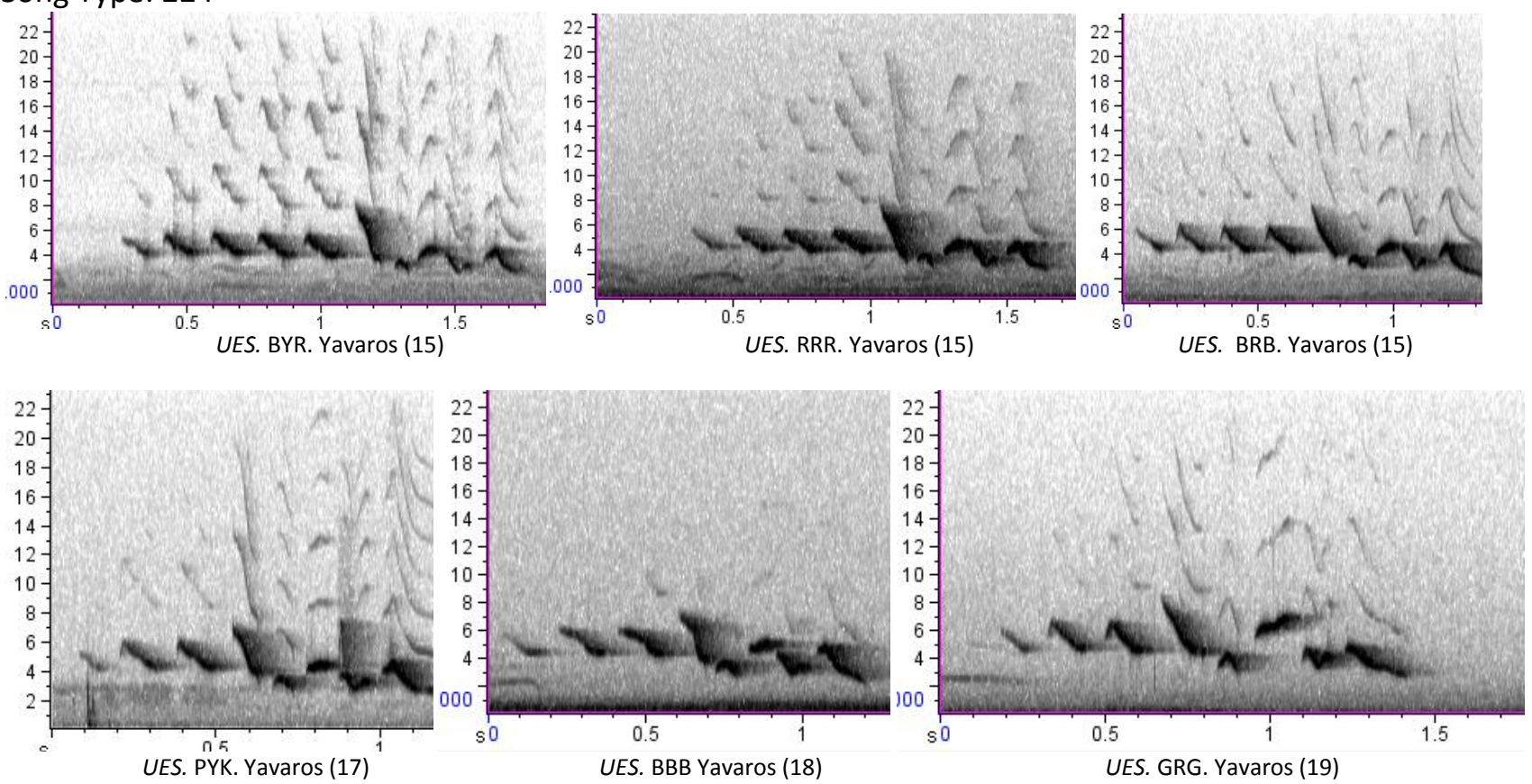

Song Type: 225
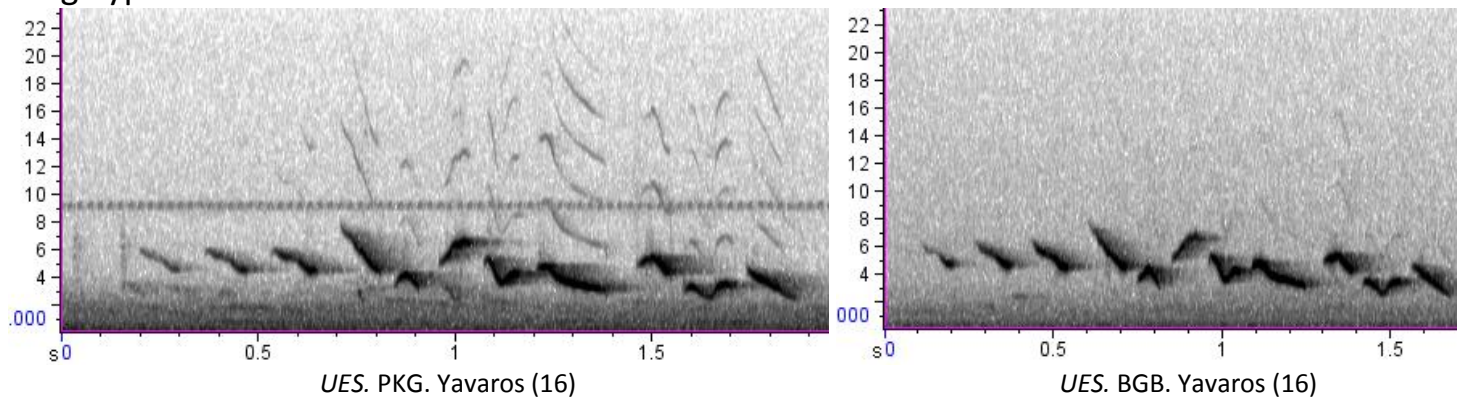